\title{
Measuring the Effects of Microplastics on Sponges
}

\section{Clifford Alan Baird}

\author{
A thesis \\ submitted to Victoria University of Wellington \\ in partial fulfilment of the requirement \\ for the degree of \\ Master of Science in Marine Biology
}

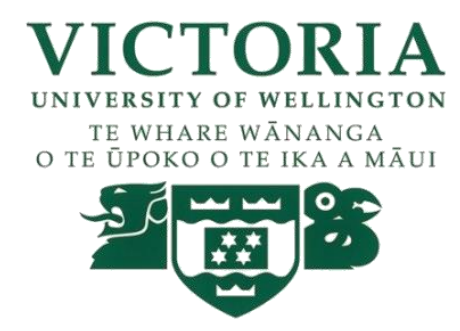

2016 



\section{Abstract:}

Microplastics (MP's) are ubiquitous throughout the marine environment, and are derived from either direct production or from the fragmentation (to $<5 \mathrm{~mm}$ ) of larger plastic pollution. Recently concern has intensified as the extent of MP pollution and its presence in the marine environment has been highlighted. Literature concerning concentrations of microplastics indicates an increasing occurrence in the marine environment, from coastal beaches to deep sea sediments. In addition, the effects microplastics have on marine organisms are well documented, with studies ranging from large pelagic animals to benthic filter feeders. However to date, there are few data on how MPs influence Porifera.

Sponges are an important component of temperate benthic ecosystems, providing a range of important functional roles. Sponges are able to adapt to many environments by exploiting a variety of food sources, from dissolved organic matter to small crustaceans. Regardless of this, sponges feed primarily on picoplankton, and are able to retain up to $99 \%$ of these from seawater. The impact microplastics have on these suspension feeders is becoming of increasing concern, and previous research has centred primarily on sponge feeding or responses to sediments. As such, this thesis is the first to focus on the metabolic responses of sponges to MPs. To examine this, two response variables were measured: $\mathrm{O}_{2}$ consumption (Respiration) and feeding (Retention efficiency).

To examine the effects of MP on sponge respiration, two temperate sponge species (Tethya bergquistae and Crella incrustans) were exposed to two different sized plastic particles $(1 \mu \mathrm{m}$ and $6 \mu \mathrm{m})$ at two different concentrations (200,000 and 400,000 beads per $\mathrm{mL}$ ). Results indicate that sponges are resilient to MP pollution. The only significant result was the effect of MP size on the respiration rates on Tethya bergquistae $(\mathrm{P}=$ 0.001 ), but there were no other significant main effects or interactions.

Marine particulates come in many shapes and sizes, as such the retention abilities of temperate sponges were tested after exposure to different types and sizes of particulates. This was achieved by subjecting the same two sponge species (Crella incrustans and Tethya bergquistae $)$ to two microplastic $(1 \mu \mathrm{m} \& 6 \mu \mathrm{m})$, two sediment $(1 \mu \mathrm{m} \& 6 \mu \mathrm{m})$ 
and two "Food" (raw sea water and Isochrysis galbana) treatments. This experiment showed some significant retention differences, but these differences were difficult to explain and largely inconclusive. This has highlighted the need for further investigation into the effects of: mixed treatments (i.e. sediments + plastics together) and varying plastic shapes $($ sphere + fibre + fragment). Finally, there is a crucial gap in knowledge regarding the fate of microplastics after ingestion by sponges.

This research outlines the potential for temperate sponges to be resilient to microplastics particles when considering respiration rates. In addition, this study also outlines the variable nature of Crella incrustans and Tethya bergquistae concerning particulate retention. As the MP concentrations used in this thesis are very high and are unlikely to be found in New Zealand in the near future, this thesis therefore demonstrates the capability for sponges to be resilient to microplastic pollution. The outcomes of my thesis highlight the importance of understanding the impacts of microplastics on benthic organisms. The marine environment is dynamic and organisms are susceptible to a multitude of stressors. As such, there is a need to explore interactions between multiple factors at the same time. 


\section{Acknowledgements:}

Firstly, I would like to thank my supervisor, Associate Professor James Bell, for his advice, support and patience throughout my Master's programme. I have thoroughly enjoyed the last two years, and am truly honoured to have been given this opportunity.

To the Bell Lab Group, thank you for your advice and assistance throughout my project. Special mention must be given to Tracey Bates for sharing her knowledge on how to keep sponges alive in the wet lab and as well as respiration/experimental design insight.

Also, huge thanks to Megan Shaffer for the initial supply, followed by continuous assistance in collection of sponges.

Thank you to the amazing team VUCEL, this thesis would not have been possible without the advice and support of the technicians, thanks to Snout and Dan, for unending diving expertise and sponge collection, and thanks to John for building me apparatus as needed. Shout out to lab friends: Ben, Bucky, Conor, Dan Megan, Mel and Phoebe, for your friendship, support, and weekly morning teas. This truly has been an amazing and unforgettable experience!

Last but not least, I would like to express my gratitude to my family. Thank you for your love and support during my studies. I could never have done it without you. I'm forever grateful for your belief, support and assistance. What an emotional rollercoaster this has been!

To Kaylee; You inspire me to further myself in everything I do, this has been a challenge but I have grown so much because of it. Don't let anybody hold you back and live your dreams. Love always, Dad. 


\section{Table of Contents:}

1 Introduction: 1

1.1 Phylum Porifera: 1

1.1.1 Biology: 1

1.1.2 Physiology: 1

1.1.3 Reproduction: 3

1.1.4 Pumping: 4

1.1.5 Respiration: 4

1.1.6 Growth and Development: 5

1.1.7 Factors influencing sponge distribution and abundance: 6

$\begin{array}{lll}\text { 1.1.8 Sponges in New Zealand: } & 7\end{array}$

1.1.9 Threats to the marine environment: $\quad 7$

1.1.10 Climate change: 8

1.1.11 Overharvesting: 9

$\begin{array}{ll}\text { 1.1.12 Invasive species: } & 9\end{array}$

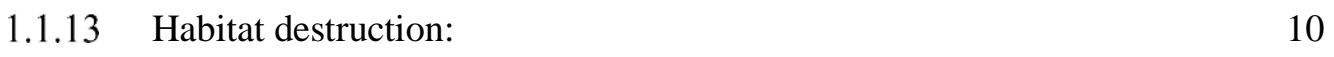

$\begin{array}{ll}1.1 .14 \text { Pollution: } & 10\end{array}$

$\begin{array}{ll}1.2 \text { Microplastics: } & 12\end{array}$

1.2.1 Mechanisms for Plastic Presence: 13

$\begin{array}{lll}\text { 1.2.2 Reasons for Concern: } & 14\end{array}$

1.2.3 Effects of Microplastics: 15

$\begin{array}{lll}\text { 1.2.4 Interactions with animals: } & 16\end{array}$

1.3 Thesis Research: 19

1.3.1 Aims: 21

2 The Effects of Microplastics on Temperate sponge Respiration: 22

2.1 Abstract: 22

2.2 Introduction: 23

2.3 Methods: 25

2.3.1 Sponge collection and husbandry: 25

2.3.2 Respiration: 26

$\begin{array}{lll}\text { 2.3.3 Treatments: } & 28\end{array}$

$\begin{array}{lll}\text { 2.3.4 Statistical analysis: } & 29\end{array}$

\begin{tabular}{ll}
2.3 .5 & Respiration rates: \\
\hline
\end{tabular}

2.4 Results: 30

2.4.1 Crella incrustans: $\quad 30$ 
2.4.2 Tethya bergquistae: 31

2.5 Discussion: 33

2.5.1 Metabolic responses to microplastics: 33

2.5.2 Conclusion: 35

3 The Effect of Microplastics on Temperate Sponge Particle Retention: $\quad 36$

3.1 Abstract: 36

3.2 Introduction: 38

3.3 Methods: 41

3.3.1 Sample collection: $\quad 41$

3.3.2 Particle Retention: $\quad 41$

3.3.3 Haemocytometer protocol: $\quad 42$

3.3.4 Treatments: 43

3.3.5 Statistical analysis: $\quad 43$

3.3.6 Particle retention: 44

3.4 Results: 44

3.4.1 Crella incrustans: $\quad 44$

3.4.2 Tethya bergquistae: $\quad 47$

3.5 Discussion: $\quad 49$

3.5.1 Particle retention: $\quad 50$

3.5.2 POM Weights: 51

3.5.3 Conclusion: 52

4 General discussion: 53

4.1.1 Overview: 53

4.1.2 Response to microplastics: $\quad 54$

4.1.3 Limitations and Future Direction: 56

5 References: 59

$\begin{array}{lll}6 & \text { Appendix: } & 75\end{array}$ 


\section{List of Figures:}

\section{Chapter 1:}

1.1: $\quad$ Schematic drawing of sponge structures and water flow. ................................... 2

1.2: Graph depicting global $\mathrm{CO}_{2}$ concentrations for the last 800 thousand years. ........ 8

1.3: Plastic debris floating in the ocean, Microbeads as seen under a microscope, .... 11

1.4: $\quad$ Tethya bergquist pink golf ball sponge and Crella incrustans with palmate fans,

\section{Chapter 2:}

2.1: $\quad$ Map of New Zealand, focusing in on Wellington region 25

2.2: $\quad$ Crella sp and Tethya sp mounted upon meshed plates. 26

2.3: Diagram of the experimental setup, temperature and oxygen probes fitted in a rubber bung, with the treatment chamber and a magnetic stirring bead.

2.4: Respiration rates of Crella incrustans following exposure to microplastics......

2.5: $\quad$ Respiration rates of Tethya berquistae following exposure to microplastics. 32

\section{Chapter 3:}

3.1: $\quad$ Treatment chamber $(75 \mathrm{~mL})$

3.2: Retention efficiency (mean values) for Crella incrustans following exposure to microplastics, sediments and Isochrysis galbana and raw sea water.

3.3: $\quad$ Mean weight of Particulate Organic Matter (POM) following Crella incrustans exposure to microplastics, sediments and Isochrysis galbana.

3.4: $\quad$ Retention efficiency (mean values) of Tethya bergquistae after exposure to microplastics, sediments, Isochrysis galbana and raw sea water.

3.5: $\quad$ Mean weight of Particulate Organic Matter (POM) following Tethya bergquistae exposure to microplastics, sediments and Isochrysis galbana. 48 


\section{Appendix:}

6.1: Correlation graph of Buoyant weight vs Water displacement .............................. 76

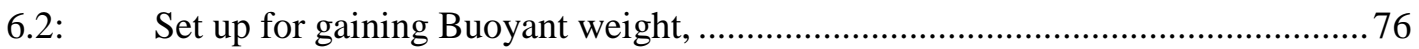




\section{List of Tables:}

\section{Chapter 2:}

1: $\quad$ Results of repeated measures ANOVA, comparing the mean respiration rates of Crella incrustans in relation to microplastic size, treatments and across days.... 31

2: $\quad$ Results of repeated measures ANOVA, comparing the mean respiration rates of Tethya bergquistae in relation to microplastic size, treatments and across days. 32

\section{Chapter 3:}

3: $\quad$ Results from a Welch's Two-way ANOVA, analysing the means of Cell retention per gram of Crella incrustans AFDM $(n=5)$, comparing particle types and sizes.

4: $\quad$ Output from one way ANOVA, comparing the means of Particulate Organic Matter (POM) weight in surrounding waters $(n=5)$.

5: $\quad$ Results from a Two-way ANOVA, analysing the means of Cell retention per gram of Tethya bergquistae AFDM $(\mathrm{n}=5)$, comparing particle types and sizes. 48

6: $\quad$ Output from one way ANOVA, comparing the means of Particulate Organic Matter (POM) weight in surrounding waters $(n=5)$. 


\section{Introduction:}

\subsection{Phylum Porifera:}

\subsubsection{Biology:}

Sponges are a ubiquitous and ecologically important group in all marine and freshwater ecosystems (Bergquist 1978; Zhuravlev and Riding 2001; Thorp and Covich 2009; Maloof et al. 2010). They were among the first multicellular animals to evolve some 580 million years ago in the early Cambrian (Li et al. 1998; Kelly 2007). There are approximately 8000 described sponge species, and they account for a large percentage of biomass in marine epifaunal communities (Bergquist 1978), and as such are a major component of benthic marine environments.

Sponges perform a number of important functional roles (Bell 2008) including: facilitating primary production; bentho-pelagic coupling; stabilisation and erosion of reef substrate or framework; nitrogen and silicon cycling; water filtration and release of secondary metabolites (Diaz and Rützler 2001; Bell and Barnes 2003; Taylor et al. 2007). Sponges are also crucial contributors to the marine ecosystem, acting as spatial competitors, hosts of microbial symbionts, important consumers, and as food to certain species (Wulff 2006a). In addition, recent studies have highlighted how sponges can be essential at an ecosystem level, as they capture dissolved organic matter (DOM) and make the nutrients and energy available to higher trophic levels (Gili and Coma 1998; de Goeij et al. 2013).

\subsubsection{Physiology:}

Sponges are multicellular animals and are similar to other animals in that they lack cell walls and produce sperm cells. However, they lack true tissues and organs, instead consisting of two thin layers of cells (the outer pinacoderm and the inner choanoderm) with mesohyl and skeletal elements between (Brusca et al. 1990). Sponges are thought to be largely heterotrophic, although tropical sponges in oligotrophic waters harbour phototrophic bacteria to compensate for a lack of organic nutrition (Cheshire and Wilkinson 1991). Sponges do not have nervous, digestive or circulatory systems, and 
most rely on maintaining a constant water flow through their bodies to obtain food and oxygen and to remove wastes (Leys et al. 2011). In most sponges the mesohyl functions as an endoskeleton and is strengthened by mineral spicules or spongin fibres (Hooper and Van Soest 2002).

Sponges utilise three basic body plans: asconoid, syconoid and leuconoid (Figure 1.1). The simplest body structure is asconoid, and is characterized by a stalk-like spongocoel surrounded by a single layer of choanocytes. The simplicity of this shape however, limits the size of the animal, because pumping capacity is heavily dependent on the area covered by choanocytes (Larsen and Riisgåd 1994). The syconoid structure helps to overcome this limitation by effectively folding in on itself, greatly increasing surface area (Hickman 2001). The inner pockets are lined with choanocytes, which connect to the outer pockets via ostia (Barnes and Ruppert 1968). This increases the number of choanocytes and pumping capacity, enabling Syconoid sponges to grow larger. And finally the Leuconoid body plan increases pumping capacity further by filling the interior almost completely with a network of chambers lined with choanocytes. This vastly increases the surface area for pumping, and as a result these sponges can attain larger sizes and take a wider range of forms, for example encrusting sponges (Hickman 2001).

Figure not available due to copyright permission

Figure 1.1: Schematic drawing of sponge structures and water flow. Depicted by the arrows, water is actively pumped through the ostia to choanocyte-lined chambers where food is extracted. Filtered water is then passed out the exhalant canal (osculum) along with waste products and $\mathrm{CO}_{2}$. Figure taken from http://4.bp.blogspot.com. 


\subsubsection{Reproduction:}

Sponges can reproduce both sexually or asexually. Most sponges are hermaphrodites, and although lacking gonads still produce sperm and eggs. Sperm are produced by choanocytes or entire choanocyte chambers that sink into the mesohyl and form spermatic cysts (Paulus and Weissenfels 1986). Eggs are formed by transformation of archeocytes, or in some species also from choanocytes (Leys and Ereskovsky 2006). During spawning, sperm are expelled via the osculum, where if they contact another sponge of the same species, the water flow carries them to choanocytes that engulf them. From there they are then carried through the mesohyl to the eggs (Brusca et al. 2003). A few species release fertilized eggs into the water, but most retain the eggs until they hatch. Larvae are all motile, being surrounded by an outer layer of cells whose flagella or cilia enable the larvae to move. After swimming for a few days the larvae typically sink and crawl until they find a place to settle (Bergquist 1978).

There are also three asexual methods of reproduction: fragmentation, budding and by producing gemmules. Fragments of sponges may be detached by currents or waves. They use their pinacocytes and choanocytes for mobility and reshape their mesohyl in order to re-attach themselves to a suitable surface (Maldonado and Uriz 1999b), where they then rebuild themselves as small but fully functional sponges. Very early experiments revealed that surviving cells from some sponge species can reform a complete organism and if multiple sponges are blended together, each species will recombine independently (Wilson and Penney 1930).

Some sponge species reproduce by budding. Budding is a form of asexual reproduction in which a new organism develops from an outgrowth or bud at one particular site. The new organism remains attached as it grows, separating from the parent organism only when it is mature (Simpson and Gilbert 1973; Simpson and Fell 1974; Reiswig and Miller 1998). Finally, some Porifera can reproduce through the production of gemmules. Gemmules are "survival pods" which a few marine sponges and many freshwater species can produce (Bergquist 1978; Brusca et al. 2003). Spongocytes make gemmules by wrapping shells of spongin, often reinforced with spicules, round clusters of archeocytes that are full of nutrients (Simpson and Fell 1974). These gemmules then become dormant, and in this state can survive extreme temperatures, desiccation, hypoxia and, typically with freshwater species, variations in salinity (Reiswig and Miller 1998). 


\subsubsection{Pumping:}

Sponges are specialised to feed by rapidly filtering and removing food particles from the water column (Bergquist 1978; Riisgård et al. 1993). This is achieved by actively pumping water through small surface pores, called ostia (Vogel 1974; Vogel 1977). Water movement is created by the beating of flagella associated with choanocytes, these cells also collect and remove food particles, notably pico- and -ultraplankton ( 0.2 and 2 $\mu \mathrm{m})$ (Reiswig 1971a; Pile et al. 1997), from the water as it passes through the sponge (Vogel 1977). Past studies have suggested sponges are not selective when they retain particles (Reiswig 1971a; Wolfrath and Barthel 1989), however, more recent studies found evidence for preferential retention of bacteria and picoplankton species in calcareous and demosponges in New Zealand (Perea-Blázquez et al. 2010; PereaBlázquez et al. 2013).

Early research found that pumping rates remain constant over long periods of time (Jørgensen 1955; Jørgensen 1966). However, recent studies have found that sponges with a functional canal system are capable of varying their pumping rates (Reiswig 1971a; Pile et al. 1997; Tompkins-MacDonald and Leys 2008), or even suspending pumping altogether for several hours (Gerrodette and Flechsig 1979; Bannister et al. 2012) in response to environmental stressors (such as sediment). Reproductive episodes also result in diminished pumping activity, most likely due to many choanocytes being transformed for gamete production (see de Caralt et al. (2007). In addition to feeding, pumping is also vital in respiration and waste removal, and as such is an essential aspect of sponge biology.

\subsubsection{Respiration:}

Respiration is essentially the transport of oxygen to tissues and cells, with the release of oxidation products and $\mathrm{CO}_{2}$ (Raven and Johnson 1986), as sponges lack specialised respiratory surfaces and systems, oxygen and $\mathrm{CO}_{2}$ are therefore exchanged via diffusion between the environment and the sponge cells (Burggren and Roberts 1991). In the case of sponges, these gases diffuse across the cells lining the inhalant canals, the exterior of their body, and through the choanocytes (Hoffmann et al. 2005). At the cellular level, respiration is the conversion of organic molecules and oxygen to energy (Lucas and Watson 2002), driving processes such as basal metabolism, locomotion, and secondary 
production (e.g. growth and reproduction) (Coma et al. 2000). Oxygen is fundamental to all energetic processes in the bodies of aerobic organisms. Consequently, consumption of $\mathrm{O}_{2}$ provides an indication of total energy expenditure in conditions, either normal or under stress (Hadas et al. 2008).

Respiration is a direct measure of metabolic demand, as energetic reserves are used to fuel the production of ATP (Marsh and Manahan 1999). This therefore represents a cost to the organism. In some instances increased respiration rates may provide a temporary benefit (such as energy for reproduction, repair or evasion from predators), however elevated respiration has been shown to be harmful to sponges (Lohrer et al. 2006), and one that is ultimately detrimental to organisms if sustained at higher than normal rates (Clarke 1991).

Respiration has been utilised to discern the effects of both biotic and abiotic factors, from temperature (Cheshire and Wilkinson 1991; Vohmann et al. 2009) to sedimentation (Gerrodette and Flechsig 1979; Bannister et al. 2012), and food availability (PereaBlázquez 2011). However, the cost associated with increased or decreased respiration rates on sponges has proved difficult to measure (Clarke 1991). In regards to sponges, there are indications that fluctuating, or elevated respiration rates change when exposed to increased temperatures (Reiswig 1971a; Barthel 1988; Coma et al. 2000) or sediments (Kowalke 2000; Bannister et al. 2012), with the later studies speculating that the resulting reduction in $\mathrm{O}_{2}$, was likely due to cessation of pumping to prevent clogging of the filtering apparatus. Very few studies have investigated changes in metabolic rates in combination with other indicators of sponge health (i.e. pumping, or feeding); consequently the cost at the individual level is largely unknown.

\subsubsection{Growth and Development:}

Sponges are nearly impossible (unless followed from recruitment) to age, and currently there is no definitive method for aging sponges. However, there are suggestions that carbon isotope analysis of spicules could be an accurate measure (Fallon et al. 2010). To date sponge age is often estimated based on measurements of growth rates (Ayling 1983). Sponge growth is influenced by various factors, including sedimentation (Roberts 2002), wave action (Bell et al. 2002) and food availability (Turon et al. 1998). Due to this ability to acclimate to different environmental conditions, sponge morphology may vary 
considerably, with some sponges exhibiting different morphologies within the same species depending on environmental variables (Meroz-Fine et al. 2005). Sponges can also display plasticity in their structural components (e.g. size and number of spicules) and these variations in spicule morphology could be a direct response to environmental conditions (Palumbi 1986; Meroz-Fine et al. 2005). For example; in areas of high energy water flow, stronger and thicker spicules may provide structural support and protection against injury (Palumbi 1986).

\subsubsection{Factors influencing sponge distribution and abundance:}

Sponge physiology and subsequently distribution, abundance, and diversity are affected by a range of abiotic and biotic factors (Carballo et al. 2008). Physical influences include: temperature (Barnes 1999; Duckworth and Battershill 2001; Whalan et al. 2008), light availability (Wilkinson and Trott 1985; Cheshire and Wilkinson 1991), sedimentation (Carballo 2006; Powell et al. 2010), salinity (Roberts et al. 2006), and substrate composition and angle (Bell and Barnes, 2000). Biological factors range from predation (Wulff 1994; Wulff 1995; Wulff 2000); mutualistic and symbiotic interactions (Uriz et al. 1992; Wulff 1997); concentration and type of plankton (Pile et al. 1997; Ribes et al. 1999); spatial competition (Engel and Pawlik 2000; de Voogd et al. 2003), and disease (Cerrano et al. 2000; Maldonado et al. 2010a). These factors do not work independently however, with sponge assemblages likely to have multiple physical and biological factors influencing sponges at the same time (Berman 2012), with some sponge species being more sensitive to environmental change and anthropogenic activities (Halpern et al. 2007). Understanding how sponges will react to increasing environmental degradation and modification is paramount, especially with the onset of climate change and the potential for community structures to change (Bell et al. 2013). As such, any variation in sponge diversity and abundance could have significant consequences for biological interactions in the marine environment (Brodie 2014; Gaylord et al. 2015). 


\subsubsection{Sponges in New Zealand:}

Around New Zealand, sponges are one of the most dominant groups in benthic marine communities (Berman 2012) and in some locations have been reported as some of the largest contributors to benthic biomass (Batham 1956). As of 2010 roughly 730 sponge species have been described or are in the process of being described from the waters around New Zealand, this however, is estimated to be only a small portion of NZ's total species (Cook and Archer 2010).

Prior attention has primarily addressed the ecology of sponges from the tropics and Northern Hemisphere (Bell et al. 2015). Temperate research has focused primarily on sponge functional roles (Perea-Blázquez et al. 2010; Berman 2012; Cárdenas et al. 2012; Perea-Blazquez et al. 2012; Cárdenas et al. 2014). As such, there are fewer studies investigating the impacts on sponges. Early publications regarding New Zealand sponges concentrated on growth, morphology and behaviour (Bergquist 1968), with more recent focus on population dynamics (Duckworth and Battershill 2001), interactions with macroalgae (Cárdenas et al. 2012), and their role in bentho-pelagic coupling (PereaBlázquez 2011; Perea-Blázquez et al. 2012). Contrastingly, there are few studies investigating sponge responses to environmental stressors in New Zealand (See Bates 2015), although this may be due to NZ's comparatively pristine nature compared to other parts of the world.

\subsubsection{Threats to the marine environment:}

The fate of the world's oceans is becoming increasingly scrutinized with the realisation that increased anthropogenic pressures are seriously threatening the future sustainability of marine species and ecosystems (Halpern et al. 2007). As such, loss of biodiversity is one of the greatest environmental concerns of modern society (Cardinale et al. 2012; Gardner et al. 2013). Marine environments are subject to a plethora of stressors which can be labelled under five broad categories; climate change, overharvesting, habitat destruction, invasive species and pollution. 


\subsubsection{Climate change:}

Atmospheric carbon dioxide $\left(\mathrm{CO}_{2}\right)$ levels have risen by $75 \%$ since 1970 , and currently stand at around 400 parts per million (ppm), with latest scenarios projecting $\mathrm{CO}_{2}$ levels to be between 730 and 1088 ppm by 2100 (Field et al. 2014). This rate of increase is alarming as it is 100 times faster (Figure 1.2) than any change experienced during the last 650,000 years (Siegenthaler et al. 2005).

Figure not available due to copyright permission

Figure 1.2: Graph depicting global $\mathrm{CO}_{2}$ concentrations for the last 800 thousand years. Source: Adapted from: https://bfi.uchicago.edu/events/CC-climate.

The Earth's climate is heavily influenced by greenhouse gases in the atmosphere (Charlson et al. 1992), and the rise in $\mathrm{CO}_{2}$ over the past century has resulted in an increase in global air temperature by approximately $0.4-0.8^{\circ} \mathrm{C}$. As the atmospheric temperature rises, the oceans react in two ways. Firstly, this energy is also transferred to the ocean waters resulting in a concurrent increase in sea surface temperature (SST) (Field et al. 2014). And secondly, as the concentration of atmospheric $\mathrm{CO}_{2}$ increases, surface waters of the ocean act as a buffer by taking up $\mathrm{CO}_{2}$ via air-sea gas exchange (Tracey et al. 2013). While this partially lessens the extent of global warming, the uptake of carbon dioxide has a profound effect on ocean chemistry, effectively lowering the $\mathrm{pH}$ of seawater, a process known as 'ocean acidification' (OA). The most recognised effect of $\mathrm{OA}$ is a concurrent decline in calcium carbonate saturation $\left(\mathrm{CaCO}_{3}\right)$, and an increase in dissolved inorganic carbon (DIC) (Caldeira and Wickett 2005). This decline in $\mathrm{CaCO}_{3}$ is 
particularly worrisome as it is essential to the growth and formation of shells and skeletons for many organisms (Barnes and Peck 2008; Beniash et al. 2010).

\subsubsection{Overharvesting:}

Overharvesting is described as populations that are harvested at a rate that is unsustainable, given their natural rates of mortality and capacities for reproduction (Jackson et al. 2001). Overharvesting resources for extended periods of time can deplete natural resources to the point where they are unable to recover within a short time frame (Hayden et al. 2015). With an exponential increase in human population, expanding markets, and increasing demand, combined with improved access and techniques for capture, the exploitation of many species has exceeded sustainable levels. Overharvesting can lead to resource depletion, including extinction at the population level and even extinction of whole species (Powles et al. 2000). In addition, depleting the numbers or amount of certain resources has also been shown to affect the quality or morphology of these species, also known as Darwinian debt (Cookson 2004).

Sometimes the potential profits gained from fishing outweighs the biological growth of the resource (Harwood et al. 2014). In these situations economic forces can therefore drive these populations towards extinction (Powles et al. 2000). For example the overexploitation of grouper versus a billion dollar fishing industry (Sadovy de Mitcheson et al. 2013). Over exploitation of a species can also result in cascade effects, particularly if a habitat loses its apex predators, resulting in an increase in their prey species. This can lead the prey to overexploiting their own food resources until population numbers decline, sometimes towards the point of population extinction. For example Estes and Palmisano $(1974 ; 1989)$ outline how the overexploitation of otters in Alaska led to an explosion of sea urchin populations and thus kelp overgrazing.

\subsubsection{Invasive species:}

Aquatic invasive species are plants and animals that evolved in one location and are introduced through a variety of means into another location (Funk 2015). When an alien species arrives in a new location it can either: find its new habitat unwelcoming and die off, survive with little environmental impact, or it can thrive, altering the existing ecosystem and wildlife in a variety of ways (Walsh et al. 2016). Invasive species that prosper usually do so because their new habitat lacks natural predators to control their 
population, and the damage they create comes mainly from consuming native species, competing with them for food or space, or introducing disease (Leppäkoski et al. 2013).

There are numerous mechanisms for invasion including ballast water (Padilla and Williams 2004), ship hulls and on marine debris/trash (Bax et al. 2003; Gregory 2009), the aquarium and exotic pet trade (Albins 2013; Côté et al. 2013; Otero et al. 2013), and finally global warming is a potential vector for invasion, from the spread of warmer waters to melting ice caps allowing access to previously inaccessible areas (Taylor and Kumar 2013; McKeon et al. 2015).

\subsubsection{Habitat destruction:}

Most areas of the world's oceans are experiencing increased habitat loss, however coastal areas being in close proximity to human population centres, have suffered disproportionately largely due to anthropogenic stresses such as; construction of coastal protection, land reclamation, aggregate (sand and gravel) extraction, recreation and developments including ports, harbours and industries (Halpern et al. 2008). These critical areas, which include estuaries, swamps, marshes, and wetlands, serve as breeding grounds or nurseries for nearly all marine species (Lehtinen et al. 1999; Lotze et al. 2006). As such habitat loss has far-reaching impacts on the entire ocean's biodiversity (Beck et al. 2001; Able 2005). Habitat degradation occurs as a result of a number of activities; tourism (Davenport and Davenport 2006); ships (Chou 2006), oil spills (Peterson and Vieglais 2001; Peterson et al. 2003) and destructive fishing techniques (Thrush and Dayton 2002; Fox et al. 2003; Wilberg et al. 2011) and as such, are felt throughout the marine environment (Rothschild et al. 1994; Pikitch et al. 2004).

\subsubsection{Pollution:}

Marine pollution is a result of the entry of chemicals, particles, industrial, agricultural and residential waste, or noise into the world's oceans. The majority of marine pollution comes from land, with air pollution also contributing by carrying pesticides or dirt into the ocean (Gaiero et al. 2003). Most of this pollution originates from nonpoint sources such as agricultural runoff, wind-blown debris and dust (Carpenter et al. 1998; Meyer- 
Reil and Köster 2000). However, some is directly and often deliberately introduced to the marine environment via anthropogenic sources (Benton 1995).

Marine debris, mainly discarded rubbish which floats on, or is suspended in the ocean, can threaten aquatic life through entanglement, suffocation, and ingestion (Derraik 2002). Roughly 80 to 85 percent of this trash is plastic debris (Cadée 2002; Derraik 2002), which has been rapidly accumulating since the end of World War II (Azzarello and Van Vleet 1987), with a total mass estimated to be as over 100 million metric tons (Jambeck et al. 2015). This debris ranges from discarded plastic bags and beer six pack rings, to discarded or lost fishing nets which end up in the ocean, present dangers to wildlife and fisheries (Butler and Matthews 2015). Fishing nets, in a process known as ghost fishing (Gilman 2015), entangle all manner of sea creatures, restricting movement, causing starvation, laceration and infection and suffocation (Laist 1987; Bugoni et al. 2001). In addition, many animals that live on or in the sea consume flotsam by mistake, as it often looks similar to their natural prey (Moore 2008). The ingested plastic debris, when bulky or tangled may become permanently lodged in the digestive or respiratory tracts of these animals (George 1996; Lazar and Gračan 2011).

Plastics accumulate because they don't biodegrade in the way many other substances do. They will photodegrade on exposure to the sun, however, the presence of water retards this process, causing the photodegraded plastic to disintegrate into ever smaller pieces (microplastics) while still remaining polymers (Figure 1.3) (Fries et al. 2013).

Figures not available due to copyright permission

Figure 1.3: Left: Plastic debris floating in the ocean, Photo adapted from an Article by Oliver M (Nov 18, 2014). Right: Microbeads as seen under a microscope, Photo adapted from www.mcgill.ca 


\subsection{Microplastics:}

Plastic debris in the marine environment is a globally recognised problem, affecting a wide range of ecosystems (Moore 2008; Zarfl et al. 2011). Recent concern has focused primarily on microplastics and their impacts on the marine environment (Derraik 2002; Ryan et al. 2009). Microplastics are classified as plastic particles less than $5 \mathrm{~mm}$ in diameter (National Oceanic and Atmospheric Administration; NOAA) and are likely the most numerically abundant items of plastic debris in the ocean today (Thompson 2006). The abundance of these particles is likely to increase further as single plastic items already occurring in the world's oceans ultimately degrade into millions of pieces (Betts 2008; Cole et al. 2011). In addition to this, the increasing use of microplastic beads in beauty products means microplastics are continually being added to the marine environment as the beads are rinsed down sinks and drains where they are too small to be removed by conventional filtering (Gregory 1996; Browne et al. 2007; Fendall and Sewell 2009). Furthermore, recent evidence suggests that microplastic input will increase as the polar icecaps recede (Obbard et al. 2014). As sea ice forms it collects and traps particles in the "body" of ice and as a result over time the Arctic ice shelf has accumulated microplastics (Gregory et al. 2002). Obbard et al. (2014) sampled ice in the arctic (during the HOTRAX and ICESCAPE expeditions) and confirmed that microplastic particles in the ice cores number up to 2 orders of magnitude higher than that of the Pacific gyre. This is particularly troubling because with the onset of climate change and the projected loss of the Arctic ice cap, these particles will be released back into the surrounding waters.

Introduced into the literature in 2004 , the term microplastic has been widely used to describe plastic fragments in the marine environment (Thompson et al. 2004b). However, microplastics vary in size (typically between $0.01-5 \mathrm{~mm}$ ) and quantification methodologies vary between studies ( $\mathrm{Ng}$ and Obbard 2006; Barnes et al. 2009). In the majority of open-water studies, microplastics have been collected with plankton nets and particles smaller than the net mesh $(\sim 0.33 \mathrm{~mm})$ have evaded capture (Cole et al. 2011). Studies that bulk-sampled marine sediment have managed to retain particles of all sizes; however, efficient identification of smaller microplastics $(<0.03 \mathrm{~mm})$ has been a serious challenge, making it difficult to quantify microplastic loads (Thompson et al. 2004b) and highlighting a lack of knowledge and the need for further research. 
Microplastics are of increasing concern as they have the ability to bio-accumulate and bio-magnify throughout food chains, affecting animals in the benthic zone through to the pelagic zone. Moreover, there are differing mechanisms for the production of microplastics and finally microplastics can act as contaminants, leeching toxins into the surrounding tissues of animals that have ingested them. These major issues are important to address and discuss as microplastic loading in the oceans continues to increase and animals become more exposed to them.

\subsubsection{Mechanisms for Plastic Presence:}

Microplastic particle accumulation can be classified into two ways, primary plastics and secondary plastics (Cole et al. 2011; Lusher et al. 2013). Primary plastics refer to direct inputs into the marine environment and secondary refers to the degradation and breakdown of larger plastic debris. Primary plastic involves the direct input of contaminants as micrometre-sized plastic particles to the marine environment, such as cosmetic beads / exfoliating scrubs and clothing fibres from washing machines (Fendall and Sewell 2009; Thompson et al. 2009). These particles, because of their small size, pass through wastewater treatment filters into waste water and from there into the ocean (Gregory 1996; Browne et al. 2007; Fendall and Sewell 2009). Secondary microplastics on the other hand are derived from already existing larger plastic debris. Sources of secondary microplastics include: degradation, oxidation and mechanical abrasion of larger items entering the system from rivers, runoff, tides, winds, and catastrophic events, along with debris already afloat in the sea such as lost cargo and fishing / aquaculture gear (Andrady 2003; Andrady 2005; Browne et al. 2007; Thompson et al. 2009).

The sources of these particles are well known, however, knowledge of their relative contribution and geographic distribution is limited (Law and Thompson 2014). Once in the ocean, microplastics are transported passively by complex current systems (Ryan et al. 2009; Doyle et al. 2011), resulting in large variability in surface concentrations making long-term trends difficult to determine, even in areas where many studies have been undertaken (western North Atlantic (Law et al. 2010); and eastern North Pacific Oceans (Law et al. 2014). Oceanographic models and environmental observations have found concentrations of up to 106 pieces $\mathrm{km}^{2}$ of floating microplastic in subtropical ocean gyres (Maximenko et al. 2012). These gyres, usually far from land-based sources (Law et al. 
2010), are where converging surface currents trap and retain floating debris (Eriksen et al. 2013). Likewise similarly high concentrations have been observed in enclosed basins such as the Mediterranean Sea (Collignon et al. 2012).

In coastal sediments microplastics are also ubiquitous, with quantities typically ranging from 2 to 30 particles per $250 \mathrm{ml}$ of sediment (Browne et al. 2011) and more recently Arctic sea ice has been identified as a reservoir of microplastics (Obbard et al. 2014). With the exception of localized spills, the relationships between microplastic concentration and its sources are poorly understood, due to complex transport mechanisms and unknown fragmentation rates (Law and Thompson 2014).

\subsubsection{Reasons for Concern:}

Microplastics may have different effects from larger items of debris, largely because of their size. Floating microplastics provide habitats for diverse communities of microorganisms (Gregory 2009), these assemblages differ from those in surrounding seawater and vary with polymer type (Zettler et al. 2013). In addition, microplastics are ingested by a diverse range of organisms, particularly filter feeding organisms such as mussels, which retain particles after consumption (Browne et al. 2008). Absorption of small quantities of microplastics has the potential to disrupt physiological processes, for example Wright et al. (2013b) determined that microplastics were detrimental to marine worms by compromising their ability to store energy.

A recent benthic study indicated that microplastics that are introduced into the food web by feeding at one trophic level may also transfer to other, higher trophic level organisms (Farrell and Nelson 2013). This could have consequences for organisms at higher trophic levels if any contaminants that are transferred have the potential for bio-magnification (Teuten et al. 2009). An example of this is polymer ingestion by fish during normal feeding activity, resulting from the density of plastic in the marine environment and subsequent transference to fur seals (Eriksson and Burton 2003).

Plastic debris accumulates harmful persistent organic pollutants (POP's) such as dichlorodiphenyltrichloroethane (DDT), polychlorinated biphenyls (PCBs), and polybrominated diphenyl ethers (PBDEs) from seawater (Ogata et al. 2009). POPs have recently been traced on the surface of microplastic pellets and postconsumer plastic fragments, where they absorb and concentrate lipophilic contaminants by several orders 
of magnitude compared to ambient seawater (von Moos et al. 2012). These contaminants are then released upon ingestion (Teuten et al. 2009) as reported in marine worms (Browne et al. 2013) and fish (Rochman et al. 2013a). The transfer of these pollutants depends on the polymer, the contaminant, and the condition of the organism ingesting them (Heskett et al. 2012). There is also concern that plastic debris might facilitate the transport of monomers and potentially toxic additives, such as plasticisers, flame retardants, and antimicrobial agents that are incorporated into plastics during manufacture (Mato et al. 2001; Oehlmann et al. 2009; Teuten et al. 2009). For example, plasticisers, such as bisphenol-A (BPA), can affect the hormonal systems and reproductive output of molluscs, fish, crustaceans and insects (Endo et al. 2005; Teuten et al. 2007; Oehlmann et al. 2009). However, it is unclear whether microplastics in the marine environment can transport chemicals to biota in concentrations high enough to cause significant damage (Cole et al. 2014).

The potential for harm from microplastics could increase with decreasing particle size, but size distributions and generation and degradation rates are mostly unknown. Ingestion of microplastics by mammals, fish, birds, and invertebrates is now well documented (Fossi et al. 2012; Cole et al. 2013; de Witte et al. 2014), however the resulting effects on natural populations are difficult to ascertain (Law and Thompson 2014).

\subsubsection{Effects of Microplastics:}

\subsubsection{Accumulation in water:}

As plastics are buoyant they are at the mercy of currents and tides (Koelmans et al. 2014). This leads to accumulation of particles in certain areas around the world, for example ocean gyres. The accumulation of large quantities of plastic has multiple effects on the surrounding waters (Cole et al. 2011). Due to abrasion (Eriksen et al. 2013) and damage from UV (Andrady 2003) these large plastics are degraded into thousands of smaller particles (microplastics), which accumulate in seawater and as such become available to a range of ecosystems (Galgani et al. 2014), affecting organisms ranging from large marine mammals to benthic filter/suspension feeders.

Numerous studies have tried to quantify exactly just how much plastic there is in the world's oceans, however as the study area is large and an open system, exact numbers are difficult to ascertain (Martins and Sobral 2011). However, many site-specific studies of 
plastic concentrations have been conducted, including Wright et al. (2013b), where maximum plastic debris concentrations in a Swedish harbour next to a polyethylene (PE) plant were documented as 100,000 particles $\mathrm{m}^{-3}$. This high number shows the extent to which microplastics are able to contaminate an ecosystem.

\subsubsection{Accumulation in beaches/sediments:}

Microparticles travel vast distances, washing up on beaches or sinking to the deep sea and settling in sediments (Claessens et al. 2011; Van Cauwenberghe et al. 2013; Nuelle et al. 2014). As previously mentioned, these particles absorb toxins and as they build-up in sediments the amount of chemicals in the substrate increases, potentially leaving the area lethal to benthic organisms and settling larvae (Sánchez et al. 2013).

While the majority of plastics are initially positively buoyant, through degradation and fouling most eventually accumulate on the seafloor, where depending on the properties of the polymer they can potentially remain for thousands of years (Stefatos et al. 1999; Barnes et al. 2009; Galgani et al. 2010). Data on the distribution and abundance of plastic accumulation on the seabed are still scarce (Galgani et al. 2010) and even less is known regarding the long-term dynamics of plastic accumulation in the oceans.

\subsubsection{Interactions with animals:}

Organisms swimming in the water column are particularly susceptible to microplastics, where it is suggested that they mistake these particles for food (Hoss and Settle 1990), or unintentionally ingest them while swimming (Fossi et al. 2012; Fossi et al. 2014b). An example of this was found in the English Channel where ingested microplastic debris was recovered from 10 species of fish (Lusher et al. 2013).

\subsubsection{Plankton:}

Setälä et al. (2014) revealed that plastic microspheres are widely ingested by various planktonic taxa in the Baltic Sea. As a result, trophic transfer of microplastic litter may potentially take place in both benthic and pelagic food webs. This is problematic as Murray and Cowie (2011) discovered that omnivorous feeders can ingest plastics via passive grazing from sediments or via a trophic pathway. Many different zooplankton 
taxa have the potential to ingest microplastics. Whether these particles pass through without harm, are toxic to the organism, or are retained and passed up the food chain, depends on the species of the organism and the size of the plastic particles ingested (Cole et al. 2014). Setälä et al. (2014) determined that mysids and polychaete larvae also ingest microplastics, and as they live partially in both the pelagic and benthic systems, they have the potential to transfer microplastics between the food webs of these environments.

Major questions remain about the risk of microplastics to marine organisms and marine ecosystems. Although quantities can be low, the widespread incidence in some areas, along with evidence of potentially harmful effects is cause for concern.

Research is limited in regards to the behaviour of different polymers in the environment, be it fragmentation, chemical release, degradation, transport, or accumulation. Furthermore, build-up of microplastics can lead to potential bio-magnification throughout food webs.

As substantial removal of microplastic litter from the environment is just not feasible, identification and elimination of the major inputs of plastic waste is necessary, as is reducing consumption. Due to rapidly increasing human population, the need for greater resource efficiency is vital in regards to reducing the quantity of debris entering the marine environment. Evidence has arisen that microparticles are accumulating in mussels cultivated for human consumption (Van Cauwenberghe and Janssen 2014). These mussels were specifically grown with consumerism in mind and were bought from a local supermarket in England. This only highlights the need to understand "cause and effect" of microplastic particles on fauna throughout the marine environment.

\subsubsection{Fish:}

Microplastics have both physical and chemical effects on the organisms that ingest them (Kaposi et al. 2014; Setälä et al. 2014). When ingested, these particles either pass through the gut or are retained in the digestive tract (Browne et al. 2008). Boerger et al. (2010) suggested that planktivorous fish ingest microplastic fibres because they are the same colour as prey items. However, this hypothesis has not been empirically tested.

The accumulation of microplastic fibres in planktivorous fish may clump up and become hazardous if they block the feeding apparatus, impede the passage of food or clog digestive tracts (Derraik 2002; Gregory 2009; Ryan et al. 2009). Rochman et al. (2014b) studied the effects of plastics on lanternfish, a deep sea fish that is well known for its 
extensive vertical migrations during the night to feed on zooplankton from the epipelagic zone (Catul et al. 2011; Van Noord et al. 2013). As a consequence of their vertical migrations, these fish are subjected to and ingest plastic debris (Boerger et al. 2010; Davison and Asch 2011; Van Noord et al. 2013). Rochman et al. (2013b) suggested that not only does this harm the lanternfish, but ultimately impacts other organisms in open ocean food webs, including top predators and commercially important fish. Moreover, experimental evidence demonstrates that PBDEs can transfer from plastic to organisms, including fish, upon ingestion (Browne et al. 2013; Rochman et al. 2014a). Furthermore, large filter feeding sharks such as the Mediterranean basking shark, have been found to possess high levels of plastic additives in their muscle tissues from ingestion of microplastics during feeding (Fossi et al. 2014a), further highlighting the susceptibility of large pelagic species to microplastics.

\subsubsection{Marine Mammals and Birds:}

Many large marine mammals and birds are affected by microplastics. The impacts of plastics being ingested by these charismatic megafauna are relatively well known (D'Ilio et al. 2011; Tanaka et al. 2013; Fossi et al. 2014b). Marine mammals are indirectly impacted as they are often top predators, and as such they are susceptible to biomagnification of toxins due to accumulation of microplastics in their prey (Kannan et al. 2001; Van de Vijver et al. 2005; Houde et al. 2006). A recent example was outlined by Houde et al. (2006) where bottlenose dolphins were found to have toxins associated with plasticizers in their tissues. It was determined that the toxins originated in prey species and were directly transferred to the bottlenose dolphins, increasing by several orders of magnitude in the process. Many large marine mammals filter feed relying on their main prey phytoplankton (Fossi et al. 2012). Phytoplankton are in general the same size as microplastics, and as a result baleen mammals are susceptible to ingesting microplastics as they feed (Rochman et al. 2013a).

Not only are marine mammals affected by microplastics but birds are also susceptible to the impacts associated with these particles. Microplastics have been found to accumulate in the gut of seabirds, where they not only block up digestive tracts (Dickerman and Goelet 1987; Pierce et al. 2004) but also leach toxins into the surrounding tissues (Pettit et al. 1981; Sievert and Sileo 1993). Recent examples of microplastic effects on seabirds have been documented for the wedge-tailed shearwater (Verlis et al. 2013) and various seabirds from the Mediterranean (Codina-García et al. 2013), where it was found that 
microparticles accumulated in the gut of numerous seabirds (171 birds from 9 species), again highlighting the negative influence that microplastics pose in the marine environment. While awareness of the effects and repercussions of microplastics has increased in recent years, there is still a profound lack of knowledge regarding definitive concentrations in seawater and the effects that these particles may have on food webs. The marine environment is notoriously difficult to monitor, due to its sheer size and "open" nature, and understanding interactions between anthropogenic inputs and the natural ecosystems is paramount, as these stressors may lead to complex difficulties arising in the future.

\subsection{Thesis Research:}

Tethya bergquistae and Crella incrustans (Figure 1.4) were the two species chosen for this study. Both species are common demosponges inhabiting shallow-water rocky reefs in New Zealand (Berman and Bell 2010; Berman 2012). All samples were collected from the Wellington Region, with sites chosen due to high sponge biomass (Berman 2012), and ease of accessibility. Tethya bergquistae (Sarà and Sarà 2004) and Crella incrustans (Battershill et al. 1984) were chosen because they are readily available, abundant on the Wellington South Coast and can be easily maintained under laboratory conditions.

Wellington's south coast is a dynamic environment, frequently exposed to high-energy south-easterly swells and north-westerly winds. These combined with large storm events, are capable of creating wave heights exceeding $13 \mathrm{~m}$ (Carter et al. 2008). The south coast area is heavily influenced by the Cook Strait, a current formed by three major water bodies: the Southland Current, East Cape Current and D'Urville current. These currents, in combination with the dynamic nature of the Wellington South Coast are highly influential to intertidal and subtidal communities, allowing the region to support a large biomass of sponges (Berman and Bell 2010; Berman 2012). 

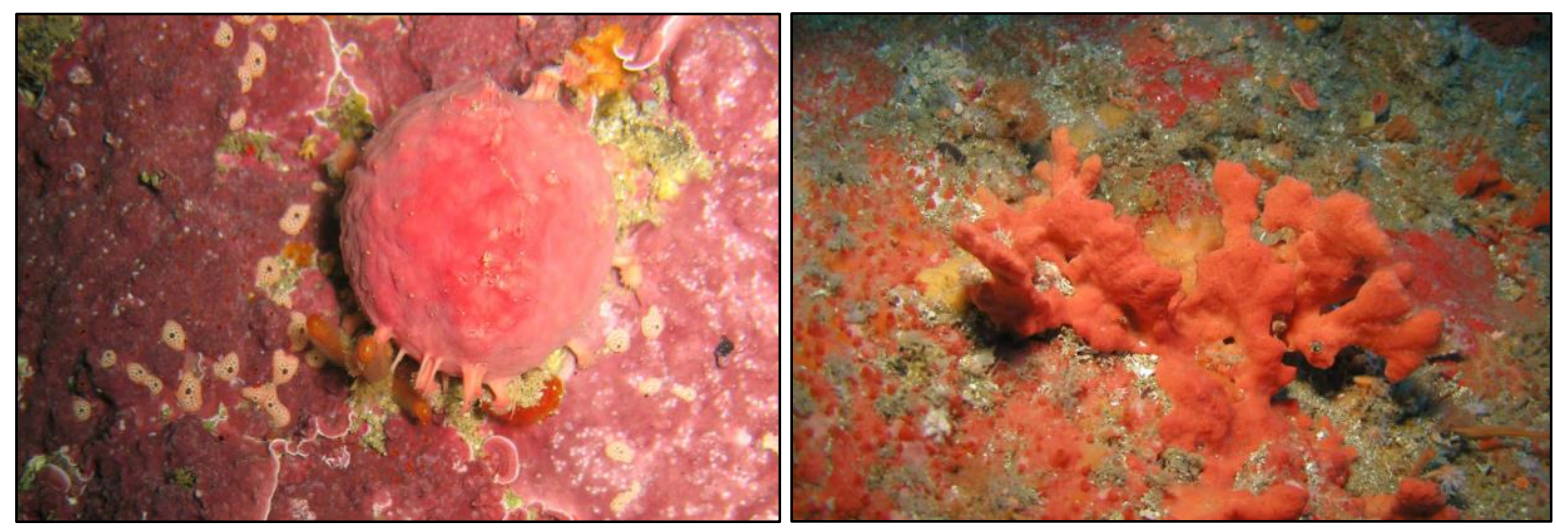

Figure 1.4: Left: Tethya bergquistae pink golf ball sponge. Photo by Crispin Middleton. Right: Crella incrustans with palmate fans. Photo by Mike Page

T. bergquistae is a spherical golf-ball sponge, growing up to $6 \mathrm{~cm}$ in diameter, commonly found on subtidal exposed coastlines in high-light environments with strong currents or wave action (Battershill et al. 1984). This species reproduces year-round (Bergquist 1968) via sexual reproduction and asexual budding, with budding seeming to be exacerbated by the addition of external stressors (see Bates 2015).

The second species, $C$. incrustans, exhibits several contrasting morphologies, growing as a massive sponge in sheltered environments or as an encrusting sponge in areas of high water movement (Battershill et al. 1984). As a result this species has a wide distribution throughout New Zealand, in a variety of sheltered and exposed habitats (Bergquist 1968). Both species are important structural components of shallow-water reef systems due to their abundance (Berman 2012), competitive and facilitative interactions with algae (Cárdenas et al. 2014), and their interactions with the water column (Perea-Blázquez 2011).

However, despite this, environmental changes may have additional impacts on rocky reef communities, but little is known of physiological responses of sponges to environmental factors. Additionally, shallow water sponges are likely to be affected by changing environmental conditions such as increasing plastic pollution, particularly if these stressors alter community composition of rocky reefs. 


\subsubsection{Aims:}

The overall aim of this thesis was to investigate how these temperate sponges will be impacted by increased loads of microplastics introduced into seawater. An emphasis was placed on physiological and functional responses of sponges to this stressor, for example; sponge health and respiration after microplastic ingestion and feeding retention in response to different particle types.

The specific aims of this study are to:

1. Measure the effect of microplastics on oxygen consumption rates of temperate sponges.

2. Compare the feeding retention of temperate sponges, when subjected to a variety of particulates.

3. Compare the responses of two sponge species, and determine if responses are species specific 


\section{The Effects of Microplastics on Temperate sponge Respiration:}

\subsection{Abstract:}

Microplastic pollution is of increasing concern throughout the marine environment. These small particles $(<5 \mathrm{~mm})$ are often ingested by animals that mistake them for food or filter them from the water column. Once ingested, microplastics have the potential to leach toxins into surrounding tissues and clog feeding mechanisms Microplastics are of particular concern to suspension feeders as they actively pump ambient water as a means of feeding. Sponges are ubiquitous throughout benthic marine systems where they play an essential role in the ecosystem from impacting substrate to facilitating primary production. Sponges are capable of filtering vast amounts of seawater and as such, they are susceptible to suspended particulates in the surrounding waters. Respiration has been shown to be a suitable measure of sponge stress in previous studies investigating the effect of sediment, temperature and $\mathrm{pH}$ on sponges. Therefore the respiration rate of temperate sponges was measured in this study to determine the effect of microplastics on their health. Two temperate sponges Crella incrustans and Tethya bergquistae were exposed to microplastics in a controlled environment $(75 \mathrm{~mL}$ chamber) and the oxygen consumption measured over 45 minutes. Individuals from each species were exposed to one of two treatments or a control, including a solution of 200,000 beads per $\mathrm{mL}$ (treatment 1), a solution of 400,000 beads per $\mathrm{mL}$ (treatment 2) or filtered seawater (control). The respiration rate of ten individuals from each species was measured in each treatment over the course of three days. On completion of the experiment, the ash free dry mass (AFDM) of each sponge was obtained to determine the amount of oxygen consumed as $\mathrm{mg} \mathrm{O}_{2} \mathrm{~g}(\mathrm{AFDM})^{-1} \mathrm{~L}^{-1}$. Crella incrustans showed no significant main effects or interactions across any of the microplastic sizes, treatments or days. In addition however, there was a significant main effect of microplastic size $(P=0.001)$ for $T$. bergquistae. The results from this study indicate no direct effect of microplastic pollution on the immediate health of two temperate sponges, with the exception of microplastic size on $T$. bergquistae. 


\subsection{Introduction:}

Plastic debris in the marine environment is a universally recognised problem, affecting a wide range of ecosystems (Moore 2008; Zarfl et al. 2011). Global production of plastic has continued to rise with some 299 million tons of plastics being produced in 2013 alone, representing a 4 percent increase over 2012. Recovery and recycling, however, remain insufficient, and millions of tons of plastics end up in landfills and entering the oceans each year, with estimates that at least 5.25 trillion plastic particles weighing 268,940 tons are currently floating in the sea (Eriksen et al. 2014).

Recent concern has focused primarily on microplastics and their impacts on the marine environment (Derraik 2002; Ryan et al. 2009). Broadly described, a "microplastic" is any plastic particle under $5 \mathrm{~mm}$ (NOAA), however, they vary in size $(0.001 \mathrm{~mm}-5 \mathrm{~mm})$ and in the way they are quantified (Ng and Obbard 2006; Barnes et al. 2009). Due to the small size of these particles, they are readily available to be ingested or taken up by many organisms. For example, Setälä et al. (2014) revealed that plastic microspheres are widely ingested by various planktonic taxa in the Baltic Sea. As a result, trophic transfer of microplastic litter may potentially take place in both benthic and pelagic food webs. This is problematic as Murray and Cowie (2011) discovered; omnivorous feeders can ingest plastics via passive grazing from sediments or via a trophic pathway. Many different zooplankton taxa have the potential to ingest microplastics. Whether these particles pass through without harm, are toxic to the organism, or are retained and passed up the food chain, depends on the species of the organism and the size of the plastic particles ingested (Cole et al. 2014). Setälä et al. (2014) determined that mysids and polychaete larvae can ingest microplastics, and as they live partially in both the pelagic and benthic systems, they have the potential to transfer microplastics between the food webs of these environments.

Arguably benthic organisms are subject to the greatest risk from microplastics as they are generally unable to move away from contaminated areas (von Moos et al. 2012) and because many benthic organisms are filter or suspension feeders (Farrell and Nelson 2013; Goldstein and Goodwin 2013). There have been a variety of studies performed on filter and suspension feeders. For example, studies examining feeding in the blue mussel (Mytilus edulis) by Browne et al. (2008) showed that microspheres of polystyrene are drawn through the inhalant siphon and filtered via the gill. On the gill, filamentous cilia 
captured plastic particles and rapidly transported them to the gut, where they accumulated in the digestive cavity and tubules. The particles were then translocated from the gut cavity to the circulatory system in as little as 3 days where they persisted in the circulatory system for over 48 days (Browne et al. 2008). Similarly von Moos et al. (2012), supporting Browne et al. (2008), provided the first proof that microplastics are taken up into digestive cells of $M$. edulis where they induce distinct adverse effects, and that polarized light microscopy can be used to track and localize microplastic particles within organisms and organs. Due to the vulnerability of filter and suspension feeders to plastic pollution, coupled with increasing volumes of litter with no foreseeable end, it is vital that we understand how these particles will affect these crucial members of temperate ecosystems.

Sponges are ubiquitous throughout the marine environment, being an important ecological group in benthic marine systems, fulfilling many functional roles including; bio-erosion (Rützler 1975), facilitation of primary production (Bell 2008), and filtering large volumes of water (Ribes et al. 1999). Sponges are also key spatial competitors, involved in competitive interactions with many different species (Wulff 2006a; Taylor et al. 2007). Conversely, the distribution, abundance and physiology of sponges is controlled by a number of abiotic factors, including temperature (Duckworth and Battershill 2001), light (Irving and Connell 2002), sedimentation (Carballo 2006), and substrate composition and angle (Bell and Barnes 2000a), therefore they are sensitive to environmental changes (Bell et al. 2015). Due to large sponge abundance (Pile et al. 1997), and their ecological importance in the marine environment (Wulff 2006b; Bell 2008), there is an increasing need to understand the physiological responses of sponges to changing environmental factors, such as increased marine pollution. Of equal importance is the fact that environmental degradation can alter sponge diversity and abundance, which in turn may influence the distribution of other ecologically important organisms (Ward-Paige et al. 2005; Peterson et al. 2006; Powell et al. 2010).

The overall aim of this experiment was to investigate the effect of microplastics on respiration rates of Tethya bergquistae and Crella incrustans. More specifically, I investigated if these species had a change in their metabolic demand over time, in response to stress from plastic pollution, and if such responses were similar between the 
two plastic sizes, or if they were size specific. With increasing rates of plastic pollution, and the likelihood that this will continue for some time, I hypothesized that respiration rates would be higher in response to elevated plastic pollution. If size-dependent responses exist, I believed that the $1 \mu \mathrm{m}$ microplastic beads would have more effect, as they are of similar size to the sponges' natural food source (Pile et al. 1996) and as such will be more easily ingested by the experimental specimens.

\subsection{Methods:}

\subsubsection{Sponge collection and husbandry:}

Tethya bergquistae and Crella incrustans were chosen as the study organisms. These species are a suitable model for other demosponges as they are abundant and found in a wide range of habitats. Sponge specimens were collected from the South Coast and Harbour of Wellington, New Zealand (Figure 2.1), specifically Breaker Bay (-41.331343, 174.831824), Princess Bay (-41.344904, 174.787688), Moa Point $(-41.342674,174.808311)$ and Shark Bay $(-41.301133,174.817476)$ via SCUBA from depths of 5-10 m. These sites were chosen because they are sponge-dominated systems and are easily accessible.
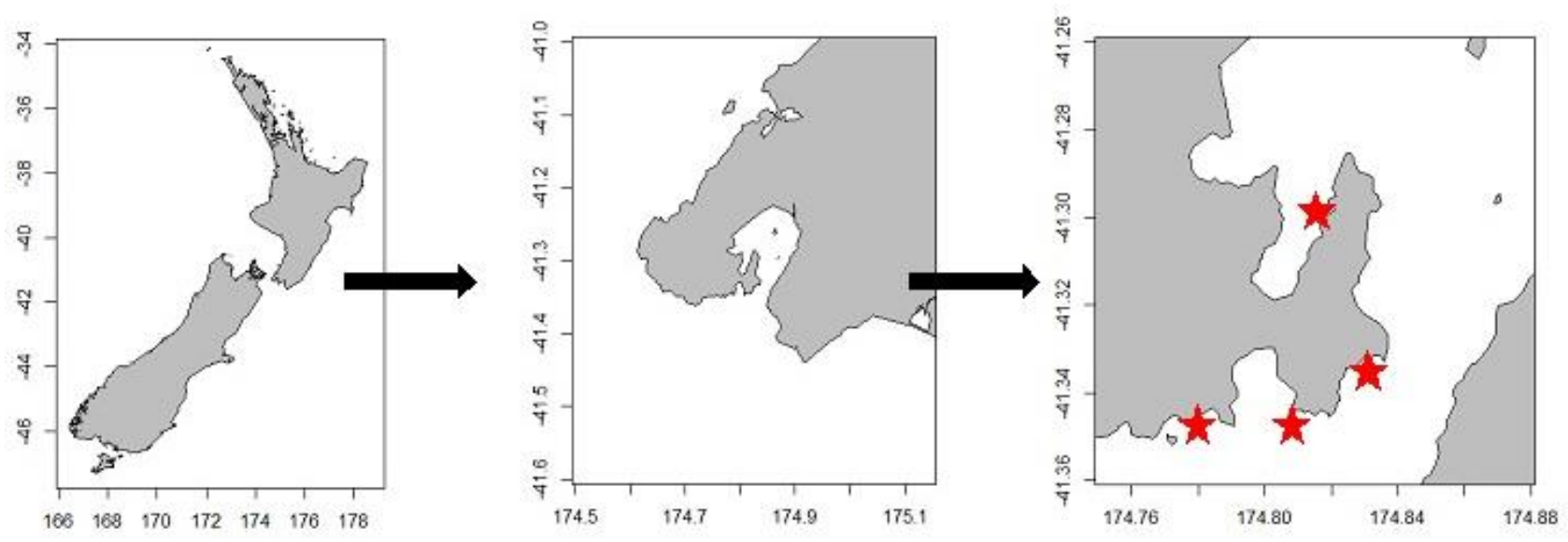

Figure 2.1: Map of New Zealand, focusing in on Wellington region. The Wellington South coast collection sites are marked by red stars. 
Following collection the sponges were transferred to Victoria University Coastal Ecology Laboratory (VUCEL) where they were placed in an open flow sea table, where raw sea water was continuously fed at a rate of approximately $4 \mathrm{~L} \mathrm{~min}^{-1}$, which is optimal for sponge survival (See Bates 2015). Visible surface-associated fouling organisms were gently removed from all individuals with tweezers, and the sponges were then sewn on to plates with cotton and left to acclimate. T. bergquistae were attached whole, however $C$. incrustans were cut into approximately $3 \mathrm{~cm}^{3}$ pieces (Figure 2.2). Both species were then left to heal completely before the experiment began. Approximately three weeks was sufficient time to allow the $C$. incrustans cut surfaces to heal, consistent with other sponge studies (Zocchi et al. 2003; Nickel 2004; Hadas et al. 2008).
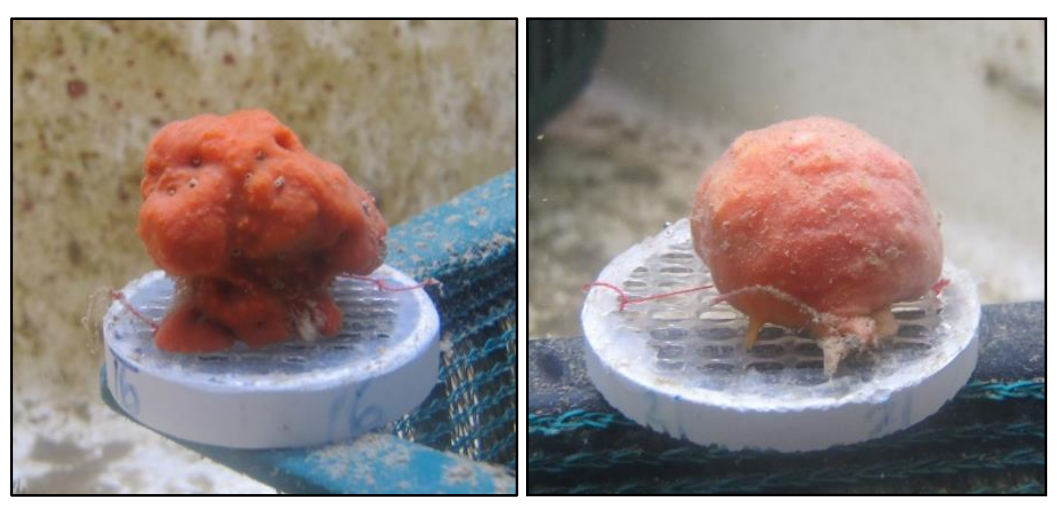

Figure 2.2: Left -Crella sp mounted upon a meshed plate. Right - Tethya $\mathrm{sp}$ attached to a mesh plate. Photos by C.Baird.

\subsubsection{Respiration:}

Following acclimation, each sponge was transferred from the holding tank into a respiration chamber similar to that employed by Gatti et al. (2002). Each chamber was 75 $\mathrm{mL}$ in volume and incorporated a magnetic stirrer, the chambers were then fitted with lids (Figure 2.3) and any oxygen bubbles were carefully removed via syringe. Each lid possessed an opening through which a rubber bung was placed. Through this bung a Presens Pst 3 oxygen sensor and a temperature probe were inserted, allowing the sensors to become submerged within the chamber. Each chamber was considered airtight due to an O-ring around the lid, and the rubber bung creating tight seals around the sensors. In addition, vaseline was put around the bung and sensors to ensure no additional airflow or water intake. 
An oxygen probe (FIBOX 3- fiber-optic oxygen meter, PreSensGmbH, Germany) was used to measure the initial oxygen concentration $(\mathrm{mg} / \mathrm{L})$ within the chambers. The probe was calibrated at the beginning of each day in $100 \mathrm{~mL}$ of water containing $1 \mathrm{~g}$ of sodium sulphite $\mathrm{Na}_{2} \mathrm{SO}_{3}$ for $0 \%$ saturation, or with air bubbled through it for 20 minutes for $100 \%$ saturation.

During testing care was taken when introducing the oxygen probe not to knock the chambers as this would cause the sponge to close its oscula, affecting respiration rates. Oxygen concentrations were measured every 10 seconds over a 45 minute period or until oxygen concentrations reached $70 \%$ of the initial reading, this was the repeated every 24 hours for three consecutive days, with sponges returned to the sea table in-between testing.

The amount of oxygen used by each animal was calculated as the difference between the initial and final oxygen concentrations within the chambers.

The water volume in each chamber was measured at the end of each experiment to allow for the volume occupied by the animal. The oxygen concentration $(\mathrm{mg} / \mathrm{L})$ was corrected to allow for the volume of water and converted into an hourly rate to provide the amount of oxygen consumed per hour by each animal $\left(\mathrm{mg} \mathrm{O}_{2}\right.$ animal $\left.{ }^{-1} \mathrm{~h}^{-1}\right)$. To express the respiration rates as the amount of oxygen consumed by organic tissue, the ash free dry mass (AFDM) of each sponge was determined at the end of each experiment. The AFDM was calculated as the difference between the dry weight and the ash weight after incineration in a muffle furnace. Dry weight was obtained by placing the sponges in an oven at $80^{\circ} \mathrm{C}$ for 48 hours then weighing (to the nearest $0.0001 \mathrm{~g}$ ). Ash weight was attained from the sponges by placing them into clean labelled aluminium trays and placing them in a muffle furnace $\left(500^{\circ} \mathrm{C}\right.$ for 6 hours), which removes all organic matter; they were then subsequently weighed. The overall respiration rate of each animal was defined as the amount of oxygen consumed per gram of organic tissue per hour $\left(\mathrm{mg} \mathrm{O}_{2} \mathrm{~g}\right.$ $\left.(\mathrm{AFDM})^{-1} \mathrm{~h}^{-1}\right)$. 


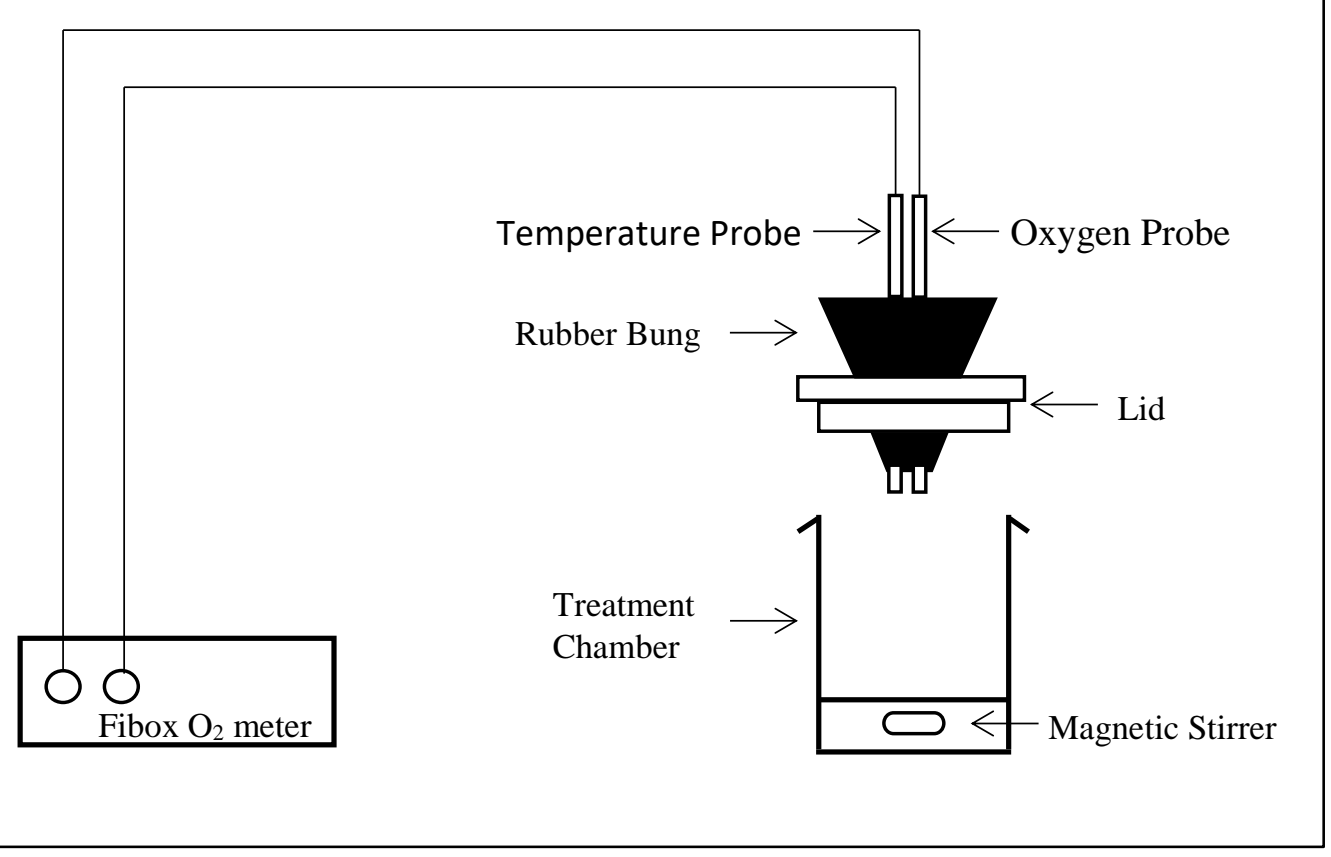

Figure 2.3: Diagram of the experimental setup, temperature and oxygen probes fitted in a rubber bung, with the treatment chamber and a magnetic stirring bead.

In addition, an empty chamber filled with treatment water was measured for 45 minutes to control for electrode drift (Gatti et al. 2002), or photosynthesis and respiration of micro-organisms in the water. Any change in air saturation during the blank experiment was then subtracted from the total sponge respiration that occurred during the same time period.

\subsubsection{Treatments:}

In order to test the effects of microplastics on sponges, two treatments and a control (raw seawater) was chosen for each of the study species. The treatments chosen were 1) $\sim 200,000$ beads per $\mathrm{mL}$ and 2) 400,000 beads per $\mathrm{mL}$. Each treatment had 10 replicates per microplastic size $(1 \mu \mathrm{m}$ and $6 \mu \mathrm{m})$, with $\mathrm{n}=60$ per species. The beads used were Polysciences, Inc. Polybead ${ }^{\circledR}$ Polystyrene Black dyed 1.00 micron Microspheres, and Polysciences, Inc. Polybead ${ }^{\circledR}$ dyed Violet 6.0 micron Microspheres. The numbers of microplastics in the waters surrounding New Zealand are undocumented, mostly due to a general lack of plastic pollution in these waters. As such, the "normal" treatment number was chosen as a reflection of the natural concentrations of picoplankton (Marie et al. 1997), the primary food for sponges (Reiswig 1971b; Van de Vyver 1975; Huysecom et 
al. 1988; Pile et al. 1996) and subsequently a "high" treatment being double those numbers.

As the response variable is dependent on the sponge actively pumping, it was necessary to ensure this had been initiated before data collection. Observing active pumping in sponges is usually shown by adding a dye to the water near the incurrent pore of the sponge (for example, Vogel 1977; Imsiecke 1993; Ilan and Abelson 1995; Pile and Young 2006), however previous attempts at this were unsuccessful with Tethya berquistae and Crella incrustans (see Bates 2015). In this case the program used (OxyView v6.02) allows an oxygen consumption curve to be observed and as such, only once sponges showed a clear respiration response were the data collected.

\subsubsection{Statistical analysis:}

Initial analyses were performed by Primer 6 and PERMANOVA+ (2009), with all further statistical tests conducted by IBM SPSS Statistics (version 23, 2015). In all cases tests were performed to check for the presence of outliers, and to confirm the assumptions of normality, homogeneity of variances, and sphericity (in the case of Crella incrustans the data were logged to meet Mauchly's assumption of sphericity). The species were analysed separately as they were collected from separate locations around Wellington. In the case of Crella incrustans, specimens were collected from Wellington Harbour (Shark Bay) a soft bottomed, silty substrate. Contrastingly, Tethya bergquistae samples were acquired from the Wellington South Coast, a hard bottomed rocky shore. Due to the contrasting habitats at these locations each species was analysed separately. They were also collected and experimented on at different times in the year; Tethya bergquistae during June--October and Crella incrustans during October-January.

\subsubsection{Respiration rates:}

A three-way repeated measures permutational analysis of variance (PERMANOVA) was run to determine if there was an interaction between three factors (microplastic size, treatment and time) on the oxygen consumption rates of temperate sponge species. 
Days (3 levels; day one, day 2 and day 3) were nested into associated treatments (3 levels; control of 0,200,000 and 400,000 beads per mL), and the treatments were nested within MP size (2 levels; $1 \mu \mathrm{m}$ and $6 \mu \mathrm{m}$ ).

\subsection{Results:}

\subsubsection{Crella incrustans:}

The effects of microplastics on respiration rates in this species were highly variable (ranging from $3.91-47.25 \mathrm{mg} \mathrm{O}_{2} \mathrm{~g}(\mathrm{AFDM})^{-1} \mathrm{~h}^{-1}$ for $1 \mu \mathrm{m}$ treatments and $0.68-50.98$ $\mathrm{mg} \mathrm{O}_{2} \mathrm{~g}(\mathrm{AFDM})^{-1} \mathrm{~h}^{-1}$ for the $6 \mu \mathrm{m}$ treatments) across both MP sizes, all concentrations and time. (Figure 2.4). This was confirmed by the 3 way repeated measures PERMANOVA, which indicated no significant difference between any main effects or any of the interactions (Table 1).

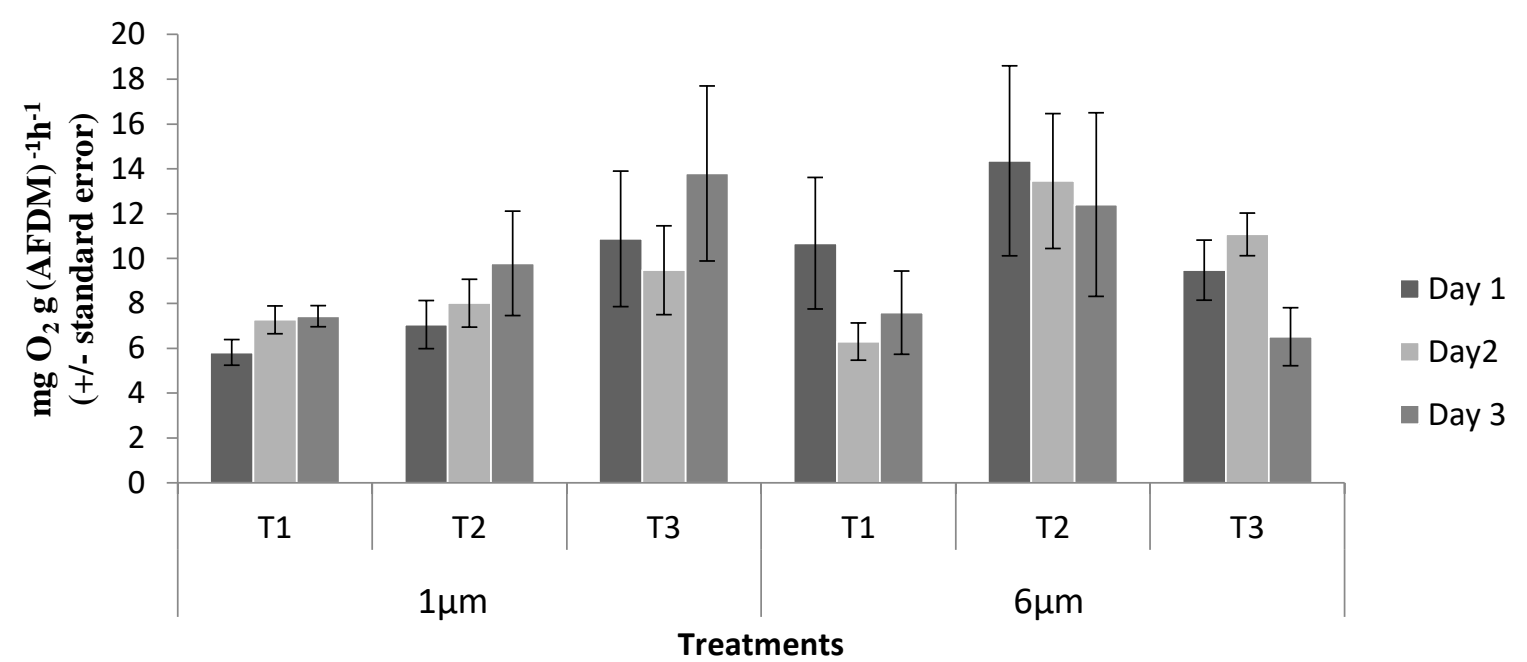

Figure 2.4: Respiration rates of Crella incrustans following exposure to microplastics. Bars are grouped by days into treatments and then into microplastic size. Error bars show one standard error $(\mathrm{n}=10)$. T1, $\mathrm{T} 2$ and $\mathrm{T} 3$ represent the control, 200,000 and 400,000 beads per mL respectively. 
Table 1: Results of repeated measures ANOVA, comparing the mean respiration rates of Crella incrustans in relation to microplastic size, treatments and across days.

\section{PERMANOVA table of results}

\begin{tabular}{lllllll}
\hline Source & \multicolumn{1}{c}{ S } & \multicolumn{1}{c}{ SS } & \multicolumn{1}{c}{ MS } & Pseudo-F & P(perm) & Unique perms \\
\hline MP size & 1 & $5.24 \mathrm{E}-02$ & $5.24 \mathrm{E}-02$ & $5.54 \mathrm{E}-03$ & 0.98 & 998 \\
Treatment & 2 & 2.1838 & 1.0919 & 0.11563 & 0.906 & 999 \\
Day & 2 & $1.17 \mathrm{E}-02$ & $5.85 \mathrm{E}-03$ & $6.20 \mathrm{E}-04$ & 1 & 998 \\
MP size x Treatment & 2 & 1.7426 & 0.87129 & $9.23 \mathrm{E}-02$ & 0.931 & 999 \\
MP size x Day & 2 & 1.5209 & 0.76046 & $8.05 \mathrm{E}-02$ & 0.953 & 997 \\
Treatment x Day & 4 & 0.10771 & $2.69 \mathrm{E}-02$ & $2.85 \mathrm{E}-03$ & 1 & 999 \\
MP size x Treatment x Day & 4 & 0.67817 & 0.16954 & $1.80 \mathrm{E}-02$ & 1 & 999 \\
Res & 162 & 1529.7 & 9.4427 & & & \\
Total & 179 & 1536 & & & & \\
\hline
\end{tabular}

\subsubsection{Tethya bergquistae:}

The effects of microplastics on this species were also highly variable (the $1 \mu \mathrm{m}$ treatments ranged from $0-8.13 \mathrm{mg} \mathrm{O}_{2} \mathrm{~g}(\mathrm{AFDM})^{-1} \mathrm{~h}^{-1}$ and the $6 \mu \mathrm{m}$ treatments ranged from $\left.0-52.98 \mathrm{mg} \mathrm{O} \mathrm{O}_{2}(\mathrm{AFDM}){ }^{-1} \mathrm{~h}^{-1}\right)$, with analysis of respiration rates being inconsistent across all three factors (MP size, Concentrations and Days) (Figure 2.5). This was confirmed by the 3 way repeated measures PERMANOVA, which showed no significant difference in all but one of these interactions or main effects (Table 2). There was a significant effect of the size of microplastic on respiration rate $\left(F_{1}=19.085 ; P=\right.$ 0.001) for this species, with all three $6 \mu \mathrm{m}$ treatments showing higher respiration rates than the $1 \mu \mathrm{m}$ treatments. 


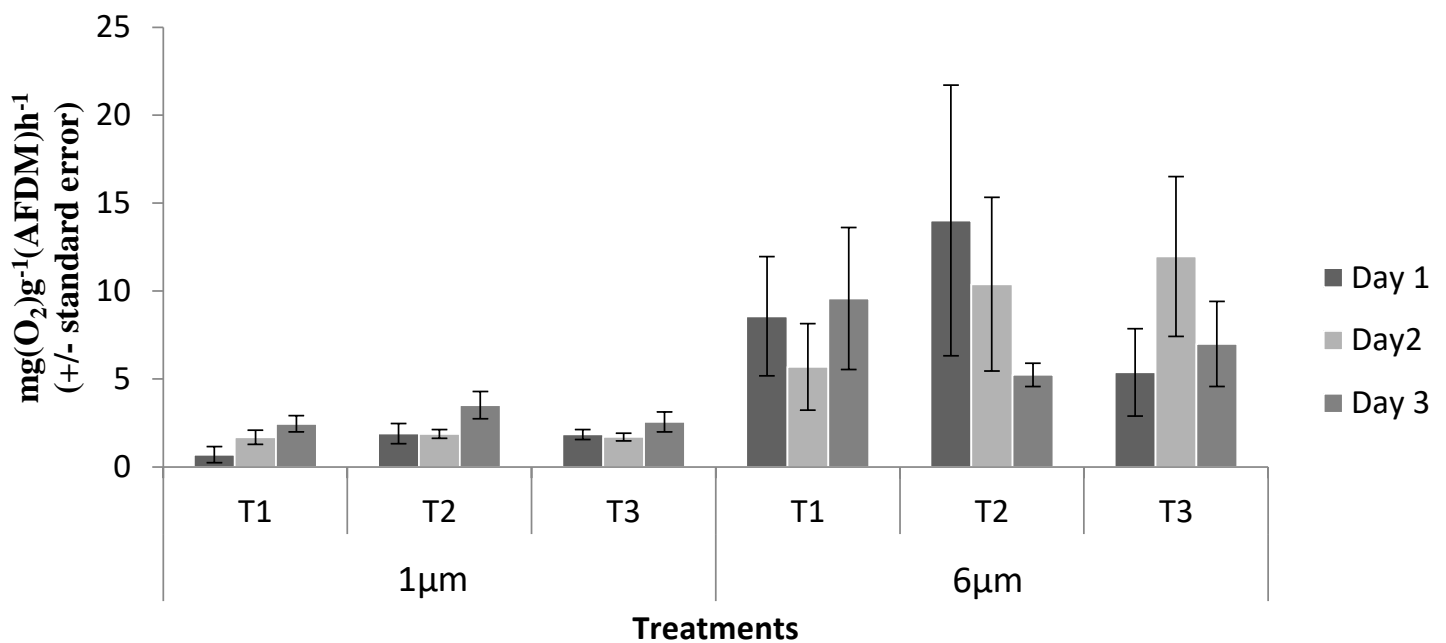

Figure 2.5: Respiration rates of Tethya bergquistae following exposure to microplastics. Bars are grouped by days into treatments and then into microplastic size. Error bars show one standard error $(\mathrm{n}=10)$. $\mathrm{T} 1, \mathrm{~T} 2$ and $\mathrm{T} 3$ represent the control, 200,000 and 400,000 beads per $\mathrm{mL}$ respectively.

Table 2: Results of repeated measures ANOVA, comparing the mean respiration rates of Tethya bergquistae in relation to microplastic size, treatments and across days.

\begin{tabular}{lcccccc}
\hline \hline \multicolumn{7}{c}{ PERMANOVA table of results } \\
\hline Source & $d f$ & SS & MS & F & P(perm) & Unique perms \\
\hline MP size & 1 & 1972.6 & 1972.6 & 19.085 & 0.001 & 997 \\
Treatment & 2 & 62.977 & 31.489 & 0.30465 & 0.802 & 999 \\
Day & 2 & 7.7525 & 3.8762 & $3.75 \mathrm{E}-02$ & 0.997 & 998 \\
MP size x Treatment & 2 & 16.018 & 8.0088 & $7.75 \mathrm{E}-02$ & 0.974 & 999 \\
MP size x Day & 2 & 108.88 & 54.439 & 0.5267 & 0.633 & 998 \\
Treatment x Day & 4 & 281.87 & 70.469 & 0.68178 & 0.64 & 998 \\
MP size x Treatment x Day & 4 & 345.65 & 86.413 & 0.83604 & 0.511 & 999 \\
Res & 162 & 16744 & 103.36 & & & \\
Total & 179 & 19540 & & & & \\
\hline
\end{tabular}




\subsection{Discussion:}

Microplastics are found throughout the marine environment, and increasing concern has focused on the effects these pollutants have on benthic organisms. Due to the small size of these particles they have become available to a wide variety of biota (Barnes et al. 2009). Moreover, the persistent and widespread nature of microplastics suggests that interactions between benthic filter/suspension feeders are increasingly likely.

Previous research in regards to temperate sponge respiration has focused primarily on the effects of sediments (Murray 2009) or temperature and pH (Bates 2015). In addition, those studies concerning microplastics and benthic marine organisms have concentrated mainly on uptake and retention (Farrell and Nelson 2013; Goldstein and Goodwin 2013). As such, to my knowledge this is the first investigating the effects of microplastics on the respiration of temperate sponges.

The aim of this study was to determine how temperate sponge oxygen consumption responded to increased plastic pollution. This was achieved by subjecting two abundant temperate sponges Tethya bergquistae and Crella incrustans, to two different sized particles $(1 \mu \mathrm{m}$ and $6 \mu \mathrm{m})$ and three different concentrations of these plastics $(0,200,000$ and 400,000 beads per $\mathrm{mL}$ ). Sponges were isolated in closed system treatment chambers $(75 \mathrm{~mL})$, and subjected to one of three treatments/concentrations. When sponge respiration was observed to be underway, the oxygen consumption was then measured for 45 mins. This was repeated for three consecutive days, after which each sponge was dried, incinerated and weighed to adjust for ash free dry mass.

\subsubsection{Metabolic responses to microplastics:}

Several hypotheses have been proposed to explain increased stress response to microplastic pollution in marine invertebrates, including: blockage of respiratory/circulatory systems (Brennecke et al. 2015), blockage of feeding appendages (Brillant and MacDonald 2000; Browne et al. 2008) and toxic leachate (Cole et al. 2011). To investigate how plastic pollution affected the energetic demands of Tethya bergquistae and Crella incrustans, this study used respiration as the standard metabolic rate (SMR) of the whole organism. Oxygen consumption rates in sponges have primarily been used as a measure of the basal energetic requirements of an individual, including, digestion, 
assimilation activity and growth, reproduction and disease resistance (Clarke 1991; McCue 2006; Hadas et al. 2008) and therefore an adequate measure of sponge health.

The results from this study indicate no significant interactions or increased metabolic demand for Crella incrustans or Tethya bergquistae in response to plastic pollution. There was however a main effect of particle size exhibited by T. bergquistae, with the larger particles size causing a higher rate of respiration. This result however is misleading as while a significant main effect is indicated between particle sizes, this also includes a significant difference between the controls for each MP size. In addition, when the sizes are examined individually, there is no significant difference between the other factors (i.e., no significance between treatments and controls). This is important to note because, both controls were raw seawater (with no added particles) and as such the respiration results for the controls should therefore be similar. The fact the controls are not similar and are not significantly different from their respective treatments indicates an additional unaccounted for factor such as, biological variability.

One possible hypothesis for particle size effect is differences in sponge morphology. Crella incrustans is a thickly encrusting sponge, and is fibrous and flexible in texture. Contrastingly, Tethya bergquistae is a solitary spherical sponge and is barely compressible in texture with a thick cortex. As discovered by Reiswig (1971b), sponges with high tissue density show preferential size selection with high capture efficiency for smaller particles, while sponges with lower density are less efficient but without size selection. To determine this, further examination is required (as tissue densities were not measured). However, as previously stated there are discrepancies with the control data, leaving the likelihood of this scenario suspect.

The more likely explanation for the significant effect of size is that these experiments were run from June (Winter) to January (Summer), with the $1 \mu \mathrm{m}$ trials having been run in the earlier months. As such ambient temperature may have been an influencing issue. Previous research in this regard has indicated that warmer temperatures cause temperate sponges to increase $\mathrm{O}_{2}$ consumption (see Bates (2015), this therefore could account for the discrepancies indicated by the results in this study. In addition increased temperatures seem to, in $T$ bergquistae, elicit a budding response (Bates 2015), thereby increasing respiration in an effort to reproduce (Coma and Ribes 2003). All Crella incrustans trials were run in the later months and therefore the lack of significance between microplastic sizes further alludes to the effect of temperature on sponge respiration. 


\subsubsection{Conclusion:}

The results from this chapter indicate that plastic pollution, does not affect oxygen consumption for Tethya bergquistae or Crella incrustans. While there was a main effect of particle size for $T$. bergquistae this result is possibly confounded. On the whole, elevated concentrations of microbeads showed no clear effect on metabolic demand for either temperate sponge species. Moreover, the concentrations used (while relative to natural picoplankton concentrations) are extremely unlikely to occur naturally in the foreseeable future. With microplastic pollution expected to increase the outcome of this experiment highlighting the potential resilience of temperate sponges is encouraging 


\section{Microplastics Particle Retention by Temperate Sponges:}

\subsection{Abstract:}

Microplastic loading is steadily increasing in the marine environment raising concern over how marine life, in particular filter feeders are able to react and adapt to these persistent particulates. As a result there is an increasing focus on the retention abilities of filter feeders when subjected to microplastic loading. Sponges are benthic suspension feeders capable of filtering huge amounts of water every day, while retaining up to $99 \%$ of picoplankton in the process. This ability to efficiently remove particulates leaves sponges vulnerable to the surrounding environment, in particular microplastics suspended in ambient waters. To investigate the retention efficiencies of temperate sponges when subjected to different particles, two species; Crella incrustans and Tethya bergquistae were exposed to one of six treatments for one hour in a controlled environment. Ambient water samples were taken at time $=0$ and again at time $=60$ mins. At the end of the experiment the ash free dry mass (AFDM) of each sponge was determined and the remaining water was filtered to determine the weight of residual particulate organic matter (POM). Treatments were divided into three groups, controls (raw seawater and Isochrysis galbana), sediments $(1 \mu \mathrm{m}$ and $6 \mu \mathrm{m})$ and microplastics $(1 \mu \mathrm{m}$ and $6 \mu \mathrm{m})$. Results for this experiment varied across each of the species with respect to particle type. Crella incrustans showed significant retention differences between raw seawater and 1 $\mu \mathrm{m}$ microplastic $(\mathrm{P}=0.009)$. Tethya bergquistae showed significant differences in retention between raw sea water and $1 \mu \mathrm{m}$ sediments $(\mathrm{P}=0.044)$ and significant differences between $6 \mu \mathrm{m}$ sediment and $6 \mu \mathrm{m}$ microplastic $(\mathrm{P}=0.017)$. With respect to particle size, Crella incrustans showed significant differences in retention of raw sea water and Isochrysis galbana $(\mathrm{P}<0.001)$, and significant retention differences between 1 $\mu \mathrm{m}$ sediment versus $6 \mu \mathrm{m}$ sediment $(\mathrm{P}<0.001)$. Tethya bergquistae exhibited a significant retention difference between $1 \mu \mathrm{m}$ sediment and $6 \mu \mathrm{m}$ sediment $(\mathrm{P}<0.001)$. In addition, both species exhibited significant decrease in POM weight for the $6 \mu \mathrm{m}$ sediment trial compared to the other 5 trials (Crella incrustans $(\mathrm{P}=0.006)$ and Tethya bergquistae $(\mathrm{P}=$ $<0.001)$. This study outlines the variability of temperate sponge species when retaining 
certain particle types and sizes. There was no conclusive support for any one type or size of particle being retained preferentially. This study has highlighted the potential risks posed by microplastic particles in benthic marine ecosystems as they are rapidly taken up by sponges. 


\subsection{Introduction:}

Microplastics are defined as any plastics particle smaller than $5 \mathrm{~mm}$ (Arthur et al. 2009) and are derived from either the degradation of larger debris or from direct production (Costa et al. 2010; Andrady 2011). Recent estimates quantify microplastic pollution in the world's oceans to be in the realm of five trillion floating particles corresponding to some 250,000 tons (Eriksen et al. 2014) and accounting for roughly $1 / 4$ of all plastic pollution (see chapter 1). Due to the pervasive nature and small sizes of these particles (Cózar et al. 2014), their ingestion and therefore impact on marine life is of growing concern, notably for filter or suspension feeders (Wegner et al. 2012; Browne et al. 2013; Cole et al. 2013; Wright et al. 2013a). The effects of microplastics have been studied across a number of invertebrate species for example: crabs (Watts et al. 2014), mussels (Browne et al. 2008; von Moos et al. 2012; Avio et al. 2015; Van Cauwenberghe et al. 2015), oysters (Sussarellu et al. 2016), sea cucumbers (Graham and Thompson 2009), lugworms (Besseling et al. 2013), barnacles (Goldstein and Goodwin 2013), isopods (Hämer et al. 2014), and some plankton species (Lee et al. 2013; Besseling et al. 2014; Setälä et al. 2014; Cole et al. 2015). These studies all similarly report the detrimental effects microplastics have on their respective organisms. Whether by inflammatory responses or the translocation of particles to the circulatory systems, the reported outcomes are reduced fitness and decreased survival and fecundity rates. In addition, Farrell and Nelson (2013) outlined the "natural" trophic transfer of microplastics from mussels (Mytilus edulis) to crabs (Carcinus maenas), and the translocation of these particles to the haemolymph and tissues of the crab after ingestion, further highlighting the potential harmful and continuous effects of plastic pollution. Despite this seemingly extensive research, the role microplastics play on sponge health and physiology has yet to be examined.

Sponges are ubiquitous organisms encompassing species living in freshwater or marine ecosystems. Excluding a small family of predatory, carnivorous species, sponges are primarily filter or suspension feeders (Pile et al. 1997), comprising the principal suspension feeding macroinvertebrates in many benthic communities. Sponges are capable of filtering large volumes of seawater, and have the ability to process the water column within 2 hours (Reiswig 1974), while potentially retaining up to $95 \%$ to $99 \%$ of 
ultraplankton in the process (Reiswig 1971a; Reiswig and Brown 1977; Pile and Young 2006). Sponge feeding is achieved by pumping ambient water through an intricate aquiferous system that intersperses throughout the organism (Thomassen and Riisgdrd 1995), a process enabled by the beating of a flagellum at the centre of each choanocyte microvilli collar. When seawater flowing through the incurrent canals enters a chamber lined by these monoflagellated, collar cells (choanocytes), flow velocity is decreased and any suspended particles are redirected towards the microvilli of the choanocytes (Maldonado et al. 2010b). The microvilli collar acts as a sieve, retaining particles from the surrounding waters until they are phagocytosed by the pseudopodia of the choanocyte (Maldonado et al. 2010b).

Sponges are very efficient at removing and retaining a variety of organisms including; viruses (Hadas et al. 2006), bacteria and cyanobacteria (Reiswig 1971b; Pile et al. 1996; Pile et al. 1997; Pile and Young 2006). The filtering system of sponges is specialized to efficiently retain picoplankton (size range 0.1 to $2 \mu \mathrm{m}$ ), and less effectively nanoplankton ( 2 to $20 \mu \mathrm{m}$ ), which together provide the bulk of the sponge diet (Ribes et al. 1999; Kowalke 2000). Sponges are also capable of retaining some larger organisms, such as yeast cells, heterotrophic and autotrophic flagellates, ciliates and diatoms (Frost 1978; Imsiecke 1993).

While it was widely acknowledged that sponges are generally unselective when it comes to feeding (Duckworth et al. 2006), there have been recent studies showing preferential retention of bacteria and picoplankton species (Perea-Blázquez et al. 2010; PereaBlázquez et al. 2013). Additionally, retention rates seem to vary depending on particle size, with the highest retention efficiency being documented for small food particles $(<5$ $\mu \mathrm{m}$ ), possibly due to varying methods of ingestion (Reiswig 1971b; Weissenfels 1992).

Sediment levels have been shown to have a number of influences on sponges, for example: morphology (Maldonado and Uriz 1999a; McDonald et al. 2003), structure and abundance of sponge assemblages (Zea et al. 1994; Bell and Barnes 2000a; Bell and Barnes 2000b; Carballo 2006), growth rates (Roberts et al. 2006), reproduction (Whalan et al. 2008) and mortality/survival (Maldonado et al. 2008). In response to sediment pollution, sponges initiate various reactions, both passive and active (Bell and Smith 2004). Active responses include; production of mucus (Turon et al. 1998), and the reduction or complete cessation of pumping (Gerrodette and Flechsig 1979; TompkinsMacDonald and Leys 2008). While the overall effect of plastic pollution is likely 
different, they are however, of a similar size to sediments. If ingested microplastics are likely to be toxic ( $\mathrm{Li}$ et al. 2016) and are expected to be equally obstructive (Gall and Thompson 2015). Therefore I hypothesise the reactions shown in response to sediments could be similar to that of plastic pollution.

The aim of this chapter is to examine temperate sponge particle retention, with an emphasis on selectivity of particle type (food, plastics and sediments) and particle size (1 $\mu \mathrm{m}$ and $6 \mu \mathrm{m}$ ). To achieve this, two temperate sponges (Tethya bergquistae and Crella incrustans) were subjected to six treatments consisting of: a raw seawater control, Isochrysis galbana as an artificial food source, two microplastics, and finally two sediments of equal sizes to those of the MP's (Kaolin Clay and Fine White Marble Dust) were selected.

In addition, the ambient water at the end of each trial was filtered, dried and weighed. This was to confirm that any decreases in particulate counts were in fact due to sponge retention, rather than some other reason for example; being ejected in mucus or simply sinking to the bottom of the chamber.

Firstly I hypothesise that both sponges subjected to raw sea water and Isochrysis galbana will have higher retention efficiencies compared to those exposed to both plastic $(1 \mu \mathrm{m}$ and $6 \mu \mathrm{m})$ and sediment $(1 \mu \mathrm{m}$ and $6 \mu \mathrm{m})$ particles. Secondly I hypothesise, that the ambient water from the sediment and microplastic treatments will have more particulate organic matter (POM) at the completion of the experiment than the raw seawater and Isochrysis galbana trials, due to greater retention of food particles than "foreign" particulates. 


\subsection{Methods:}

\subsubsection{Sample collection:}

Sponges were collected from the South Coast and Harbour of Wellington, New Zealand (refer to Figure 2.1 in Chapter 2), specifically Breaker Bay (-41.331343, 174.831824), Princess Bay (-41.344904, 174.787688), Moa Point (-41.342674, 174.808311) and Shark Bay $(-41.301133,174.817476)$ via SCUBA from depths of 5-10 $\mathrm{m}$ in November and December 2015. Collection and husbandry of specimens followed the same protocol outlined in Chapter 2. All sponges were kept in a sea table until experimentation. The sea table had raw sea water flowing through at a rate of approximately $4 \mathrm{~L} \mathrm{~min}^{-1}$. Each trial contained 5 replicates, with a total of 30 sponges per species $(n=30)$.

\subsubsection{Particle Retention:}

In a methodology similar to that of Stabili et al. (2006), and following an acclimation period of at least 1 week for Tethya bergquistae and 3 weeks for Crella incrustans, A selected sponge was transferred from the holding tank into a testing chamber, again similar to that employed by Gatti et al. (2002) and the same used in Chapter 2. Each chamber was $75 \mathrm{~mL}$ in volume and contained a magnetic stirrer. The chambers were then fitted with a lid with a hole to introduce the treatment material (Figure 3.1). In this instance there was no need to ensure an air tight seal as oxygen concentration was not being measured. Treatments were added to the chamber with the sponge already inside, and the chamber was then placed on a magnetic stirrer at $100 \mathrm{rpm}$ and then left for $1 \mathrm{~min}$ to allow for any potential pipette disruption. A sample of $0.5 \mathrm{~mL}$ was then removed from the chamber and added to an equal measure $(0.5 \mathrm{~mL})$ of $99 \%$ ethanol. The trial was then left to run for an hour, at which time another sample of $0.5 \mathrm{~mL}$ was removed and again added to $99 \%$ ethanol $(0.5 \mathrm{~mL})$.

The remaining water in the chamber was then poured into a Filter Pump (Today's Oil-less Vacuum Pump, Sartorius Stedim All - Glass Vacuum Filter Holder) to filter particulates out of the water through glass microfibre filter paper (LabServ Filtration $47 \mathrm{~mm}$ diameter). The filter papers were weighed beforehand, and then after use, dried in an oven at $80^{\circ} \mathrm{C}$ for 48 hours. The filter papers were then weighed again (to the nearest $0.0001 \mathrm{~g}$ ) and the original weight was then subtracted to obtain particulate organic matter (POM) weight. Concurrently, to account for sponge size, the ash free dry mass (AFDM) of each 
sponge was determined at the end of each experiment. Following the protocol of chapter 2, the AFDM was calculated as the difference between the dry weight and the ash weight after incineration in a muffle furnace.

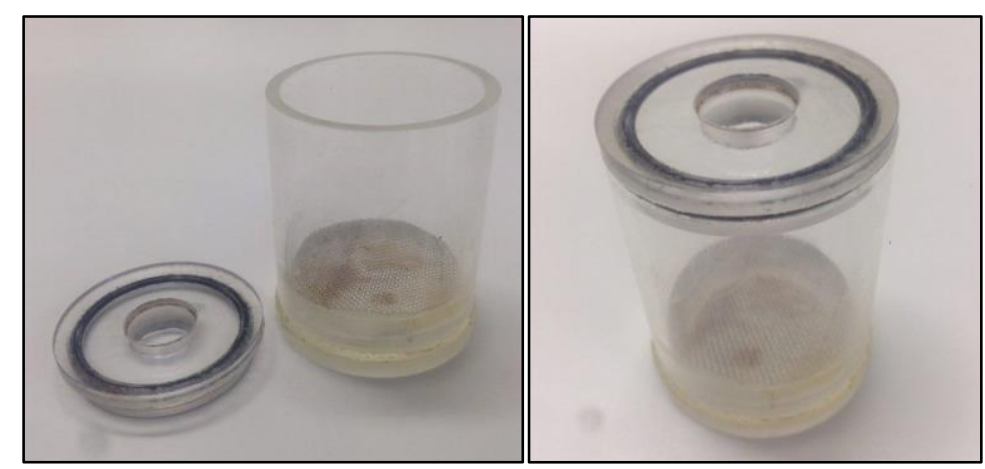

Figure 3.1: Treatment chamber (75 mL). Left shows lid off, right shows complete assembled chamber trial. Photos: Cliff Baird

\subsubsection{Haemocytometer protocol:}

All samples were stored in $1.5 \mathrm{~mL}$ Eppendorf tubes, to which ethanol (99\%) was added to preserve any organisms that may be in the water. All samples were then frozen until the completion of the experiment to safeguard from any additional degradation.

Samples were then removed and allowed to defrost, after which they were then analysed via haemocytometer, following protocols outlined by Godhe et al. (2007) and LeGresley and McDermott (2010).

Haemocytometer protocol: each water sample was thoroughly stirred, subsampled $(0.25$ $\mathrm{mL}$ ) and pipetted onto the two haemocytometer grids (each grid holding $\sim 0.1 \mathrm{~mL}$ ). The particles inside the grids were then counted and divided by the total "squares" counted (total particles counted/squares counted), the counts were then doubled (to account for 1:1 dilution in ethanol). This process was repeated three times after which the subsamples were then averaged (for greatest power of particulate count extrapolation technique) and, as per protocol, multiplied by 10,000 to gain cells $\mathrm{mL}^{-1}$.

Lugol's solution was added to appropriate samples (raw sea water, Isochrysis galbana), highlighting phytoplankton nuclei, making them easily visible and thus able to be counted with relative ease. 


\subsubsection{Treatments:}

I tested if retention rates were influenced by particle size or type. All treatments were calculated to be of similar concentration: approximately 200,000 particles per $\mathrm{mL}$ (see appendix). Raw seawater, microplastics ( $1 \mu \mathrm{m}, 6 \mu \mathrm{m}$ as described in chapter 2$)$, and sediment were utilised to determine the retention efficiency of selected sponge species when subjected to various treatments. As such sediments of equal size to the microplastics were chosen (Kaolin clay $(\sim 1 \mu \mathrm{m})$ and Fine White Marble Dust $(\sim 6 \mu \mathrm{m})$ ). Isochrysis galbana was used for this experiment as 1) it was easily accessible (being actively cultured at VUCEL); 2) is of a similar size to the larger particle plastics and sediments (4-6 $\mu \mathrm{m})$; and 3) is an adequate food source for sponges, and is widely cultured for use in the aquaculture industry (Guillard 1975). Buoyant weight was utilised to ascertain the volume of each sponge. The sponge volume was then deducted from the volume of the trial chamber. This was to determine the actual treatment volume, thereby allowing each of the treatments to be adjusted to $\sim 200,000$ beads per $\mathrm{mL}$.

Retention efficiency was calculated as percentage difference in particle abundance.

$$
R(\%)=100 \times\left[\frac{C 0-C 1}{C 0}\right]
$$

Where $C 0$ is the initial concentration at time 0 and $C 1$ is the concentration at time 60 .

\subsubsection{Statistical analysis:}

Initial analyses were performed by IBM SPSS Statistics (version 23, 2015). In all cases tests were performed to check for the presence of outliers, and to confirm the assumptions of normality and homogeneity of variances.

As the species were collected from different areas around Wellington and these locations have differing substrates, Tethya bergquistae were collected from the Wellington South coast (rocky shore) and Crella incrustans from Wellington Harbour (soft bottomed), the species were analysed separately. 


\subsubsection{Particle retention:}

To analyse the differences between particle types and sizes two-way ANOVA's were utilised (i.e. comparing the difference between initial and final readings) divided by sponge ash free dry mass (AFDM). The analysis conducted compared the mean counts of Size (2 levels: $1 \mu \mathrm{m}$ and $6 \mu \mathrm{m}$ ) to Type (3 levels: food, sediment and microplastic) and also involved an interaction term (Size x Type). Where significant results were shown, multiple comparison (LSD) post hoc tests were conducted.

In addition, to account for any particle sinking, ANOVA's were run on the particulate organic matter $(\mathrm{POM}=$ Filter paper Dry weight minus initial filter paper weight). In all cases where the assumption of homogeneity of variance was violated, Welch's ANOVA's were run which has been shown to be robust to variations of variance (O'Brien 1979). The mean $(\mu)$ POM count for treatments (6 levels: raw sea water, Isochrysis galbana, $1 \mu \mathrm{m}$ sediment, $6 \mu \mathrm{m}$ sediment, $1 \mu \mathrm{m}$ microplastic and $6 \mu \mathrm{m}$ microplastic) were compared to each other. In all analyses where significant interactions were indicated, least significant difference (LSD) post hoc tests were conducted to determine which of the treatments were significantly different.

\subsection{Results:}

\subsubsection{Crella incrustans:}

The difference in particulate counts was divided by the ash free dry mass (AFDM) of each sponge, which showed some significant differences between treatments (Figure 3.2). As the output from a Welch's two-way ANOVA showed a significant value $\left(F_{5,10.375}=\right.$ 14.837; $P<0.001$ ) (Table 3), multiple comparisons tests were conducted. The results from the LSD post hoc test indicated a significant difference between particle types, with sponges from the raw seawater treatment having higher retention than that of MP $1 \mu \mathrm{m}(P$ $=0.009$ ). Additionally there were significant differences between particle sizes; sponges in raw seawater had lower retention than in Isochrysis galbana $(P<0.001)$ and sponge retention of the Sediment $1 \mu \mathrm{m}$ was greater than for Sediment $6 \mu \mathrm{m}(P<0.001)$. 


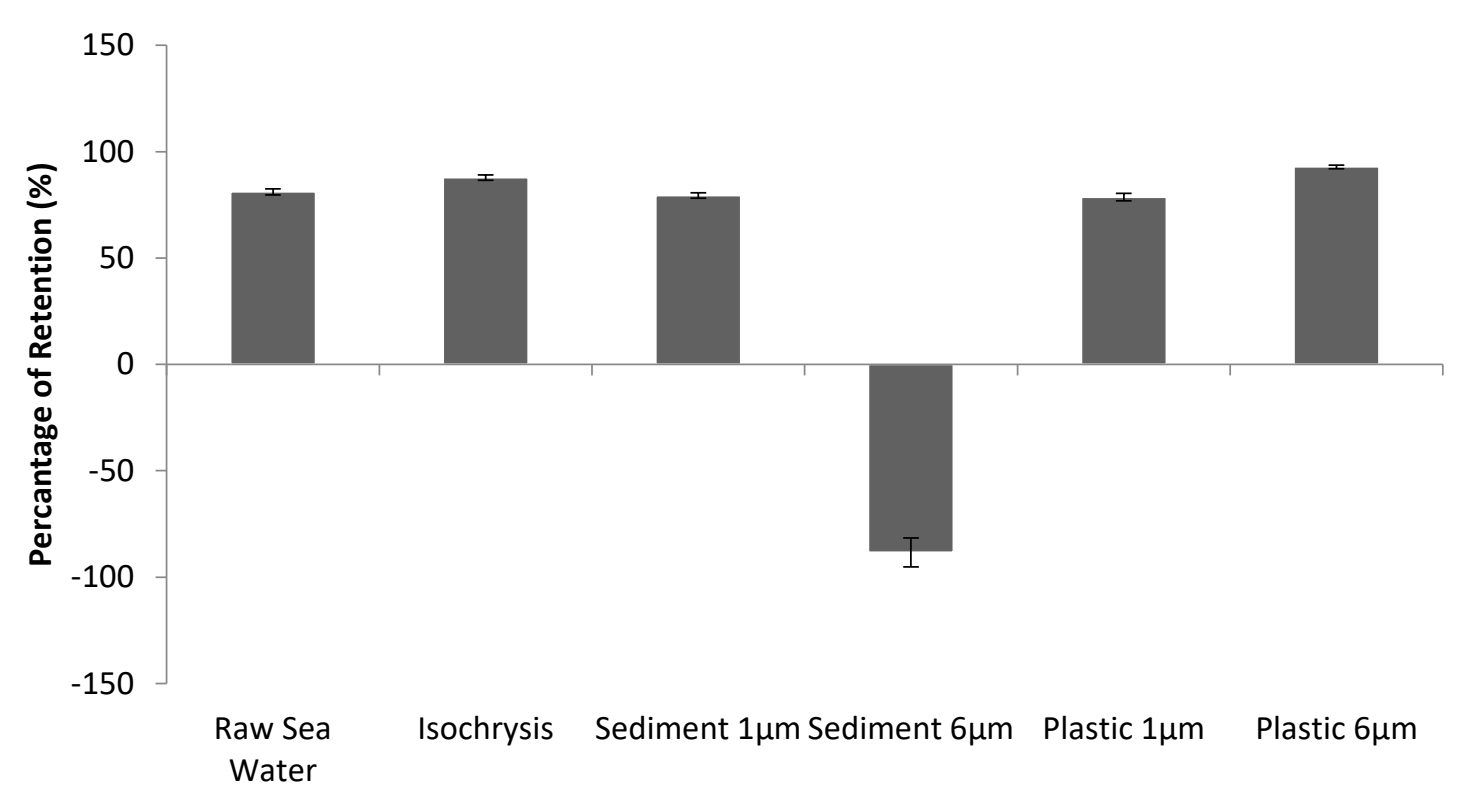

\section{Treatment}

Figure 3.2: Retention efficiency (mean values) for Crella incrustans following exposure to microplastics, sediments and Isochrysis galbana and raw sea water. Bars are grouped by sizes into treatments. Negative values indicate an increase in cells from time 0 to trial end.

Error bars show one standard error $(\mathrm{n}=5)$.

Table 3: Results from a Welch's Two-way ANOVA, analysing the means of cell retention per gram of Crella incrustans AFDM $(\mathrm{n}=5)$, comparing particle types and sizes.

\begin{tabular}{|c|c|c|c|c|}
\hline \multicolumn{5}{|c|}{ Robust Tests of Equality of Means } \\
\hline \multicolumn{5}{|c|}{ Cells $\mathrm{mL}^{-1} \mathrm{~g}^{-1}($ AFDM $) \mathrm{h}^{-1}$} \\
\hline & Statistic $^{a}$ & $d f 1$ & $d+2$ & Sig. \\
\hline Welch & 14.837 & & 10.3 & $<0.001$ \\
\hline
\end{tabular}

a. Asymptotically F distributed.

\subsubsection{Particulate Organic Matter:}

One-way ANOVA's were used to analyse the differences in the mean weight of particulates in the water at the end of the experiment. As there was a significant difference between treatments (Table 4), a Least Significant Difference (LSD) post hoc, was performed to determine which of the treatments were different from each other. In 
this case only $6 \mu \mathrm{m}$ sediment was significantly different (as denoted by the Letters in

Figure 3.3) from the other treatments $(P=0.006)$.

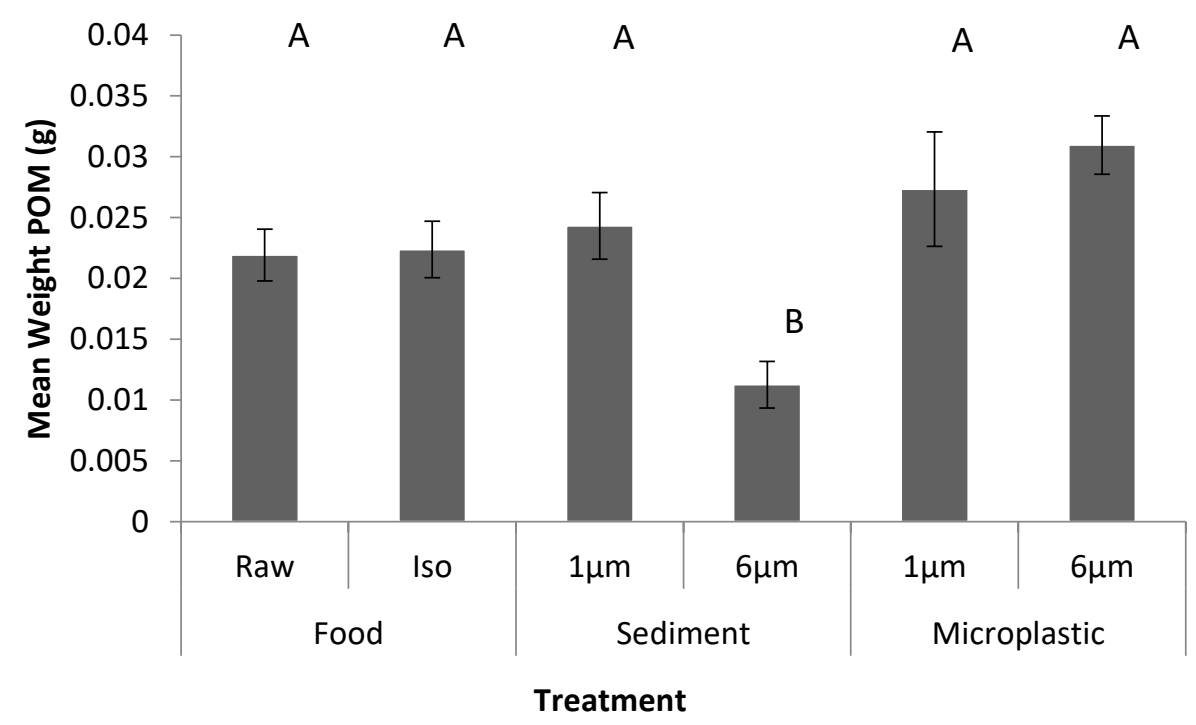

Figure 3.3: Mean weight of Particulate Organic Matter (POM) following Crella incrustans exposure to microplastics, sediments and Isochrysis galbana. Bars are grouped by treatments. Error bars show one standard error $(n=5)$. Letters above bars indicate groupings based on LSD post hoc test outcome $(\alpha=0.05)$.

Table 4: Output from one way ANOVA, comparing the means of Particulate Organic Matter (POM) weight in surrounding waters $(n=5)$.

\begin{tabular}{lccccc}
\hline \hline \multicolumn{5}{c}{ ANOVA Table of Resuts } \\
\hline $\begin{array}{l}\text { POM Dry Weight }(\mathrm{g}) \\
\text { Sum of } \\
\text { Squares }\end{array}$ & $d f$ & Mean Square & $\mathrm{F}$ & Sig. \\
\hline $\begin{array}{l}\text { Between } \\
\text { Groups }\end{array}$ & .001 & 5 & $2.233 \mathrm{E}-04$ & 4.376 & .006 \\
Within & .001 & 24 & $5.103 \mathrm{E}-05$ & & \\
Groups & .002 & 29 & & & \\
Total & .002 & & \\
\hline
\end{tabular}




\subsubsection{Tethya bergquistae:}

The difference in particulate counts was divided by the ash free dry mass (AFDM) of each sponge, which showed some significant differences between treatments (Figure 3.4). As the two-way ANOVA showed significant differences $(F 5,24=7.201 ; P=<0.001)$ (Table 5), multiple comparison tests were again conducted. The results from the LSD post hoc test indicated a significant difference between particle types with sponges in the raw sea water having lower retention rates than that of Sediment $1 \mu \mathrm{m}(P=0.044)$ and sponges from the Sediment $6 \mu \mathrm{m}$ treatment having much less retention than that of MP 6 $\mu \mathrm{m}(P=0.017)$. In addition, there were significant differences between particle sizes; sponge retention of $1 \mu \mathrm{m}$ sediment was greater than $6 \mu \mathrm{m}$ sediment $(P<0.001)$.

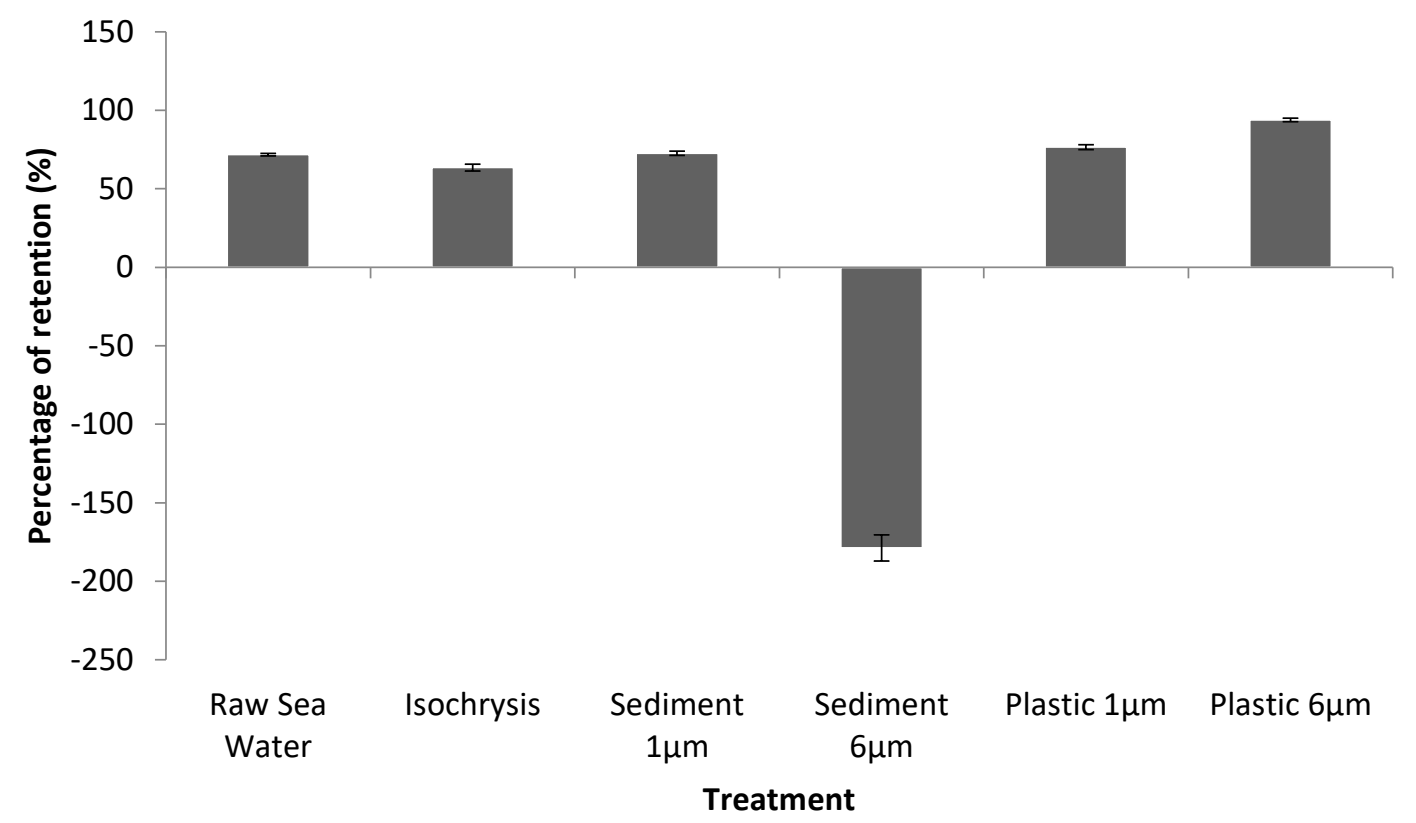

Figure 3.4: Retention efficiency (mean values) of Tethya bergquistae after exposure to microplastics, sediments, Isochrysis galbana and raw sea water. Bars are grouped by treatments. Negative values indicate an increase in cells from time 0 to trial end. Error bars show one standard error $(n=5)$. 
Table 5: Results from a Two-way ANOVA, analysing the means of Cell retention per gram of Tethya bergquistae AFDM $(\mathrm{n}=5)$, comparing particle types and sizes.

\begin{tabular}{lccccr}
\hline \multicolumn{5}{c}{ ANOVA Table of Results } \\
\hline CellsmL $^{-1} \mathrm{~g}^{-1}(\mathrm{AFDM}) \mathrm{h}^{-1}$ & & & & \\
& Sum of Squares & $d f$ & Mean Square & $\mathrm{F}$ & Sig. \\
\hline $\begin{array}{l}\text { Between } \\
\text { Groups }\end{array}$ & $2.732 \mathrm{E}+12$ & 5 & $5.463 \mathrm{E}+11$ & 7.201 & $<0.001$ \\
$\begin{array}{l}\text { Within } \\
\text { Groups }\end{array}$ & $1.821 \mathrm{E}+12$ & 24 & $7.587 \mathrm{E}+10$ & & \\
Total & $4.553 \mathrm{E}+12$ & 29 & & & \\
\hline
\end{tabular}

\subsubsection{Particulate Organic Matter:}

One Way ANOVA's were used to analyse the differences in the mean weight of particulates in the water at the end of the experiment. As there was a significant difference between treatments (Table 6), a Least Significant Difference (LSD) post hoc test was performed to determine which of the treatments were different from each other. Again in this case only the $6 \mu \mathrm{m}$ sediment treatment was significantly different (as denoted by the Letters in Figure 3.5) from the other treatments $(P<0.001)$.

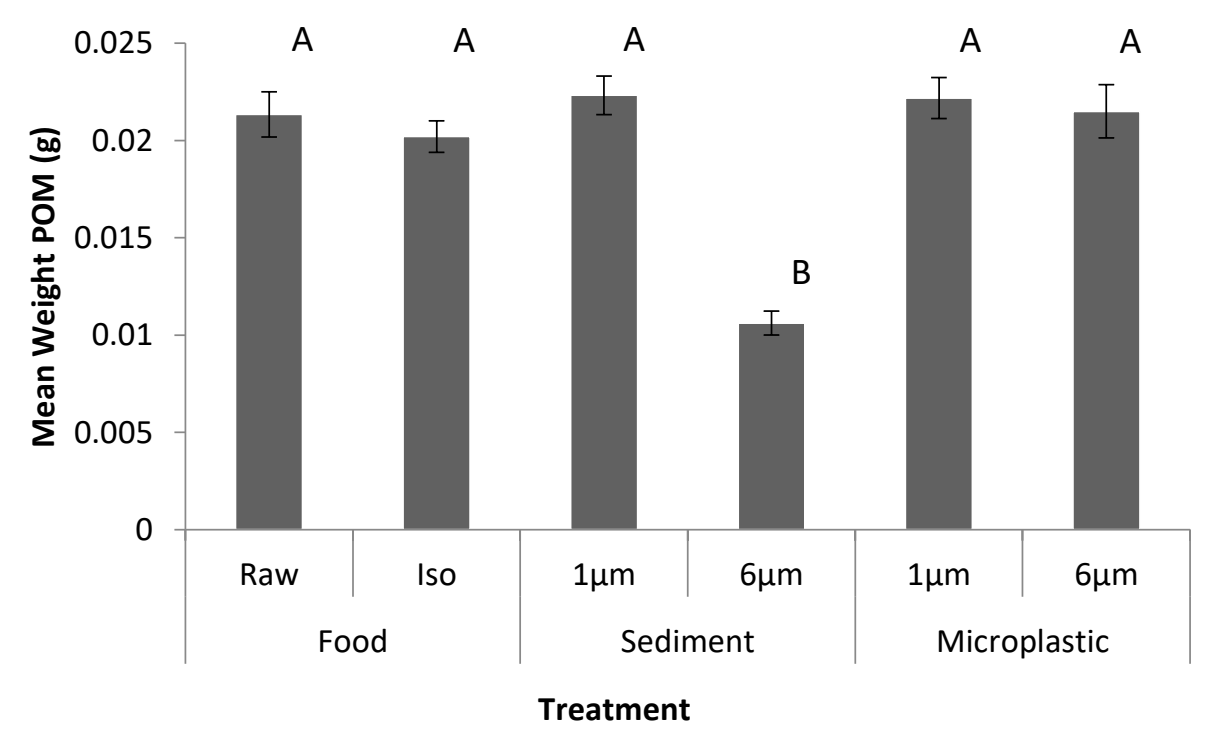

Figure 3.5: Mean weight of Particulate Organic Matter (POM) following Tethya bergquistae exposure to microplastics, sediments and Isochrysis galbana. Bars are grouped by treatments. Error bars show one standard error $(n=5)$. Letters above bars indicate groupings based on LSD post hoc test outcome $(\alpha=0.05)$. 
Table 6: Output from one way ANOVA, comparing the means of Particulate Organic Matter (POM) weight in surrounding waters $(n=5)$.

\begin{tabular}{lrrrrr}
\hline \hline \multicolumn{5}{c}{ ANOVA Table of Results } \\
\hline $\begin{array}{l}\text { POM Dry Weight }(\mathrm{g}) \\
\text { Sum of } \\
\text { Squares }\end{array}$ & df & Mean Square & F & Sig. \\
\hline $\begin{array}{l}\text { Between } \\
\text { Groups }\end{array}$ & .001 & 5 & $1.016 \mathrm{E}-04$ & 15.371 & $<0.001$ \\
$\begin{array}{l}\text { Within } \\
\text { Groups }\end{array}$ & .000 & 24 & $6.612 \mathrm{E}-06$ & & \\
Total & .001 & 29 & & & \\
\hline
\end{tabular}

\subsection{Discussion:}

Microplastic pollution is becoming a global concern as it is found throughout all areas of the marine environment. The increasing demand and use of global plastics in recent years has meant the input of plastic particles into the world's oceans has steadily increased. As microplastic input in the ocean increases, so does the interaction between plastic particles and marine organisms. As a result, the need to infer the impact these particles have on these organisms is of paramount importance. Previous studies have investigated the various effects of both sediment particles and microplastic particles on a range of marine invertebrates (Box and Mossa 1999; Bannister et al. 2012; Van Cauwenberghe et al. 2015). However, none to date have focused on the retention efficiencies of temperate sponges after exposure to various sediment and microplastic particles.

The aim of this study was to determine the effect of various forms of particulates on the retention efficiencies of temperate sponges. Two abundant temperate sponges Tethya bergquistae and Crella incrustans were subjected to three different particulate types. The three particulate types consisted of two treatments each including raw sea water and Isochrysis galbana representing food particulates, $1 \mu \mathrm{m}$ and $6 \mu \mathrm{m}$ sediment particulates and $1 \mu \mathrm{m}$ and $6 \mu \mathrm{m}$ microplastic particulates. Sponges were isolated into treatment chambers and subjected to one of these six treatments. Water samples were taken at $\mathrm{t}=0$ mins and $t=60$ mins, and analysed via a haemocytometer. In addition, the water chamber contents were filtered and dried together with the sponges. 


\subsubsection{Particle retention:}

The two sponge species exhibited variable particle retention for both particle type and size. In regards to particle type, $C$. incrustans showed significantly higher retention rates of particles in raw sea water trials compared to microplastic $1 \mu \mathrm{m}$ trials, while Tethya bergquistae showed significantly higher retention of raw sea water particles compared to $1 \mu \mathrm{m}$ sediment particles and also $T$. bergquistae exhibited a significantly higher retention in the $6 \mu \mathrm{m}$ sediment trials compared to $6 \mu \mathrm{m}$ MP trials.

In regards to particle size, $C$. incrustans had significantly higher retention of particles in raw sea water trials compared to Isochrysis galbana trials and showed significantly higher retention of $1 \mu \mathrm{m}$ sediment particles compared to $6 \mu \mathrm{m}$ sediment particles. Tethya bergquistae however, only showed one significant difference with higher retention of 1 $\mu \mathrm{m}$ sediment particles compared to $6 \mu \mathrm{m}$ sediment trials.

As expected, most trials decreased in particle counts over the 60 minute treatment period with the exception of the $6 \mu \mathrm{m}$ sediment trial which interestingly showed an increase in particle counts for both species. While this outcome was initially confusing Pile et al. (1997) suggested that previously retained foreign particles can be actively ejected from sponge mucous, resulting in higher concentrations of particles in the exhalant samples than in the ambient waters. This could potentially explain the observed result in this experiment, as particles may have been ejected from the sponges after relocation to the trial chamber. However, this seems unlikely as there is no other indication of sediment ejection after relocation in all of the other treatments.

It has been well documented that sponges are highly efficient filter feeders (Reiswig 1971b; Pile et al. 1996; Wehrl et al. 2007). However, particle size has been shown to be an important factor in sponge retention efficiency (Stuart and Klumpp 1984; Ribes et al. 1999; Duckworth et al. 2006). The results of my experiment support previous findings as both species exhibited significant differences in retention rates between $1 \mu \mathrm{m}$ and $6 \mu \mathrm{m}$ sediment particles. Although interestingly, the $6 \mu \mathrm{m}$ sediment trials for both species showed an increase of particulates throughout the experiment, an explanation for this observation could be that the larger particles in the $6 \mu \mathrm{m}$ sediment trials initially settled on the bottom of the trial chamber before the $t=0$ sample was taken and were then re- 
suspended via the magnetic stirrer and active filtering by the sponge to increase the concentration at $\mathrm{t}=60$ mins.

Finally, experimental error could be a possible explanation for the results obtained in the $6 \mu \mathrm{m}$ sediment trials. Perhaps particulate counting inaccuracy occurred as it has been shown that there is always a level of associated error when using a haemocytometer (Freund and Carol 1964). However, this seems unlikely, as again there are no apparent discrepancies in the other treatment counts. More likely, initial concentration counts of the sediment treatment may have been miscalculated thus influencing the end results.

\subsubsection{POM Weights:}

I hypothesised that trials with larger sized treatments would produce heavier filter papers due to either, 1; larger and therefore heavier particles sink to the bottom of the treatment chambers, or 2; as the previous section indicates, larger particles are harder to retain and therefore there are larger amounts of particles in the surrounding waters. Interestingly, the results do not agree with the initial hypothesis. The POM mean weights were the same across all treatments, except for the $6 \mu \mathrm{m}$ sediment trial which was significantly lighter than the other trials across both species. This is surprising, as it has been previously suggested that elevated $6 \mu \mathrm{m}$ sediments in ambient water should naturally lead to a heavier POM weight. However, in this case, the POM weight was actually less. A possible explanation for this result could be that upon completion of the trial, the heavier $6 \mu \mathrm{m}$ sediments re-settled on the bottom of the chamber during transportation to the filter pump. Upon pouring the sample water into the filtration unit, some of the heavier particles may have been left behind, leading to a lighter POM weight.

The unusual results from the $6 \mu \mathrm{m}$ sediment treatments suggest an error in experimental design. As a result I recommend the experiment to be revisited/ reworked. In addition, it would be interesting to subject sponges to a mixture of particles in the same trial and ascertain if some particles are preferentially retained. This multiple stressor style experiment would be of use as it would more accurately mimic the natural environment and provide greater insight into the effects of microplastics on temperate sponges. 


\subsubsection{Conclusion:}

The results from this chapter showed some differences in the retention efficiency of two temperate sponge species when exposed to various particle types of differing sizes. However, the two temperate sponges showed no difference between plastic and sediment particle retention (with the exception of Tethya bergquistae in one instance). As sponges filter vast quantities of water, this may make them susceptible to foreign particulates in their environment. With increasing concern for growing plastic pollution, there is the potential for microplastics to become a persistent stressor. This highlights the importance of future research to determine the effects of plastic pollution in the presence of multiple stressors on temperate sponge species. 


\section{General discussion:}

\subsubsection{Overview:}

Microplastics are a globally recognised problem, with increased realisation of the impacts of these minute particles. Increased annual production and severe accumulation of microplastics have been well documented (Thompson et al. 2004a; Barnes et al. 2009; Rocha-Santos and Duarte 2015). Recent focus on the fate of these particles in the food chain has highlighted the effects they have on the benthic environment. However, irrespective of current emphasis and despite the abundance and importance of sponges in marine communities (Bergquist 1968; Berman 2012), the effects these beads have on temperate sponges in New Zealand have yet to be addressed.

The main objective of this thesis was to investigate the potential impact of microplastics on temperate sponges. An emphasis was placed on physiological and functional responses of sponges to these stressors, for example, respiration and retention efficiency. To address these aims, two shallow-water temperate sponges, Tethya bergquistae and Crella incrustans, were subjected to two separate laboratory experiments; the first of which subjected test sponges to two different sized particles $(1 \mu \mathrm{m}$ and $6 \mu \mathrm{m})$ at two concentrations $(200,000$ beads per $\mathrm{mL}$ and 400,000 beads per $\mathrm{mL})$ and measured $\mathrm{O}_{2}$ consumption as a response. Secondly, the retention efficiencies of these same two sponge species were tested after exposure to microplastics, sediments and larger food particles.

This thesis has identified some significant differences in response to particle size, highlighting the need for further investigation. This discussion will outline the contribution these results make to current research investigating the impacts of microplastics on temperate ecosystems. Finally, there will be some suggestions for some potential areas to be addressed in the future. 


\subsubsection{Response to microplastics:}

\subsubsection{Effect on respiration:}

The results from Chapter 2 indicate no significant difference in respiration rates in response to plastic pollution. As previously stated, respiration is defined as a direct measure of instantaneous metabolic demand. Respiration represents a cost to the organism as it uses up energetic reserves to fuel the production of ATP (Marsh and Manahan 1999) in an effort to maintain homeostasis (Van Cauwenberghe et al. 2015). As a result, elevating this process while allowing the individual to survive is ultimately costly to the organism (Clarke 1991).

Microplastics have been identified as causes for elevated respiration in other organisms, such as oysters (Sussarellu et al. 2016), where exacerbated metabolic demands were found after exposure. This result is found throughout the literature with examples for zooplankton (King and Packard 1975), mussels (Van Cauwenberghe et al. 2015) and crabs (Brennecke et al. 2015).

Respiration as a measure of sponge health has been used to examine the effects of a number of individual stressors. For example, research conducted by Bates (2015) measured the metabolic reaction of two temperate sponges in response to climate change stress (high temperature and $\mathrm{pH}$ ), and found elevated respiration as well as mortality under IPCC extreme scenarios. Murray (2009) has also tested the oxygen consumption of temperate sponges, focusing on the effects of sediment. It was discovered that Tethya bergquistae is largely resilient to sediment, however if the concentrations are high, negative impacts occur. These studies further highlight the potential impacts of changing environments on the respiration and thus health of temperate sponge species.

Large grain sizes have been proposed to cause abrasion to sponge assemblages (Carballo and García-Gómez 1994), while small particles are more likely to clog the filtration systems of these organisms (Maldonado et al. 2008). As such, the physical degradation caused by larger grains may cause the sponge to compensate for increased maintenance costs of repairing cell and tissue damage, thus increasing respiration rates (Pörtner et al. 1999; Abele et al. 2001; Pörtner et al. 2001). While the focus of previous research was respiration response to sediment, microplastics are of a comparable size and have the potential to be equally abrasive. While natural concentrations of MP's are much lower than those of sediments, there is still the potential for these particles to cause damage. As 
such, this comparison could also be applied to the impact noted in Chapter 2 where Tethya bergquistae respiration levels were significantly affected in response to larger sized microplastics.

\subsubsection{Particle retention:}

The results from chapter 3 illustrate that both species of temperate sponges retain a broad variety of particles. Furthermore the results indicate that the two temperate sponges have differing, but no definitive differences in retention of particle types or sizes, across all treatments.

Retention rates and efficiencies in response to microplastics have been examined for many filter feeding species including: ascidians (Randløv and Riisgård 1979), barnacles (Goldstein and Goodwin 2013), mussels (Hull et al. 2013; Van Cauwenberghe et al. 2015) and oysters (Sussarellu et al. 2016). The common trend throughout these experiments is the uptake/ingestion of plastics by animals, and is in accordance with the general results found in this experiment (excluding $6 \mu \mathrm{m}$ sediments). Contrastingly, Duckworth et al. (2006) sampled from the inhalant and exhalant waters of three coral reef sponges and analysed the microbe concentrations therein. It was found that while retention efficiency was similar among the three sponges $(\mu=86 \%)$ particle retention decreased as particle sizes increased. This indicates a clear preferential response for a certain particle size, which was not seen in this experiment.

Not only are the effects of microplastic ingestion by sponges unknown, but the suggested negative impacts of microplastics on $\mathrm{O}_{2}$ respiration are of concern. I hypothesise that microplastic particles once ingested either are treated as food and consequently phagocytised into sponge tissues (where they are either digested (Ilan and Abelson 1995) or isolated (Willenz et al. 1986)), or alternatively they accumulate on the feeding apparatus, or become caught in mucus where they are trapped until being eventually "sloughed" off (similar to that suggested by Gerrodette and Flechsig (1979).

Sponges are dominant suspension feeders in numerous benthic communities (Ribes et al. 1999). They are notable for filtering huge volumes of water (Reiswig 1971a), and have been suggested to play a large role in water cleansing or bioremediation (Stabili et al. 
2006) As such, any impacts felt by these pivotal societal participants will undoubtedly have wider implications throughout the marine environment.

\subsubsection{Limitations and Future Direction:}

While adding to an existing knowledge base, there are areas where the experiments conducted in this research could have been improved upon. Moreover, there is a need for future investigations, focusing primarily on the responses of temperate sponges under multiple stressors as this would be more reflective of the natural environment.

In the respiration experimental set up, sponges were exposed to particles for limited periods of time ( $<60$ mins) each day, before being returned to the holding tanks. Such a short exposure time may not have been sufficient to elicit appropriate or accurate responses from each sponge. Several studies have documented decreased levels of tolerance of marine organisms with exposure time (Yamada and Ikeda 1999; Garrard et al. 2013; Suckling et al. 2015). Therefore it is suggested that prolonged periods of exposure, while not only potentially producing a more definitive result, would be more representative of conditions faced in "natural" marine situations.

A more accurate measure of particulate counting may have resulted in differing results found in this study (especially with the $6 \mu \mathrm{m}$ sediment). Several studies employing microbeads have been undertaken successfully (Marie et al. 1997; Marie et al. 2000), with particles that have been actively fed to animals being primarily examined under a fluorescent microscope (Farrell and Nelson 2013). Furthermore, tiny particles have also been successfully quantified using dual beam flow cytometry (Pile et al. 1996). While the particulate counting in chapter 3 was consistent across all three replicate samples, it has been shown that there is always a level of associated error when using a haemocytometer (Freund and Carol 1964). As such, this author proposes a more accurate/definitive counting process would be of benefit to future studies.

Sussarellu et al. (2016), has suggested that smooth spherical polystyrene microbeads behave and have possible differing effects than that of plastic debris present in the marine environment. The smooth round shape of the polystyrene beads was not expected to cause any physical damage to the animals, however the potential for damage is higher from other particle shapes such as fibres (from entanglement or clogging of the feeding apparatus/digestive tract) or fragments with sharp edges, which may cause physical 
injuries (Wright et al. 2013a). Furthermore, these "natural" shapes are likely to be more abundant among microplastics found in coastal sediments (Browne et al. 2010; Claessens et al. 2011; Hidalgo-Ruz et al. 2012) and are therefore more representative of the microplastics assemblage available to these temperate sponges. Therefore, future examination should include the use of fibres or fragments in conjunction with manufactured beads.

Finally, the fate of microplastics once ingested is an interesting idea. Previous studies primarily focusing on the ingestion of microbeads by other filter feeders have shown the translocation of microbeads from the gut to the circulatory system (Browne et al. 2008). This is an interesting result, and it would be exciting and valuable to conduct this research with temperate sponges to discover the fate of microbeads once ingested.

The present study has highlighted the need for future investigations to both combine microplastics contamination with additional stressors and reveal the fate of these pollutants once ingested. This would clarify the effect that a globally increasing input of microplastics may have on temperate sponges and the overall impact this may have to the marine benthic environment as a whole. Microplastic pollution is becoming of increasing concern throughout the marine environment. As global plastic usage has increased in recent years so have the concentrations of plastic being input into oceans, which is then made available to marine organisms. As such, the need to infer the impact these particles have on these creatures is of paramount importance. Some studies have previously investigated the effect of microplastic particles on marine invertebrates, such as mussels (Van Cauwenberghe et al. 2015). Additionally multiple authors have analysed the effects of sediment particles on these species (including sponges) (Box and Mossa 1999; Bannister et al. 2012), however to my knowledge, none to date have focused on the ability of these species to distinguish between these particulates.

In conclusion, this thesis has outlined the potential risks posed by microplastic pollution including effects on temperate sponge respiration and retention efficiency. This research has indicated no significant increase of oxygen consumption after exposure to severe concentrations of microplastics. In addition, I have highlighted the mixed responses of retention efficiency of temperate sponge species to various particulates. As microplastic concentrations increase globally, there is increasing concern as to the fate and potential 
hazard these pollutants pose to the marine environment. However, in regards to temperate sponges the results gathered here, while emphasising a need for further experimentation, are certainly encouraging. In terms of microplastics and their impacts on some sponge species, not all is as bleak as it seems. 


\section{References:}

Abele D, Tesch C, Wencke P, Pörtner HO (2001) How does oxidative stress relate to thermal tolerance in the Antarctic bivalve Yoldia eightsi? Antarctic science 13: 111-118

Able KW (2005) A re-examination of fish estuarine dependence: evidence for connectivity between estuarine and ocean habitats. Estuarine, Coastal and Shelf Science 64: 5-17

Albins MA (2013) Effects of invasive Pacific red lionfish Pterois volitans versus a native predator on Bahamian coral-reef fish communities. Biological Invasions 15: 29-43

Andrady A (2005) Plastics in the marine environment: a technical perspective Proceedings of the Plastic Debris Rivers to Sea Conference

Andrady AL (2003) Plastics and the Environment. John Wiley \& Sons

Andrady AL (2011) Microplastics in the marine environment. Marine Pollution Bulletin 62: 15961605 doi 10.1016/j.marpolbul.2011.05.030

Arthur C, Baker J, Bamford H (2009) Proceedings of the International Research Workshop on the Occurrence, Effects, and Fate of Microplastic Marine Debris, September 9-11, 2008

Avio CG, Gorbi S, Milan M, Benedetti M, Fattorini D, d'Errico G, Pauletto M, Bargelloni L, Regoli F (2015) Pollutants bioavailability and toxicological risk from microplastics to marine mussels. Environmental Pollution 198: 211-222 doi 10.1016/j.envpol.2014.12.021

Ayling AL (1983) Growth and regeneration rates in thinly encrusting demospongiae from temperate waters. The Biological Bulletin 165: 343-352

Azzarello MY, Van Vleet ES (1987) Marine birds and plastic pollution. Marine Ecology Progress Series 37: 295-303

Bannister RJ, Battershill CN, de Nys R (2012) Suspended sediment grain size and mineralogy across the continental shelf of the Great Barrier Reef: Impacts on the physiology of a coral reef sponge. Continental Shelf Research 32: 86-95 doi 10.1016/j.csr.2011.10.018

Barnes DK (1999) High diversity of tropical intertidal zone sponges in temperature, salinity and current extremes. African Journal of Ecology 37: 424-434

Barnes DK, Galgani F, Thompson RC, Barlaz M (2009) Accumulation and fragmentation of plastic debris in global environments. Philosophical Transactions of the Royal Society B: Biological Sciences 364: 1985-1998

Barnes DK, Peck LS (2008) Vulnerability of Antarctic shelf biodiversity to predicted regional warming. Climate Research

Barnes RD, Ruppert EE (1968) Invertebrate zoology. WB Saunders Philadelphia

Barthel K-G (1988) Feeding of three Calanus species on different phytoplankton assemblages in the Greenland Sea. Meeresforschung 32: 92-106

Bates T (2015) Sponge physiology and function in a changing ocean: responses to ocean acidification and increased sea surface temperature. Wellington, New Zealand: Victoria University of Wellington.

Batham E (1956) Ecology of southern New Zealand sheltered rocky shore Transactions of the Royal Society of New Zealand, pp 447-465

Battershill C, Bergquist P, Ward V, Pritchard K (1984) Marine sponges: forty-six sponges of Northern New Zealand. University of Auckland Marine Laboratory Bulletin 14: 149

Bax N, Williamson A, Aguero M, Gonzalez E, Geeves W (2003) Marine invasive alien species: a threat to global biodiversity. Marine policy 27: 313-323

Beck MW, Heck Jr KL, Able KW, Childers DL, Eggleston DB, Gillanders BM, Halpern B, Hays CG, Hoshino K, Minello TJ (2001) The Identification, conservation, and management of estuarine and marine nurseries for fish and invertebrates: A better understanding of the habitats that serve as nurseries for marine species and the factors that create sitespecific variability in nursery quality will improve conservation and management of these areas. Bioscience 51: 633-641 
Bell J, Barnes D, Turner J (2002) The importance of micro and macro morphological variation in the adaptation of a sublittoral demosponge to current extremes. Marine Biology 140: 75-81

Bell JJ (2008) The functional roles of marine sponges. Estuarine, Coastal and Shelf Science 79: 341-353

Bell JJ, Barnes D (2003) Effect of disturbance on assemblages: an example using Porifera. The Biological Bulletin 205: 144-159

Bell JJ, Barnes DK (2000a) The influences of bathymetry and flow regime upon the morphology of sublittoral sponge communities. Journal of the Marine Biological Association of the UK 80: 707-718

Bell JJ, Barnes DK (2000b) A sponge diversity centre within a marine 'island' Island, Ocean and Deep-Sea Biology. Springer, pp 55-64

Bell JJ, Davy SK, Jones T, Taylor MW, Webster NS (2013) Could some coral reefs become sponge reefs as our climate changes? Glob Chang Biol 19: 2613-2624 doi 10.1111/gcb.12212

Bell JJ, McGrath E, Biggerstaff A, Bates T, Cardenas CA, Bennett H (2015) Global conservation status of sponges. Conservation Biology 29: 42-53 doi 10.1111/cobi.12447

Bell JJ, Smith D (2004) Ecology of sponge assemblages (Porifera) in the Wakatobi region, southeast Sulawesi, Indonesia: richness and abundance. Journal of the Marine Biological Association of the UK 84: 581-591

Beniash E, Ivanina A, Lieb NS, Kurochkin I, Sokolova IM (2010) Elevated level of carbon dioxide affects metabolism and shell formation in oysters Crassostrea virginica. Marine Ecology Progress Series 419: 95-108

Benton T (1995) From castaways to throwaways: marine litter in the Pitcairn Islands. Biological Journal of the Linnean Society 56: 415-422

Bergquist PR (1968) The marine fauna of New Zealand: Porifera, Demospongiae. Department of Scientific and Industrial Research

Bergquist PR (1978) Sponges. University of California Press

Berman J (2012) Patterns of temporal and spatial variability of sponge assemblages

Berman J, Bell JJ (2010) Spatial variability of sponge assemblages on the Wellington South Coast, New Zealand. Open Marine Biology Journal 4: 12-25

Besseling E, Wang B, Lürling M, Koelmans AA (2014) Nanoplastic affects growth of S. obliquus and reproduction of D. magna. Environmental science \& technology 48: 12336-12343

Besseling E, Wegner A, Foekema EM, van den Heuvel-Greve MJ, Koelmans AA (2013) Effects of microplastic on fitness and PCB bioaccumulation by the lugworm Arenicola marina (L.). Environmental Science \& Technology 47: 593-600 doi 10.1021/es302763x

Betts K (2008) Why small plastic particles may pose a big problem in the oceans. Environmental Science \& Technology 42: 8995-8995

Boerger CM, Lattin GL, Moore SL, Moore CJ (2010) Plastic ingestion by planktivorous fishes in the North Pacific Central Gyre. Marine Pollution Bulletin 60: 2275-2278

Box JB, Mossa J (1999) Sediment, land use, and freshwater mussels: prospects and problems. Journal of the North American Benthological Society: 99-117

Brennecke D, Ferreira EC, Costa TM, Appel D, da Gama BA, Lenz M (2015) Ingested microplastics (>100 mum) are translocated to organs of the tropical fiddler crab Uca rapax. Marine Pollution Bulletin 96: 491-495 doi 10.1016/j.marpolbul.2015.05.001

Brillant M, MacDonald B (2000) Postingestive selection in the sea scallop, Placopecten magellanicus (Gmelin): the role of particle size and density. Journal of Experimental Marine Biology and Ecology 253: 211-227

Brodie J (2014) Dredging the Great Barrier Reef: Use and misuse of science. Estuarine, Coastal and Shelf Science 142: 1-3 doi 10.1016/j.ecss.2014.01.010 
Browne MA, Crump P, Niven SJ, Teuten E, Tonkin A, Galloway T, Thompson R (2011)

Accumulation of microplastic on shorelines woldwide: sources and sinks. Environmental Science \& Technology 45: 9175-9179 doi 10.1021/es201811s

Browne MA, Dissanayake A, Galloway TS, Lowe DM, Thompson RC (2008) Ingested microscopic plastic translocates to the circulatory system of the mussel, Mytilus edulis (L.). Environmental Science \& Technology 42: 5026-5031

Browne MA, Galloway T, Thompson R (2007) Microplastic-an emerging contaminant of potential concern? Integrated environmental assessment and Management 3: 559-561

Browne MA, Galloway TS, Thompson RC (2010) Spatial patterns of plastic debris along estuarine shorelines. Environmental Science \& Technology 44: 3404-3409

Browne MA, Niven SJ, Galloway TS, Rowland SJ, Thompson RC (2013) Microplastic moves pollutants and additives to worms, reducing functions linked to health and biodiversity. Current Biology 23: 2388-2392 doi 10.1016/j.cub.2013.10.012

Brusca R, Brusca G, Burness T (2003) Invertebrates.Sinauer, Sunderland, MA

Brusca RC, Brusca GJ, Haver NJ (1990) Invertebrates. Sinauer Associates Sunderland, MA

Bugoni L, Krause Lg, Petry MVn (2001) Marine debris and human impacts on sea turtles in southern Brazil. Marine pollution bulletin 42: 1330-1334

Burggren W, Roberts J (1991) 9 Respiration and Metabolism. Comparative Animal Physiology, Environmental and Metabolic Animal Physiology 1: 353

Butler CB, Matthews TR (2015) Effects of ghost fishing lobster traps in the Florida Keys. ICES Journal of Marine Science: Journal du Conseil 72: i185-i198

Cadée GC (2002) Seabirds and floating plastic debris. Marine Pollution Bulletin 44: 1294-1295

Caldeira K, Wickett ME (2005) Ocean model predictions of chemistry changes from carbon dioxide emissions to the atmosphere and ocean. Journal of Geophysical Research: Oceans 110

Carballo J, García-Gómez J (1994) The Northeastern Atlantic species Mycale micracanthoxea Buizer \& Van Soest, 1977 (Porifera, Poecilosclerida) in the Strait of Gibraltar (southern Spain). Beaufortia 44: 11-16

Carballo JL (2006) Effect of natural sedimentation on the structure of tropical rocky sponge assemblages. Ecoscience 13: 119-130 doi 10.2980/11956860(2006)13[119:eonsot]2.0.co;2

Carballo JL, Vega C, Cruz-Barraza JA, Yanez B, Nava H, Avila E, Wilson M (2008) Short-and longterm patterns of sponge diversity on a rocky tropical coast: evidence of large-scale structuring factors. Marine Ecology 29: 216-236

Cárdenas CA, Bell JJ, Davy SK, Hoggard M, Taylor MW (2014) Influence of environmental variation on symbiotic bacterial communities of two temperate sponges. FEMS Microbiology Ecology 88: 516-527 doi 10.1111/1574-6941.12317

Cárdenas CA, Davy SK, Bell JJ (2012) Correlations between algal abundance, environmental variables and sponge distribution patterns on southern hemisphere temperate rocky reefs. Aquatic Biology 16: 229-239 doi 10.3354/ab00449

Cardinale BJ, Duffy JE, Gonzalez A, Hooper DU, Perrings C, Venail P, Narwani A, Mace GM, Tilman D, Wardle DA, Kinzig AP, Daily GC, Loreau M, Grace JB, Larigauderie A, Srivastava DS, Naeem S (2012) Biodiversity loss and its impact on humanity. Nature 486: 59-67 doi $10.1038 /$ nature11148

Carpenter SR, Caraco NF, Correll DL, Howarth RW, Sharpley AN, Smith VH (1998) Nonpoint pollution of surface waters with phosphorus and nitrogen. Ecological Applications 8: 559-568

Carter L, McCave I, Williams MJ (2008) Circulation and water masses of the Southern Ocean: a review. Developments in Earth and Environmental Sciences 8: 85-114

Catul V, Gauns M, Karuppasamy P (2011) A review on mesopelagic fishes belonging to family Myctophidae. Reviews in Fish Biology and Fisheries 21: 339-354 
Cerrano C, Arillo A, Bavestrello G, Calcinai B, Cattaneo-Vietti R, Penna A, Sarà M, Totti C (2000) Diatom invasion in the Antarctic hexactinellid sponge Scolymastra joubini. Polar Biology 23: 441-444

Charlson RJ, Schwartz S, Hales J, Cess RD, Coakley jJ, Hansen J, Hofmann D (1992) Climate forcing by anthropogenic aerosols. Science 255: 423-430

Cheshire A, Wilkinson C (1991) Modelling the photosynthetic production by sponges on Davies Reef, Great Barrier Reef. Marine Biology 109: 13-18

Chou LM (2006) Marine habitats in one of the world's busiest harbours The Environment in Asia Pacific Harbours. Springer, pp 377-391

Claessens M, De Meester S, Van Landuyt L, De Clerck K, Janssen CR (2011) Occurrence and distribution of microplastics in marine sediments along the Belgian coast. Marine Pollution Bulletin 62: 2199-2204 doi 10.1016/j.marpolbul.2011.06.030

Clarke A (1991) What is cold adaptation and how should we measure it? American Zoologist 31: 81-92

Codina-García M, Militão T, Moreno J, González-Solís J (2013) Plastic debris in Mediterranean seabirds. Marine Pollution Bulletin 77: 220-226

Cole M, Lindeque P, Fileman E, Halsband C, Galloway TS (2015) The impact of polystyrene microplastics on feeding, function and fecundity in the marine copepod Calanus helgolandicus. Environmental Science \& Technology 49: 1130-1137 doi 10.1021/es504525u

Cole M, Lindeque P, Fileman E, Halsband C, Goodhead R, Moger J, Galloway TS (2013) Microplastic ingestion by zooplankton. Environmental Science \& Technology 47: 66466655 doi 10.1021/es400663f

Cole M, Lindeque P, Halsband C, Galloway TS (2011) Microplastics as contaminants in the marine environment: a review. Marine Pollution Bulletin 62: 2588-2597 doi 10.1016/j.marpolbul.2011.09.025

Cole M, Webb H, Lindeque PK, Fileman ES, Halsband C, Galloway TS (2014) Isolation of microplastics in biota-rich seawater samples and marine organisms. Scientific reports 4: 4528 doi 10.1038/srep04528

Collignon A, Hecq JH, Glagani F, Voisin P, Collard F, Goffart A (2012) Neustonic microplastic and zooplankton in the North Western Mediterranean Sea. Marine Pollution Bulletin 64: 861-864 doi 10.1016/j.marpolbul.2012.01.011

Coma R, Ribes M (2003) Seasonal energetic constraints in Mediterranean benthic suspension feeders: effects at different levels of ecological organization. Oikos 101: 205-215

Coma R, Ribes M, Gili J-M, Zabala M (2000) Seasonality in coastal benthic ecosystems. Trends in Ecology \& Evolution 15: 448-453

Cook SdC, Archer D (2010) New Zealand coastal marine invertebrates. Canterbury University Press

Cookson C (2004) Over-harvesting leads to a Darwinian debt as only the smaller cod survive. The Financial Times 28 August 20041

Costa MF, Do Sul JAI, Silva-Cavalcanti JS, Araújo MCB, Spengler Â, Tourinho PS (2010) On the importance of size of plastic fragments and pellets on the strandline: a snapshot of a Brazilian beach. Environmental Monitoring and Assessment 168: 299-304

Côté IM, Green SJ, Morris Jr JA, Akins JL, Steinke D (2013) Diet richness of invasive Indo-Pacific lionfish revealed by DNA barcoding. Marine Ecology, Progress Series 472: 249-256

Cózar A, Echevarría F, González-Gordillo JI, Irigoien X, Úbeda B, Hernández-León S, Palma ÁT, Navarro S, García-de-Lomas J, Ruiz A (2014) Plastic debris in the open ocean. Proceedings of the National Academy of Sciences 111: 10239-10244

D'llio S, Mattei D, Blasi M, Alimonti A, Bogialli S (2011) The occurrence of chemical elements and POPs in loggerhead turtles (Caretta caretta): An overview. Marine pollution bulletin 62: 1606-1615 
Davenport J, Davenport JL (2006) The impact of tourism and personal leisure transport on coastal environments: a review. Estuarine, Coastal and Shelf Science 67: 280-292

Davison P, Asch RG (2011) Plastic ingestion by mesopelagic fishes in the North Pacific Subtropical Gyre. Marine Ecology Progress Series 432: 173-180

de Caralt S, Otjens H, Uriz MJ, Wijffels RH (2007) Cultivation of sponge larvae: settlement, survival, and growth of juveniles. Marine Biotechnology 9: 592-605

de Goeij JM, van Oevelen D, Vermeij MJ, Osinga R, Middelburg JJ, de Goeij AF, Admiraal W (2013) Surviving in a marine desert: the sponge loop retains resources within coral reefs. Science 342: 108-110

de Voogd NJ, Becking LE, Hoeksema BW, Noor A, van Soest RW (2003) Sponge interactions with spatial competitors in the Spermonde Archipelago. Bollettino dei Musei e degli Istituti Biologici dell Universita di Genova 68: 253-261

de Witte B, Devriese L, Bekaert K, Hoffman S, Vandermeersch G, Cooreman K, Robbens J (2014) Quality assessment of the blue mussel (Mytilus edulis): comparison between commercial and wild types. Marine Pollution Bulletin 85: 146-155 doi 10.1016/j.marpolbul.2014.06.006

Derraik JG (2002) The pollution of the marine environment by plastic debris: a review. Marine Pollution Bulletin 44: 842-852

Diaz MC, Rützler K (2001) Sponges: an essential component of Caribbean coral reefs. Bulletin of Marine Science 69: 535-546

Dickerman RW, Goelet RG (1987) Northern gannet starvation after swallowing styrofoam. Marine Pollution Bulletin 18: 293

Doyle MJ, Watson W, Bowlin NM, Sheavly SB (2011) Plastic particles in coastal pelagic ecosystems of the Northeast Pacific ocean. Marine Environmental Research 71: 41-52

Duckworth A, Brück W, Janda K, Pitts T, McCarthy P (2006) Retention efficiencies of the coral reef sponges Aplysina lacunosa, Callyspongia vaginalis and Niphates digitalis determined by Coulter counter and plate culture analysis. Marine Biology Research 2: 243-248

Duckworth AR, Battershill CN (2001) Population dynamics and chemical ecology of New Zealand Demospongiae Latrunculia sp. nov. and Polymastia croceus (Poecilosclerida:

Latrunculiidae: Polymastiidae). New Zealand Journal of Marine and Freshwater Research 35: 935-949

Endo S, Takizawa R, Okuda K, Takada H, Chiba K, Kanehiro H, Ogi H, Yamashita R, Date T (2005) Concentration of polychlorinated biphenyls (PCBs) in beached resin pellets: variability among individual particles and regional differences. Marine Pollution Bulletin 50: 11031114

Engel S, Pawlik JR (2000) Allelopathic activities of sponge extracts. Marine Ecology Progress Series 207: 273-281

Eriksen M, Lebreton LC, Carson HS, Thiel M, Moore CJ, Borerro JC, Galgani F, Ryan PG, Reisser J (2014) Plastic Pollution in the World's Oceans: More than 5 Trillion Plastic Pieces Weighing over 250,000 Tons Afloat at Sea. PLoS One 9: e111913 doi 10.1371/journal.pone.0111913

Eriksen M, Maximenko N, Thiel M, Cummins A, Lattin G, Wilson S, Hafner J, Zellers A, Rifman S (2013) Plastic pollution in the South Pacific subtropical gyre. Marine Pollution Bulletin 68: 71-76

Eriksson C, Burton H (2003) Origins and biological accumulation of small plastic particles in fur seals from Macquarie Island. AMBIO: A Journal of the Human Environment 32: 380-384

Estes JA, Duggins DO, Rathbun GB (1989) The ecology of extinctions in kelp forest communities. Conservation Biology 3: 252-264

Estes JA, Palmisano JF (1974) Sea otters: their role in structuring nearshore communities. Science 185: $1058-1060$ 
Fallon S, James K, Norman R, Kelly M, Ellwood M (2010) A simple radiocarbon dating method for determining the age and growth rate of deep-sea sponges. Nuclear Instruments and Methods in Physics Research Section B: Beam Interactions with Materials and Atoms 268: 1241-1243

Farrell P, Nelson K (2013) Trophic level transfer of microplastic: Mytilus edulis (L.) to Carcinus maenas (L.). Environmental Pollution 177: 1-3 doi 10.1016/j.envpol.2013.01.046

Fendall LS, Sewell MA (2009) Contributing to marine pollution by washing your face: microplastics in facial cleansers. Marine Pollution Bulletin 58: 1225-1228 doi 10.1016/j.marpolbul.2009.04.025

Field C, Barros V, Dokken D, Mach K, Mastrandrea M, Bilir T, Chatterjee M, Ebi K, Estrada Y, Genova R (2014) IPCC, 2014: Climate Change 2014: Impacts, Adaptation, and Vulnerability. Part A: Global and Sectoral Aspects. Contribution of Working Group II to the Fifth Assessment Report of the Intergovernmental Panel on Climate Change. Cambridge University Press, Cambridge, United Kingdom and New York, NY, USA

Fossi MC, Coppola D, Baini M, Giannetti M, Guerranti C, Marsili L, Panti C, de Sabata E, Clo S (2014a) Large filter feeding marine organisms as indicators of microplastic in the pelagic environment: The case studies of the Mediterranean basking shark (Cetorhinus maximus) and fin whale (Balaenoptera physalus). Marine Environmental Research doi 10.1016/j.marenvres.2014.02.002

Fossi MC, Coppola D, Baini M, Giannetti M, Guerranti C, Marsili L, Panti C, de Sabata E, Clo S (2014b) Large filter feeding marine organisms as indicators of microplastic in the pelagic environment: the case studies of the Mediterranean basking shark (Cetorhinus maximus) and fin whale (Balaenoptera physalus). Marine Environmental Research 100: 17-24 doi 10.1016/j.marenvres.2014.02.002

Fossi MC, Panti C, Guerranti C, Coppola D, Giannetti M, Marsili L, Minutoli R (2012) Are baleen whales exposed to the threat of microplastics? A case study of the Mediterranean fin whale (Balaenoptera physalus). Marine Pollution Bulletin 64: 2374-2379 doi 10.1016/j.marpolbul.2012.08.013

Fox HE, Pet JS, Dahuri R, Caldwell RL (2003) Recovery in rubble fields: long-term impacts of blast fishing. Marine Pollution Bulletin 46: 1024-1031

Freund M, Carol B (1964) Factors affecting haemocytometer counts of sperm concentration in human semen. Journal of Reproduction and Fertility 8: 149-155

Fries E, Dekiff JH, Willmeyer J, Nuelle M-T, Ebert M, Remy D (2013) Identification of polymer types and additives in marine microplastic particles using pyrolysis-GC/MS and scanning electron microscopy. Environmental Science: Processes \& Impacts 15: 1949-1956

Frost TM (1978) In situ measurements of clearance rates for the freshwater sponge Spongilla lacustris. Limnology and Oceanography 23: 1034-1039

Funk JL (2015) Invasive Species: A Global Problem in Need of a Global Solution. BioScience 65: 623-624

Gaiero DM, Probst J-L, Depetris PJ, Bidart SM, Leleyter L (2003) Iron and other transition metals in Patagonian riverborne and windborne materials: geochemical control and transport to the southern South Atlantic Ocean. Geochimica et Cosmochimica Acta 67: 3603-3623

Galgani F, Claro F, Depledge M, Fossi C (2014) Monitoring the impact of litter in large vertebrates in the Mediterranean Sea within the European Marine Strategy Framework Directive (MSFD): Constraints, specificities and recommendations. Marine Environmental Research doi 10.1016/j.marenvres.2014.02.003

Galgani F, Zampoukas N, Fleet D, Franeker Jv, Katsanevakis S, Maes T, Mouat J, Oosterbaan L, Poitou I, Hanke G (2010) Marine Strategy Framework Directive: Task Group 10 Report Marine Litter. Office for Official Publications of the European Communities

Gall SC, Thompson RC (2015) The impact of debris on marine life. Marine Pollution Bulletin 92: 170-179 doi 10.1016/j.marpolbul.2014.12.041 
Gardner TA, HASE A, Brownlie S, Ekstrom JM, Pilgrim JD, Savy CE, Stephens RT, Treweek J, Ussher GT, Ward G (2013) Biodiversity offsets and the challenge of achieving no net loss. Conservation Biology 27: 1254-1264

Garrard SL, Hunter R, Frommel A, Lane A, Phillips J, Cooper R, Dineshram R, Cardini U, McCoy S, Arnberg M (2013) Biological impacts of ocean acidification: a postgraduate perspective on research priorities. Marine Biology 160: 1789-1805

Gatti S, Brey T, Müller W, Heilmayer O, Holst G (2002) Oxygen microoptodes: a new tool for oxygen measurements in aquatic animal ecology. Marine Biology 140: 1075-1085

Gaylord B, Kroeker KJ, Sunday JM, Anderson KM, Barry JP, Brown NE, Connell SD, Dupont S, Fabricius KE, Hall-Spencer JM (2015) Ocean acidification through the lens of ecological theory. Ecology 96: 3-15

George RH (1996) 14 Health Problems and Diseases of Sea Turtles. The biology of sea turtles 1: 363

Gerrodette T, Flechsig A (1979) Sediment-induced reduction in the pumping rate of the tropical sponge Verongia lacunosa. Marine Biology 55: 103-110

Gili J-M, Coma R (1998) Benthic suspension feeders: their paramount role in littoral marine food webs. Trends in Ecology \& Evolution 13: 316-321

Gilman E (2015) Status of international monitoring and management of abandoned, lost and discarded fishing gear and ghost fishing. Marine Policy 60: 225-239

Godhe A, Cusack C, Pedersen J, Andersen P, Anderson DM, Bresnan E, Cembella A, Dahl E, Diercks S, Elbrächter M (2007) Intercalibration of classical and molecular techniques for identification of Alexandrium fundyense (Dinophyceae) and estimation of cell densities. Harmful Algae 6: 56-72

Goldstein MC, Goodwin DS (2013) Gooseneck barnacles (Lepas spp.) ingest microplastic debris in the North Pacific Subtropical Gyre. PeerJ 1: e184 doi 10.7717/peerj.184

Graham ER, Thompson JT (2009) Deposit-and suspension-feeding sea cucumbers (Echinodermata) ingest plastic fragments. Journal of Experimental Marine Biology and Ecology 368: 22-29

Gregory J, Stott P, Cresswell D, Rayner N, Gordon C, Sexton D (2002) Recent and future changes in Arctic sea ice simulated by the HadCM3 AOGCM. Geophysical Research Letters 29: 2821-28-24

Gregory MR (1996) Plastic 'scrubbers' in hand cleansers: a further (and minor) source for marine pollution identified. Marine Pollution Bulletin 32: 867-871

Gregory MR (2009) Environmental implications of plastic debris in marine settingsentanglement, ingestion, smothering, hangers-on, hitch-hiking and alien invasions. Philosophical Transactions of the Royal Society B: Biological Sciences 364: 2013-2025

Guillard RR (1975) Culture of phytoplankton for feeding marine invertebrates Culture of marine invertebrate animals. Springer, pp 29-60

Hadas E, Ilan M, Shpigel M (2008) Oxygen consumption by a coral reef sponge. Journal of Experimental Biology 211: 2185-2190 doi 10.1242/jeb.015420

Hadas E, Marie D, Shpigel M, Ilan M (2006) Virus predation by sponges is a new nutrient-flow pathway in coral reef food webs. Limnology and Oceanography 51: 1548-1550

Halpern BS, Selkoe KA, Micheli F, Kappel CV (2007) Evaluating and ranking the vulnerability of global marine ecosystems to anthropogenic threats. Conservation Biology 21: 1301-1315

Halpern BS, Walbridge S, Selkoe KA, Kappel CV, Micheli F, D'Agrosa C, Bruno JF, Casey KS, Ebert C, Fox HE (2008) A global map of human impact on marine ecosystems. Science 319: 948-952

Hämer J, Gutow L, Köhler A, Saborowski R (2014) Fate of microplastics in the marine isopod Idotea emarginata. Environmental Science \& Technology 48: 13451-13458

Harwood LA, Kingsley MC, Smith TG (2014) An emerging pattern of declining growth rates in belugas of the Beaufort Sea: 1989-2008. Arctic: 483-492 
Hayden A, Acheson J, Kersula M, Wilson J (2015) Spatial and Temporal Patterns in the Cod Fisheries of the North Atlantic. Conservation and Society 13: 414

Heskett M, Takada H, Yamashita R, Yuyama M, Ito M, Geok YB, Ogata Y, Kwan C, Heckhausen A, Taylor H (2012) Measurement of persistent organic pollutants (POPs) in plastic resin pellets from remote islands: Toward establishment of background concentrations for International Pellet Watch. Marine pollution bulletin 64: 445-448

Hickman CP (2001) Integrated Principles of Zoology

Hidalgo-Ruz V, Gutow L, Thompson RC, Thiel M (2012) Microplastics in the marine environment: a review of the methods used for identification and quantification. Environmental Science \& Technology 46: 3060-3075 doi 10.1021/es2031505

Hoffmann F, Larsen O, Tore Rapp H, Osinga R (2005) Oxygen dynamics in choanosomal sponge explants. Marine Biology Research 1: 160-163

Hooper JN, Van Soest RW (2002) Systema Porifera. A guide to the classification of sponges. Springer

Hoss DE, Settle LR (1990) Ingestion of plastics by teleost fishes Proceedings of the Second International Conference on Marine Debris NOAA Technical Memorandum NOAA-TMNMFS-SWFSC-154 Miami, FL, pp 693-709

Houde M, Bujas TA, Small J, Wells RS, Fair PA, Bossart GD, Solomon KR, Muir DC (2006) Biomagnification of perfluoroalkyl compounds in the bottlenose dolphin (Tursiops truncatus) food web. Environmental Science \& Technology 40: 4138-4144

Hull MS, Vikesland PJ, Schultz IR (2013) Uptake and retention of metallic nanoparticles in the Mediterranean mussel (Mytilus galloprovincialis). Aquatic Toxicology 140-141: 89-97 doi 10.1016/j.aquatox.2013.05.005

Huysecom J, Richelle-Maurer E, Van De Vyver G, Vray B (1988) Effect of bacterial concentration on retention and growth rate of the freshwater sponge Ephydatia fluviatilis. Physiological zoology: 535-542

Ilan M, Abelson A (1995) The life of a sponge in a sandy lagoon. The Biological Bulletin 189: 363369

Imsiecke G (1993) Ingestion, digestion, and egestion in Spongilla lacustris (Porifera, Spongillidae) after pulse feeding with Chlamydomonas reinhardtii (Volvocales). Zoomorphology 113: 233-244

Irving A, Connell S (2002) Sedimentation and light penetration interact to maintain heterogeneity of subtidal habitats: algal versus invertebrate dominated assemblages. Marine Ecology-Progress Series 245: 83-91

Jackson JB, Kirby MX, Berger WH, Bjorndal KA, Botsford LW, Bourque BJ, Bradbury RH, Cooke R, Erlandson J, Estes JA (2001) Historical overfishing and the recent collapse of coastal ecosystems. Science 293: 629-637

Jambeck JR, Geyer R, Wilcox C, Siegler TR, Perryman M, Andrady A, Narayan R, Law KL (2015) Plastic waste inputs from land into the ocean. Science 347: 768-771

Jørgensen CB (1955) Quantitative aspects of filter feeding in invertebrates. Biological Reviews 30: 391-453

Jørgensen CB (1966) Biology of suspension feeding

Kannan K, Koistinen J, Beckmen K, Evans T, Gorzelany JF, Hansen KJ, Jones PD, Helle E, Nyman M, Giesy JP (2001) Accumulation of perfluorooctane sulfonate in marine mammals. Environmental Science \& Technology 35: 1593-1598

Kaposi KL, Mos B, Kelaher BP, Dworjanyn SA (2014) Ingestion of microplastic has limited impact on a marine larva. Environmental Science \& Technology 48: 1638-1645 doi 10.1021/es404295e

Kelly M (2007) Porifera: Lithistid Demospongiae (rock Sponges). National Institute of Water and Atmospheric Research (NIWA) 
King FD, Packard TT (1975) Respiration and the activity of the respiratory electron transport system in marine zooplankton. Limnology and Oceanography 20: 849-854

Koelmans AA, Gouin T, Thompson R, Wallace N, Arthur C (2014) Plastics in the marine environment. Environmental Toxicology and Chemistry / SETAC 33: 5-10 doi $10.1002 /$ etc. 2426

Kowalke J (2000) Ecology and energetics of two Antarctic sponges. Journal of Experimental Marine Biology and Ecology 247: 85-97

Laist DW (1987) Overview of the biological effects of lost and discarded plastic debris in the marine environment. Marine Pollution Bulletin 18: 319-326

Larsen PS, Riisgåd HU (1994) The sponge pump. Journal of Theoretical Biology 168: 53-63

Law KL, Morét-Ferguson S, Maximenko NA, Proskurowski G, Peacock EE, Hafner J, Reddy CM (2010) Plastic accumulation in the North Atlantic subtropical gyre. Science 329: 11851188

Law KL, Morét-Ferguson SE, Goodwin DS, Zettler ER, DeForce E, Kukulka T, Proskurowski G (2014) Distribution of Surface Plastic Debris in the Eastern Pacific Ocean from an 11-Year Data Set. Environmental Science \& Technology 48: 4732-4738

Law KL, Thompson RC (2014) Oceans. Microplastics in the seas. Science 345: 144-145 doi 10.1126/science. 1254065

Lazar B, Gračan R (2011) Ingestion of marine debris by loggerhead sea turtles, Caretta caretta, in the Adriatic Sea. Marine Pollution Bulletin 62: 43-47

Lee KW, Shim WJ, Kwon OY, Kang JH (2013) Size-dependent effects of micro polystyrene particles in the marine copepod Tigriopus japonicus. Environmental Science \& Technology 47: 11278-11283 doi 10.1021/es401932b

LeGresley M, McDermott G (2010) Counting chamber methods for quantitative phytoplankton analysis-haemocytometer, Palmer-Maloney cell and Sedgewick-Rafter cell. Microscopic and molecular methods for quantitative phytoplankton analysis UNESCO (IOC Manuals and Guides): $25-30$

Lehtinen RM, Galatowitsch SM, Tester JR (1999) Consequences of habitat loss and fragmentation for wetland amphibian assemblages. Wetlands 19: 1-12

Leppäkoski E, Gollasch S, Olenin S (2013) Invasive aquatic species of Europe. Distribution, impacts and management. Springer Science \& Business Media

Leys S, Ereskovsky A (2006) Embryogenesis and larval differentiation in sponges. Canadian Journal of Zoology 84: 262-287

Leys SP, Yahel G, Reidenbach MA, Tunnicliffe V, Shavit U, Reiswig HM (2011) The sponge pump: the role of current induced flow in the design of the sponge body plan. PloS one 6: e27787

Li C-W, Chen J-Y, Hua T-E (1998) Precambrian sponges with cellular structures. Science 279: 879882

Li HX, Getzinger GJ, Ferguson PL, Orihuela B, Zhu M, Rittschof D (2016) Effects of Toxic Leachate from Commercial Plastics on Larval Survival and Settlement of the Barnacle Amphibalanus amphitrite. Environmental Science \& Technology 50: 924-931 doi 10.1021/acs.est.5b02781

Lohrer AM, Hewitt JE, Thrush SF (2006) Assessing far-field effects of terrigenous sediment loading in the coastal marine environment. Marine Ecology Progress Series 315: 13-18

Lotze HK, Lenihan HS, Bourque BJ, Bradbury RH, Cooke RG, Kay MC, Kidwell SM, Kirby MX, Peterson $\mathrm{CH}$, Jackson JB (2006) Depletion, degradation, and recovery potential of estuaries and coastal seas. Science 312: 1806-1809

Lucas A, Watson JJ (2002) Bioenergetics of aquatic animals. CRC Press

Lusher AL, McHugh M, Thompson RC (2013) Occurrence of microplastics in the gastrointestinal tract of pelagic and demersal fish from the English Channel. Marine Pollution Bulletin 67: 94-99 doi 10.1016/j.marpolbul.2012.11.028 
Maldonado M, Giraud K, Carmona C (2008) Effects of sediment on the survival of asexually produced sponge recruits. Marine Biology 154: 631-641

Maldonado M, Sánchez-Tocino L, Navarro C (2010a) Recurrent disease outbreaks in corneous demosponges of the genus Ircinia: epidemic incidence and defense mechanisms. Marine Biology 157: 1577-1590

Maldonado M, Uriz MJ (1999a) An experimental approach to the ecological significance of microhabitat-scale movement in an encrusting sponge

Maldonado M, Uriz MJ (1999b) Sexual propagation by sponge fragments. Nature 398: 476-476

Maldonado M, Zhang X, Cao X, Xue L, Cao H, Zhang W (2010b) Selective feeding by sponges on pathogenic microbes: a reassessment of potential for abatement of microbial pollution. Marine Ecology Progress Series 403: 75-89 doi 10.3354/meps08411

Maloof AC, Rose CV, Beach R, Samuels BM, Calmet CC, Erwin DH, Poirier GR, Yao N, Simons FJ (2010) Possible animal-body fossils in pre-Marinoan limestones from South Australia. Nature Geoscience 3: 653-659

Marie D, Partensky F, Jacquet S, Vaulot D (1997) Enumeration and cell cycle analysis of natural populations of marine picoplankton by flow cytometry using the nucleic acid stain SYBR Green I. Applied and Environmental Microbiology 63: 186-193

Marie D, Simon N, Guillou L, Partensky F, Vaulot D (2000) Flow cytometry analysis of marine picoplankton In Living Color. Springer, pp 421-454

Marsh AG, Manahan DT (1999) A method for accurate measurements of the respiration rates of marine invertebrate embryos and larvae. Marine Ecology Progress Series 184: 1-10

Martins J, Sobral P (2011) Plastic marine debris on the Portuguese coastline: a matter of size? Marine Pollution Bulletin 62: 2649-2653 doi 10.1016/j.marpolbul.2011.09.028

Mato Y, Isobe T, Takada H, Kanehiro H, Ohtake C, Kaminuma T (2001) Plastic resin pellets as a transport medium for toxic chemicals in the marine environment. Environmental Science \& Technology 35: 318-324

Maximenko N, Hafner J, Niiler P (2012) Pathways of marine debris derived from trajectories of Lagrangian drifters. Marine Pollution Bulletin 65: 51-62

McCue M (2006) Specific dynamic action: a century of investigation. Comparative Biochemistry and Physiology Part A: Molecular \& Integrative Physiology 144: 381-394

McDonald JI, McGuinness KA, Hooper JNA (2003) Influence of re-orientation on alignment to flow and tissue production in a Spongia sp. (Porifera:Demospongiae:Dictyoceratida). Journal of Experimental Marine Biology and Ecology 296: 13-22 doi 10.1016/s00220981(03)00302-2

McKeon C, Weber MX, Alter SE, Seavy NE, Crandall ED, Barshis DJ, Fechter-Leggett ED, Oleson KL (2015) Melting barriers to faunal exchange across ocean basins. Global change biology

Meroz-Fine E, Shefer S, Ilan M (2005) Changes in morphology and physiology of an East Mediterranean sponge in different habitats. Marine Biology 147: 243-250 doi 10.1007/s00227-004-1532-2

Meyer-Reil L-A, Köster M (2000) Eutrophication of marine waters: effects on benthic microbial communities. Marine Pollution Bulletin 41: 255-263

Moore CJ (2008) Synthetic polymers in the marine environment: A rapidly increasing, long-term threat. Environmental research 108: 131-139 doi 10.1016/j.envres.2008.07.025

Murray F, Cowie PR (2011) Plastic contamination in the decapod crustacean Nephrops norvegicus (Linnaeus, 1758). Marine Pollution Bulletin 62: 1207-1217

Murray HJR (2009) Oxygen consumption rates of sponges and the effect of UV-B radiation and sediment

Ng KL, Obbard JP (2006) Prevalence of microplastics in Singapore's coastal marine environment. Marine Pollution Bulletin 52: 761-767 doi 10.1016/j.marpolbul.2005.11.017

Nickel M (2004) Kinetics and rhythm of body contractions in the sponge Tethya wilhelma (Porifera: Demospongiae). Journal of Experimental Biology 207: 4515-4524 
Nuelle MT, Dekiff JH, Remy D, Fries E (2014) A new analytical approach for monitoring microplastics in marine sediments. Environmental Pollution 184: 161-169 doi 10.1016/j.envpol.2013.07.027

O'brien RG (1979) A general ANOVA method for robust tests of additive models for variances. Journal of the American Statistical Association 74: 877-880

Obbard RW, Sadri S, Wong YQ, Khitun AA, Baker I, Thompson RC (2014) Global warming releases microplastic legacy frozen in Arctic Sea ice. Earth's Future 2: 315-320 doi 10.1002/2014ef000240

OehImann J, Schulte-OehImann U, Kloas W, Jagnytsch O, Lutz I, Kusk KO, Wollenberger L, Santos EM, Paull GC, Van Look KJ (2009) A critical analysis of the biological impacts of plasticizers on wildlife. Philosophical Transactions of the Royal Society B: Biological Sciences 364: 2047-2062

Ogata Y, Takada H, Mizukawa K, Hirai H, Iwasa S, Endo S, Mato Y, Saha M, Okuda K, Nakashima A (2009) International Pellet Watch: Global monitoring of persistent organic pollutants (POPs) in coastal waters. 1. Initial phase data on PCBs, DDTs, and HCHs. Marine Pollution Bulletin 58: 1437-1446

Otero M, Cebrian E, Francour P, Galil B, Savini D (2013) Monitoring marine invasive species in Mediterranean marine protected areas (MPAs): a strategy and practical guide for managers. Malaga, Spain: IUCN 136

Padilla DK, Williams SL (2004) Beyond ballast water: aquarium and ornamental trades as sources of invasive species in aquatic ecosystems. Frontiers in Ecology and the Environment 2: 131-138

Palumbi SR (1986) How body plans limit acclimation: responses of a demosponge to wave force. Ecology: 208-214

Paulus W, Weissenfels N (1986) The spermatogenesis of Ephydatia fluviatilis (Porifera). Zoomorphology 106: 155-162 doi 10.1007/bf00312204

Perea-Blázquez A (2011) Interactions between sponges and the water column: nutrient utilisation and feeding by New Zealand subtidal sponges. Wellington, New Zealand: Victoria University of Wellington.

Perea-Blazquez A, Davy SK, Bell JJ (2012) Estimates of particulate organic carbon flowing from the pelagic environment to the benthos through sponge assemblages. PloS one 7: e29569

Perea-Blázquez A, Davy SK, Bell JJ (2012) Nutrient utilisation by shallow water temperate sponges in New Zealand. Hydrobiologia 687: 237-250

Perea-Blázquez A, Davy SK, Magana-Rodríguez B, Bell JJ (2013) Temporal variation in food utilisation by three species of temperate demosponge. Marine Ecology Progress Series 485: 91-103 doi 10.3354/meps10316

Perea-Blázquez A, Price K, Davy SK, Bell JJ (2010) Diet composition of two temperate calcareous sponges: Leucosolenia echinata and Leucetta sp. from the Wellington South Coast, New Zealand. Open Marine Biology Journal 4: 65-73

Peterson AT, Vieglais DA (2001) Predicting Species Invasions Using Ecological Niche Modeling: New Approaches from Bioinformatics Attack a Pressing Problem A new approach to ecological niche modeling, based on new tools drawn from biodiversity informatics, is applied to the challenge of predicting potential species' invasions. BioScience 51: 363371

Peterson BJ, Chester CM, Jochem FJ, Fourqurean JW (2006) Potential role of sponge communities in controlling phytoplankton blooms in Florida Bay. Marine EcologyProgress Series- 328: 93

Peterson CH, Rice SD, Short JW, Esler D, Bodkin JL, Ballachey BE, Irons DB (2003) Long-term ecosystem response to the Exxon Valdez oil spill. Science 302: 2082-2086 
Pettit TN, Grant GS, Whittow GC (1981) Ingestion of plastics by Laysan albatross. The Auk: 839841

Pierce KE, Harris RJ, Larned LS, Pokras MA (2004) Obstruction and starvation associated with plastic ingestion in a Northern Gannet Morus bassanus and a Greater Shearwater Puffinus gravis. Marine Ornithology 32: 187-189

Pikitch E, Santora C, Babcock E, Bakun A, Bonfil R, Conover D, Dayton P, et al., Doukakis P, Fluharty D, Heneman B (2004) Ecosystem-based fishery management. Science 305: 346347

Pile A, Patterson M, Witman J (1996) In situ grazing on plankton< $10 \mu \mathrm{m}$ by the boreal sponge Mycale lingua. Marine Ecology Progress Series 141: 95-102

Pile AJ, Patterson MR, Savarese M, Chernykh VI, Fialkov VA (1997) Trophic effects of sponge feeding within Lake Baikal's littoral zone. 2. Sponge abundance, diet, feeding efficiency, and carbon flux. Limnology and Oceanography 42: 178-184

Pile AJ, Young CM (2006) The natural diet of a hexactinellid sponge: Benthic-pelagic coupling in a deep-sea microbial food web. Deep Sea Research Part I: Oceanographic Research Papers 53: $1148-1156$ doi 10.1016/j.dsr.2006.03.008

Pörtner H-O, Berdal B, Blust R, Brix O, Colosimo A, De Wachter B, Giuliani A, Johansen T, Fischer $T$, Knust $R$ (2001) Climate induced temperature effects on growth performance, fecundity and recruitment in marine fish: developing a hypothesis for cause and effect relationships in Atlantic cod (Gadus morhua) and common eelpout (Zoarces viviparus). Continental Shelf Research 21: 1975-1997

Pörtner HO, Hardewig I, Peck LS (1999) Mitochondrial function and critical temperature in the Antarctic bivalve, Laternula elliptica. Comparative Biochemistry and Physiology Part A: Molecular \& Integrative Physiology 124: 179-189

Powell AL, Hepburn L, Smith DJ, Bell JJ (2010) Patterns of sponge abundance across a gradient of habitat quality in the Wakatobi Marine National Park, Indonesia. The Open Marine Biology Journal 4: 31-38

Powles H, Bradford MJ, Bradford R, Doubleday W, Innes S, Levings CD (2000) Assessing and protecting endangered marine species. ICES Journal of Marine Science: Journal du Conseil 57: 669-676

Randl $\varnothing \vee A$, Riisgård H (1979) Efficiency of particle retention and filtration rate in four species of ascidians. Marine Ecology Progress Series 1: 55-59

Raven PH, Johnson GB (1986) Biology. Times Mirror. Mosby College Publishing, St Louis Author (s) Biosketches Kord, B, Ph D, Assistant Professor, Department of Green Space Engineering, Malayer Branch, Islamic Azad University, Malayer, Iran PO Box 65718: 117

Reiswig H (1971a) In situ pumping activities of tropical Demospongiae. Marine Biology 9: 38-50

Reiswig HM (1971b) Particle feeding in natural populations of three marine demosponges. The Biological Bulletin 141: 568-591

Reiswig HM (1974) Water transport, respiration and energetics of three tropical marine sponges. Journal of Experimental Marine Biology and Ecology 14: 231-249

Reiswig HM, Brown MJ (1977) The central cells of sponges. Zoomorphologie 88: 81-94

Reiswig HM, Miller TL (1998) Freshwater sponge gemmules survive months of anoxia. Invertebrate biology: 1-8

Ribes M, Coma R, Gili J-M (1999) Natural diet and grazing rate of the temperate sponge Dysidea avara (Demospongiae, Dendroceratida) throughout an annual cycle. Marine Ecology Progress Series 176: 179-190

Riisgård HU, Thomassen S, Jakobsen H, Weeks J, Larsen PS (1993) Suspension-feeding in marine sponges Halichondria-panicea and Haliclona-urceolus-effects of temperature on filtration-rate and energy-cost of pumping. Marine Ecology-Progress Series 96: 177-188

Roberts CM (2002) Deep impact: the rising toll of fishing in the deep sea. Trends in Ecology \& Evolution 17: 242-245 
Roberts D, Davis A, Cummins S (2006) Experimental manipulation of shade, silt, nutrients and salinity on the temperate reef sponge Cymbastela concentrica

Rocha-Santos T, Duarte AC (2015) A critical overview of the analytical approaches to the occurrence, the fate and the behavior of microplastics in the environment. TrAC Trends in Analytical Chemistry 65: 47-53 doi 10.1016/j.trac.2014.10.011

Rochman CM, Hoh E, Hentschel BT, Kaye S (2013a) Long-term field measurement of sorption of organic contaminants to five types of plastic pellets: implications for plastic marine debris. Environmental Science \& Technology 47: 1646-1654

Rochman CM, Kurobe T, Flores I, Teh SJ (2014a) Early warning signs of endocrine disruption in adult fish from the ingestion of polyethylene with and without sorbed chemical pollutants from the marine environment. Science of The Total Environment 493: 656661

Rochman CM, Lewison RL, Eriksen M, Allen H, Cook A-M, Teh SJ (2014b) Polybrominated diphenyl ethers (PBDEs) in fish tissue may be an indicator of plastic contamination in marine habitats. Science of The Total Environment 476: 622-633

Rochman CM, Manzano C, Hentschel BT, Simonich SLM, Hoh E (2013b) Polystyrene Plastic: A Source and Sink for Polycyclic Aromatic Hydrocarbons in the Marine Environment. Environmental Science \& Technology 47: 13976-13984

Rothschild B, Ault J, Goulletquer P, Heral M (1994) Decline of the Chesapeake Bay oyster population: a century of habitat destruction and overfishing. Marine Ecology Progress Series 111: 29-39

Rützler K (1975) The role of burrowing sponges in bioerosion. Oecologia 19: 203-216

Ryan PG, Moore CJ, van Franeker JA, Moloney CL (2009) Monitoring the abundance of plastic debris in the marine environment. Philosophical transactions of the Royal Society of London Series B, Biological sciences 364: 1999-2012 doi 10.1098/rstb.2008.0207

Sadovy de Mitcheson Y, Craig MT, Bertoncini AA, Carpenter KE, Cheung WW, Choat JH, Cornish AS, Fennessy ST, Ferreira BP, Heemstra PC (2013) Fishing groupers towards extinction: a global assessment of threats and extinction risks in a billion dollar fishery. Fish and Fisheries 14: 119-136

Sánchez P, Masó M, Sáez R, De Juan S, Muntadas A, Demestre M (2013) Baseline study of the distribution of marine debris on soft-bottom habitats associated with trawling grounds in the northern Mediterranean. Scientia Marina 77: 247-255 doi 10.3989/scimar03702.10A

Sarà M, Sarà A (2004) A revision of Australian and New Zealand Tethya (Porifera: Demospongiae) with a preliminary analysis of species-groupings. Invertebrate Systematics 18: 117-156

Setälä O, Fleming-Lehtinen V, Lehtiniemi M (2014) Ingestion and transfer of microplastics in the planktonic food web. Environmental Pollution 185: 77-83

Siegenthaler U, Stocker TF, Monnin E, Lüthi D, Schwander J, Stauffer B, Raynaud D, Barnola J-M, Fischer H, Masson-Delmotte V (2005) Stable carbon cycle-climate relationship during the late Pleistocene. Science 310: 1313-1317

Sievert PR, Sileo L (1993) The effects of ingested plastic on growth and survival of albatross chicks. The status, ecology, and conservation of marine birds of the North Pacific Otawa: Canadian Wildlife Service Special Publication: 212-217

Simpson TL, Fell PE (1974) Dormancy among the Porifera: gemmule formation and germination in fresh-water and marine sponges. Transactions of the American Microscopical Society: 544-577

Simpson TL, Gilbert JJ (1973) Gemmulation, gemmule hatching, and sexual reproduction in freshwater sponges I. The life cycle of Spongilla lacustris and Tubella pennsylvanica. Transactions of the American Microscopical Society: 422-433

Stabili L, Licciano M, Giangrande A, Longo C, Mercurio M, Marzano CN, Corriero G (2006) Filtering activity of Spongia officinalis var. adriatica (Schmidt) (Porifera, Demospongiae) 
on bacterioplankton: implications for bioremediation of polluted seawater. Water Research 40: 3083-3090 doi 10.1016/j.watres.2006.06.012

Stefatos A, Charalampakis M, Papatheodorou G, Ferentinos G (1999) Marine debris on the seafloor of the Mediterranean Sea: examples from two enclosed gulfs in Western Greece. Marine Pollution Bulletin 38: 389-393

Stuart V, Klumpp D (1984) Evidence for food-resource partitioning by kelp-bed filter feeders. Marine ecology Progress series 16: 27-37

Suckling CC, Clark MS, Richard J, Morley SA, Thorne MA, Harper EM, Peck LS (2015) Adult acclimation to combined temperature and $\mathrm{pH}$ stressors significantly enhances reproductive outcomes compared to short-term exposures. Journal of Animal Ecology 84: 773-784

Sussarellu R, Suquet M, Thomas Y, Lambert C, Fabioux C, Pernet ME, Le Goic N, Quillien V, Mingant C, Epelboin Y, Corporeau C, Guyomarch J, Robbens J, Paul-Pont I, Soudant P, Huvet $A$ (2016) Oyster reproduction is affected by exposure to polystyrene microplastics. Proceedings of the National Acadamy of Sciences U S A 113: 2430-2435 doi 10.1073/pnas.1519019113

Tanaka K, Takada H, Yamashita R, Mizukawa K, Fukuwaka M-a, Watanuki Y (2013) Accumulation of plastic-derived chemicals in tissues of seabirds ingesting marine plastics. Marine Pollution Bulletin 69: 219-222

Taylor MW, Radax R, Steger D, Wagner M (2007) Sponge-associated microorganisms: evolution, ecology, and biotechnological potential. Microbiol Molecular Biology Review 71: 295347 doi 10.1128/MMBR.00040-06

Taylor S, Kumar L (2013) Potential distribution of an invasive species under climate change scenarios using CLIMEX and soil drainage: A case study of Lantana camara L. in Queensland, Australia. Journal of Environmental Management 114: 414-422

Teuten EL, Rowland SJ, Galloway TS, Thompson RC (2007) Potential for plastics to transport hydrophobic contaminants. Environmental Science \& Technology 41: 7759-7764

Teuten EL, Saquing JM, Knappe DR, Barlaz MA, Jonsson S, Björn A, Rowland SJ, Thompson RC, Galloway TS, Yamashita R (2009) Transport and release of chemicals from plastics to the environment and to wildlife. Philosophical Transactions of the Royal Society B: Biological Sciences 364: 2027-2045

Thomassen S, Riisgdrd HU (1995) Growth and energetics of the sponge Halichondria panicea. Marine Ecology Progress Series 128: 239-246

Thompson RC (2006) Plastic debris in the marine environment: consequences and solutions. Marine Nature Conservation in Europe 2006: 107

Thompson RC, Olsen Y, Mitchell RP, Davis A, Rowland SJ, John AW, McGonigle D, Russell AE (2004a) Lost at sea: where is all the plastic? Science 304: 838-838

Thompson RC, Olsen Y, Mitchell RP, Davis A, Rowland SJ, John AWG, McGonigle D, Russell AE (2004b) Lost at Sea: Where Is All the Plastic? Science 304: 838 doi 10.1126/Science.1094559

Thompson RC, Swan SH, Moore CJ, Vom Saal FS (2009) Our plastic age. Philosophical Transactions of the Royal Society B: Biological Sciences 364: 1973-1976

Thorp JH, Covich AP (2009) Ecology and classification of North American freshwater invertebrates. Academic press

Thrush SF, Dayton PK (2002) Disturbance to marine benthic habitats by trawling and dredging: implications for marine biodiversity. Annual Review of Ecology and Systematics: 449-473

Tompkins-MacDonald GJ, Leys SP (2008) Glass sponges arrest pumping in response to sediment: implications for the physiology of the hexactinellid conduction system. Marine Biology 154: $973-984$

Tracey D, Bostock H, Currie K, Mikaloff-Fletcher S, Williams M, Hadfield M, Neil H, Guy C, Cummings V (2013) The potential impact of ocean acidification on deep-sea corals and 
fisheries habitat in New Zealand waters. New Zealand Aquatic Environment and Biodiversity Report: 101

Turon X, Tarjuelo I, Uriz M (1998) Growth dynamics and mortality of the encrusting sponge Crambe crambe (Poecilosclerida) in contrasting habitats: correlation with population structure and investment in defence. Functional Ecology 12: 631-639

Uriz MJ, Rosell D, Maldonado M (1992) Parasitism, commensalism or mutualism? The case of Scyphozoa (Coronatae) and horny sponges. Marine ecology progress series. Oldendorf, 81(3), 247-255.

Van Cauwenberghe L, Claessens M, Vandegehuchte MB, Janssen CR (2015) Microplastics are taken up by mussels (Mytilus edulis) and lugworms (Arenicola marina) living in natural habitats. Environmental Pollution 199: 10-17 doi 10.1016/j.envpol.2015.01.008

Van Cauwenberghe L, Janssen CR (2014) Microplastics in bivalves cultured for human consumption. Environmental pollution 193: 65-70 doi 10.1016/j.envpol.2014.06.010

Van Cauwenberghe L, Vanreusel A, Mees J, Janssen CR (2013) Microplastic pollution in deep-sea sediments. Environmental Pollution 182: 495-499

Van de Vijver KI, Hoff P, Das K, Brasseur S, Van Dongen W, Esmans E, Reijnders P, Blust R, De Coen W (2005) Tissue distribution of perfluorinated chemicals in harbor seals (Phoca vitulina) from the Dutch Wadden Sea. Environmental Science \& Technology 39: 69786984

Van de Vyver G (1975) Phenomena of cellular recognition in sponges. Curr Top Dev Biol 10: $123-$ 140

Van Noord JE, Olson RJ, Redfern JV, Kaufmann RS (2013) Diet and prey selectivity in three surface-migrating myctophids in the eastern tropical Pacific. Ichthyological Research 60: 287-290

Verlis KM, Campbell M, Wilson S (2013) Ingestion of marine debris plastic by the wedge-tailed shearwater Ardenna pacifica in the Great Barrier Reef, Australia. Marine pollution Bulletin 72: 244-249

Vogel S (1974) Current-induced flow through the sponge, Halichondria. The Biological Bulletin 147: 443-456

Vogel S (1977) Current-induced flow through living sponges in nature. Proceedings of the National Academy of Sciences 74: 2069-2071

Vohmann A, Mutz M, Arndt H, Weitere M (2009) Grazing impact and phenology of the freshwater sponge Ephydatia muelleri and the bryozoans Plumatella emarginata and Fredericella sultana under experimental warming. Freshwater Biology 54: 1078-1092

von Moos N, Burkhardt-Holm P, Kohler A (2012) Uptake and effects of microplastics on cells and tissue of the blue mussel Mytilus edulis L. after an experimental exposure. Environmental Science Technology 46: 11327-11335 doi 10.1021/es302332w

Walsh JR, Carpenter SR, Vander Zanden MJ (2016) Invasive species triggers a massive loss of ecosystem services through a trophic cascade. Proceedings of the National Academy of Sciences 113: 4081-4085

Ward-Paige CA, Risk MJ, Sherwood OA, Jaap WC (2005) Clionid sponge surveys on the Florida Reef Tract suggest land-based nutrient inputs. Marine Pollution Bulletin 51: 570-579

Watts AJ, Lewis C, Goodhead RM, Beckett SJ, Moger J, Tyler CR, Galloway TS (2014) Uptake and retention of microplastics by the shore crab Carcinus maenas. Environmental Science Technology 48: 8823-8830 doi 10.1021/es501090e

Wegner A, Besseling E, Foekema EM, Kamermans P, Koelmans AA (2012) Effects of nanopolystyrene on the feeding behavior of the blue mussel (Mytilus edulis L.). Environmental Toxicology and Chemistry 31: 2490-2497

Wehrl M, Steinert M, Hentschel U (2007) Bacterial uptake by the marine sponge Aplysina aerophoba. Microb Ecol 53: 355-365 doi 10.1007/s00248-006-9090-4 
Weissenfels N (1992) The filtration apparatus for food collection in freshwater sponges (Porifera, Spongillidae). Zoomorphology 112: 51-55

Whalan S, Ettinger-Epstein P, de Nys R (2008) The effect of temperature on larval pre-settlement duration and metamorphosis for the sponge, Rhopaloeides odorabile. Coral Reefs 27: 783-786

Wilberg MJ, Livings ME, Barkman JS, Morris BT, Robinson JM (2011) Overfishing, disease, habitat loss, and potential extirpation of oysters in upper Chesapeake Bay. Marine Ecology Progress Series 436: 131-144

Wilkinson CC, Trott LL (1985) Light as a factor determining the distribution of sponges across the central Great Barrier Reef

Willenz P, Vray B, Maillard M-P, Van de Vyver G (1986) A quantitative study of the retention of radioactively labeled $E$. coli by the freshwater sponge Ephydatia fluviatilis. Physiological zoology: 495-504

Wilson H, Penney J (1930) The regeneration of sponges (Microciona) from dissociated cells. Journal of Experimental Zoology 56: 73-147

Wolfrath B, Barthel D (1989) Production of faecal pellets by the marine sponge Halichondria panicea Pallas (1766). Journal of Experimental Marine Biology and Ecology 129: 81-94

Wright SL, Rowe D, Thompson RC, Galloway TS (2013a) Microplastic ingestion decreases energy reserves in marine worms. Curr Biol 23: R1031-1033 doi 10.1016/j.cub.2013.10.068

Wright SL, Thompson RC, Galloway TS (2013b) The physical impacts of microplastics on marine organisms: a review. Environmental pollution 178: 483-492 doi 10.1016/j.envpol.2013.02.031

Wulff JL (1994) Sponge feeding by Caribbean angelfishes, trunkfishes, and filefishes. Soest RWM van, Kempen TMG van, Braekman JC (eds) Sponges in time and space Balkema, Rotterdam: 265-271

Wulff JL (1997) Parrotfish predation on cryptic sponges of Caribbean coral reefs. Marine Biology 129: 41-52

Wulff JL (2000) Sponge predators may determine differences in sponge fauna between two sets of mangrove cays, Belize barrier reef. Atoll Research Bulletin 477: 251-263

Wulff JL (2006a) Ecological interactions of marine sponges. Canadian Journal of Zoology 84: 146166

Wulff JL (2006b) Rapid diversity and abundance decline in a Caribbean coral reef sponge community. Biological Conservation 127: 167-176

Wulff $L$ (1995) Sponge-feeding by the Caribbean starfish Oreaster reticulatus. Marine Biology 123: $313-325$

Yamada Y, Ikeda T (1999) Acute toxicity of lowered pH to some oceanic zooplankton. Plankton Biology and Ecology 46: 62-67

Zarfl C, Fleet D, Fries E, Galgani F, Gerdts G, Hanke G, Matthies M (2011) Microplastics in oceans. Mar Pollut Bull 62: 1589-1591 doi 10.1016/j.marpolbul.2011.02.040

Zea S, Van Soest R, Van Kempen T, Braekman J (1994) Patterns of coral and sponge abundance in stressed coral reefs at Santa Marta, Colombian Caribbean. Sponges in time and space Balkema, Rotterdam: 257-264

Zettler ER, Mincer TJ, Amaral-Zettler LA (2013) Life in the "plastisphere": microbial communities on plastic marine debris. Environmental science \& technology 47: 7137-7146

Zhuravlev A, Riding R (2001) The ecology of the Cambrian radiation : New York, Columbia University Press, $525 \mathrm{p}$.

Zocchi E, Basile G, Cerrano C, Bavestrello G, Giovine M, Bruzzone S, Guida L, Carpaneto A, Magrassi R, Usai C (2003) ABA-and CADPR-mediated effects on respiration and filtration downstream of the temperature-signaling cascade in sponges. Journal of Cell Science 116: 629-636 


\section{Appendix:}

Obtaining concentrations for treatments:

1. Wanted concentration was 200,000 particles per $\mathrm{mL}$.

2. Take buoyant weight of sponge (apply to graph below), then take corresponding displacement value.

3. Trial chamber $=75 \mathrm{~mL}$

4. $75 \mathrm{~mL}-$ displacement value $=\sim \mathrm{mL}$ of water in chamber when sponge is inside

5. Take $\sim \mathrm{mL}$ and $\mathrm{x}$ by 200,000 to give wanted concentration of particulates per chamber (sponge included)

6. Then take Particulates per chamber \# and divide by Haemocytometer \# per $\mathrm{mL}$ of given treatment

7. This $=\mathrm{mL}$ of treatment per trial chamber (sponge included)

\section{Haemocytometer:}

$\underline{\text { Isochrysis }}$

Mean \# $=1710.42$

$X \operatorname{ccf}(10,000)$

$=1.71 \times 10^{7}$ per $\mathrm{mL}$

\section{$\underline{\text { Kaolin Clay }}$}

Mean \# $=4702.00$

$X \operatorname{ccf}(10,000)$

$=4.70 \times 10^{7}$ per $\mathrm{mL}$ $\underline{\text { Microplastic } 1 \mu \mathrm{m}=4.5527 \times 10^{10} \text { per } \mathrm{mL}}$ Diluted into $1 \mathrm{~L}$ $=4.5527 \times 10^{7}$ per $\mathrm{mL}$

Microplastic $6 \mu \mathrm{m}=2.01 \times 10^{8}$ per $\mathrm{mL}$ $4 \mathrm{~mL}$ diluted into $100 \mathrm{~mL}$ $=8.04 \times 10^{6}$ per $\mathrm{mL}$

$\underline{\text { Fine White Marble Dust }}$

Mean \# $=841.60$

$X \operatorname{ccf}(10,000)$

$=8.416 \times 10^{6}$ per $\mathrm{mL}$ 


\section{Buoyant Weight:}

Method of gaining Buoyant weight, See (Figure 6.2)

Raw seawater was placed into a bucket to which the sponges were added (without removing from water), each sponge was then weighed while remaining submerged, by being placed into a hanging "basket". This was connected to the bottom of the scales (which had been calibrated to account for this). Weight was noted (to the nearest $0.0001 \mathrm{~g})$.

Finally the volumes of the trial sponges were obtained, via displacement in a measuring cylinder.

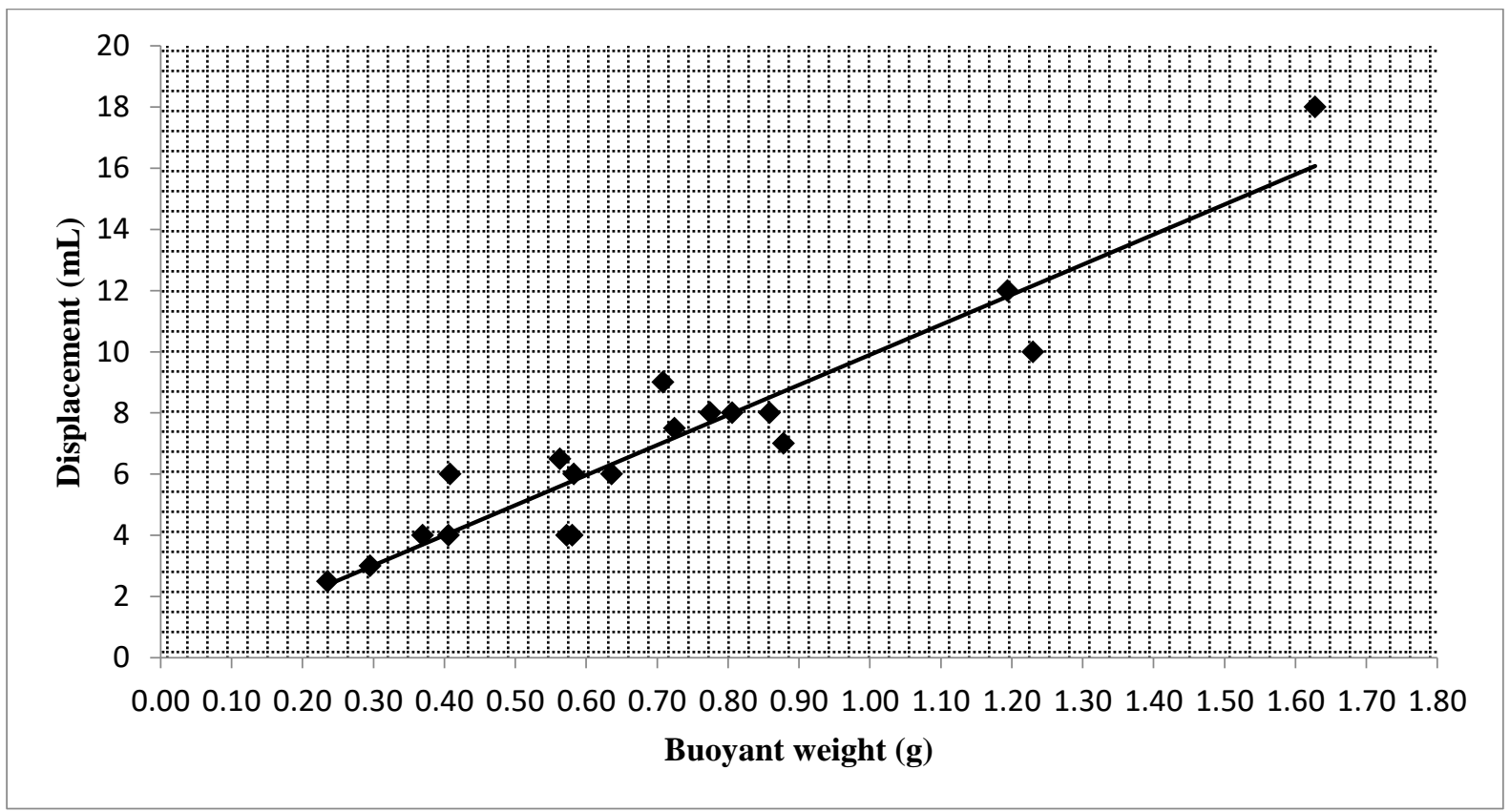

Figure 6.1: Correlation graph of Buoyant weight vs Water displacement 


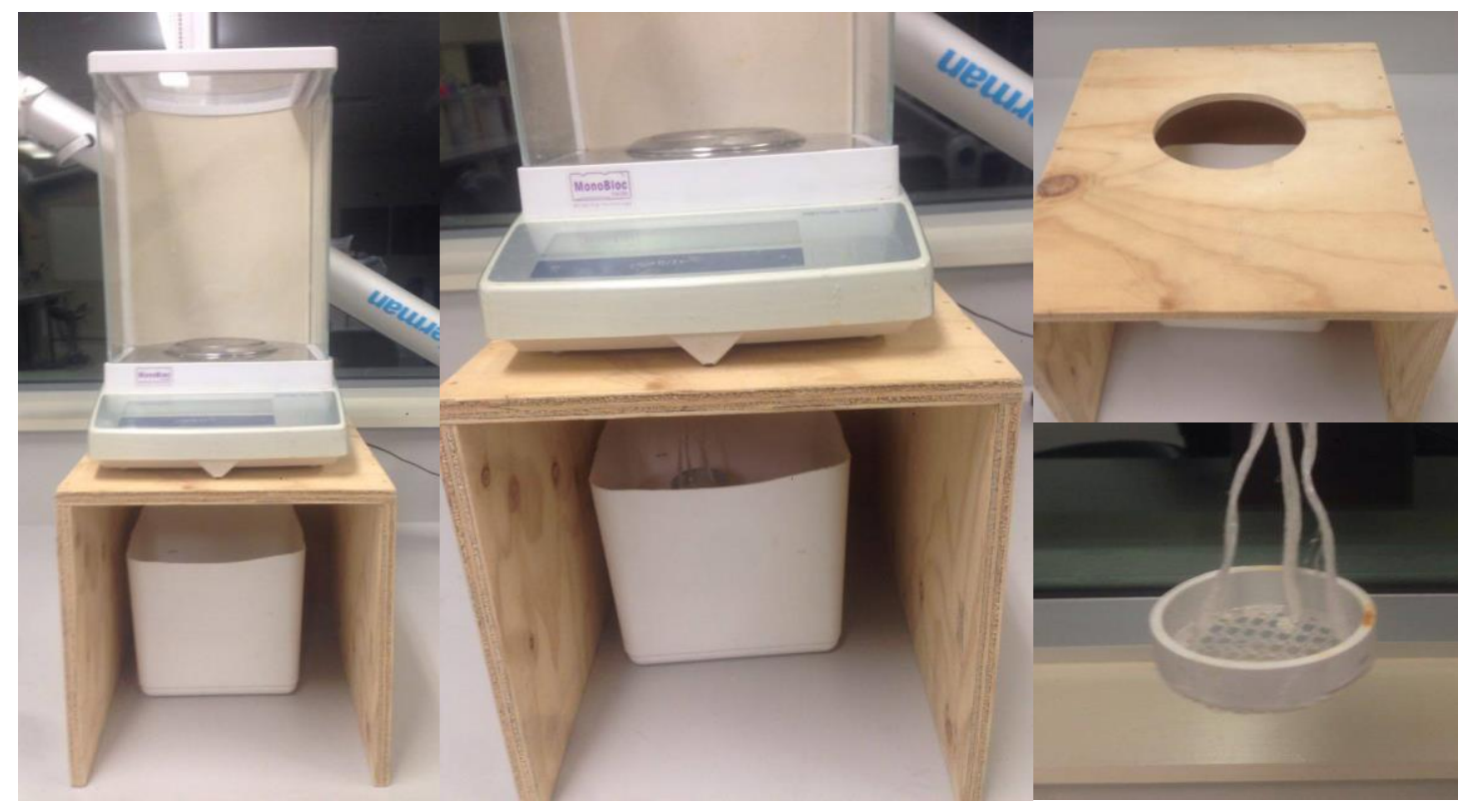

Figure 6.2: Set up for gaining Buoyant weight, 